\title{
24. R/V THOMAS WASHINGTON CRUISE ARIES V: RECONNAISSANCE SEISMIC REFLECTION PROFILES OF PROSPECTIVE DSDP SITES IN THE NORTHWEST PACIFIC
}

\author{
Bruce C. Heezen and Marie Tharp, Lamont-Doherty Geological Observatory, Palisades, New York
}

Drilling in the deep basin west of Hawaii during DSDP Leg 6 revealed an extremely difficult situation. The thin to undetectable upper transparent acoustic layer was found to consist of soft sediments. The underlying opaque layer was discovered to be a chert chalk sequence, which was difficult to drill. The heavy bottom hole assembly will buckle and break off if not supported by the hole, and, therefore, 200 to 500 feet of easily penetrable sediments are desired in order to provide support for the assembly before the drilling of hard strata can be commenced. There are extremely few sites in the entire western Pacific which combine an upper, easily penetrable sediment and an underlying clear acoustic stratigraphic sequence which can be related to the overall stratigraphy of the Pacific basin. Those members of the JOIDES Pacific Panel who had access to original records searched every available profile to come up with a selection of less than one dozen possibilities for Leg 20, most of which were admittedly marginal. The prospective sites as initially selected would have taken the Glomar Challenger on Leg 20 from Japan eastward to about longitude $160^{\circ} \mathrm{E}$ and then south to the equator and ultimately to Fiji. It was planned that the Aries V expedition would first explore the final sites for Leg 17, then explore the Mid-Pacific Mountains, and finally pick up the proposed Leg 20 traverse near Wake and run it to Japan, detailing such areas as appeared promising. The R.V. Kana Keoki at the same time was to run the traverse from the vicinity of Wake to the Equator, making special surveys of three prospective sites. Reports on these surveys are found in a chapter by Zachariadis in this volume.

In general, the abyssal clays which make up the upper transparent layer are far thinner than the minimum required by the drillers for bottom hole assembly support. Only in anomalous areas do the unconsolidated sediments approach, equal, or exceed the desired 180-foot minimum. Within about $1000 \mathrm{~km}$ of Japan, volcanic ash is carried out by the wind in sufficient quantities to provide an uppermost layer of sufficient thickness. This deposit was employed during Leg 20 to spud in Sites 194, 195, 196, and 197. Site 198 was located on an anomalous thickening on the archipelagic apron of Marcus Island. Site 51 of Leg 6 was located in a small turbidite pond while Site 52 was on the volcanogenic wedge east of the island arc. The survey carried out along $170^{\circ} \mathrm{E}$ effectively eliminated each prospect north of $5^{\circ} \mathrm{N}$ by demonstrating insufficient thickness of transparent sediment. The seismic reflection profiles run by ARIES $\mathrm{V}$ demonstrated the presence of attractive sites in the region of the Mid-Pacific Mountains. These sites were to have been drilled by Leg 17 . Unfortunately, the drilling of these thick accumulations was not undertaken on that leg.

In the deep basin west and northwest of the Mid-Pacific Mountains, the seismic profiler gave very little promise of providing minimum requirements for spudding-in. A prospect found on two Conrad profiles was further explored by ARIES $\mathrm{V}$ and given a more detailed study on ARIES VII.

During the early stages of exploration, drilling objectives were easily modified to meet the limitations of drilling technique. However, most of the obvious sites in the west Pacific have now been drilled, and further exploration of the oldest areas by drilling will have to await development of techniques to spud-in without the present minimum of 180 feet of soft sediment. 


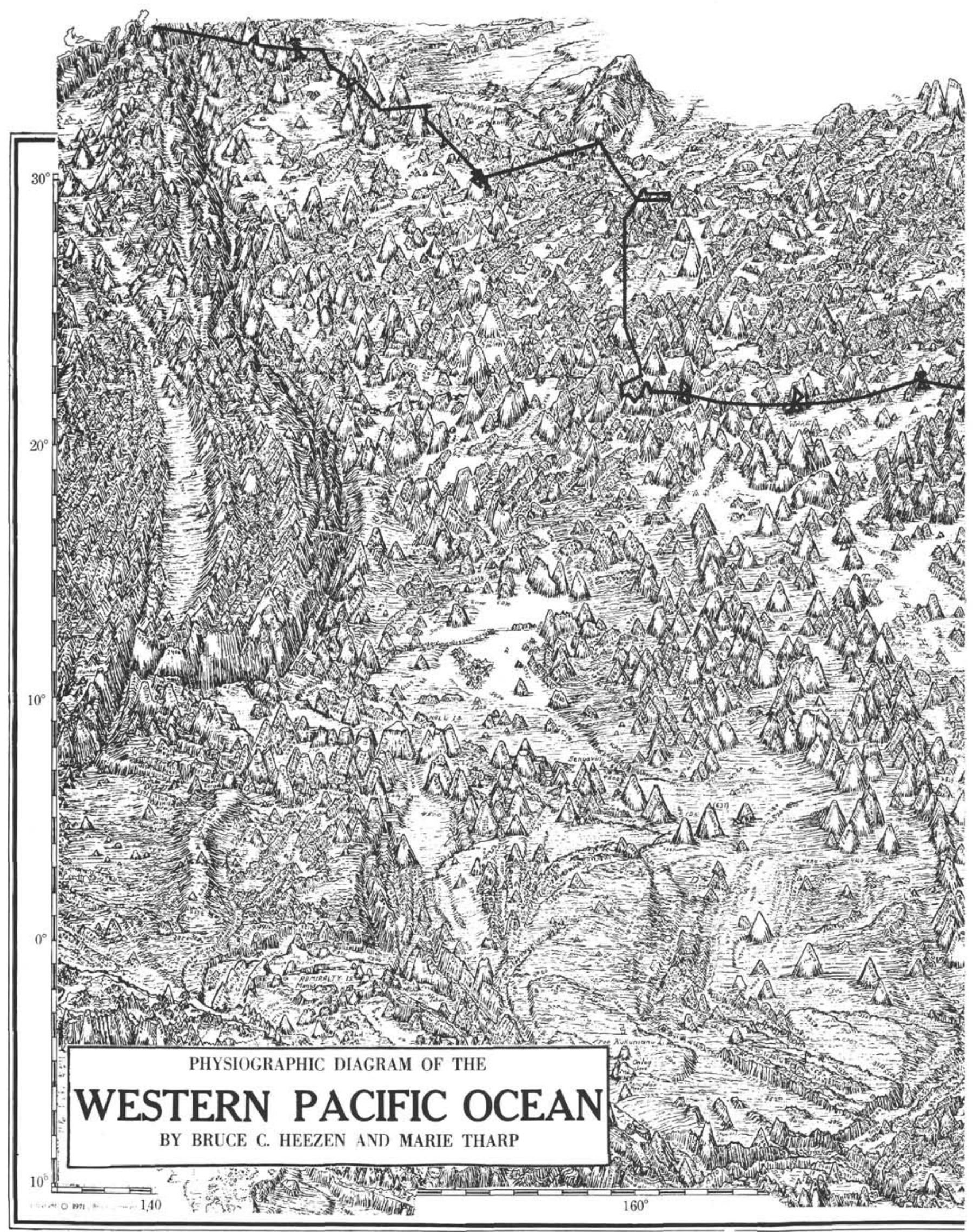

Figure 1. Physiographic diagram of the western Pacific showing the track of R.V. Thomas Washington cruise ARIES V. Diagram by B. C. Heezen and M. Tharp. Published by the Geological Society of America. Copyright 1971. 


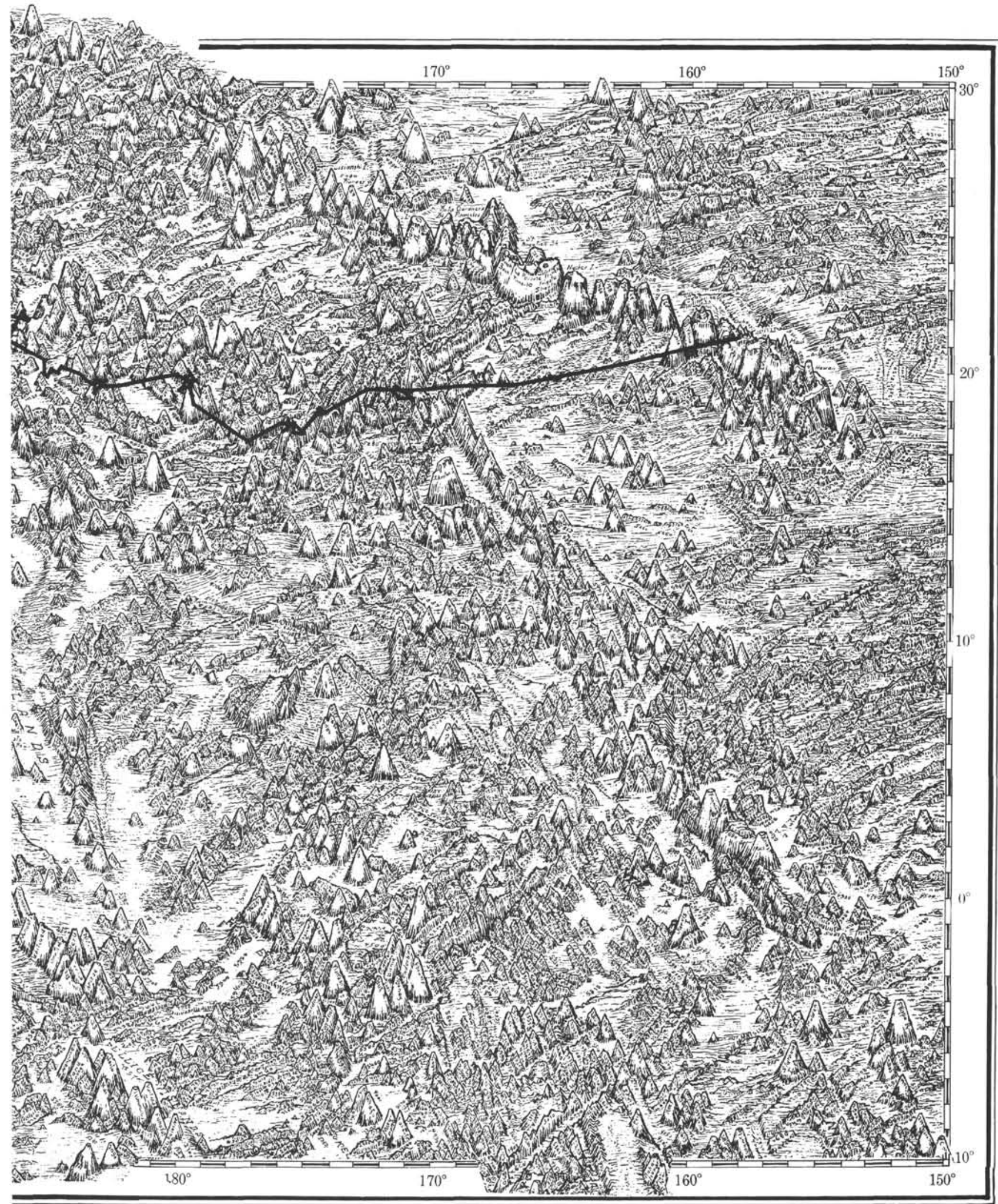

Figure 1. (Continued). 


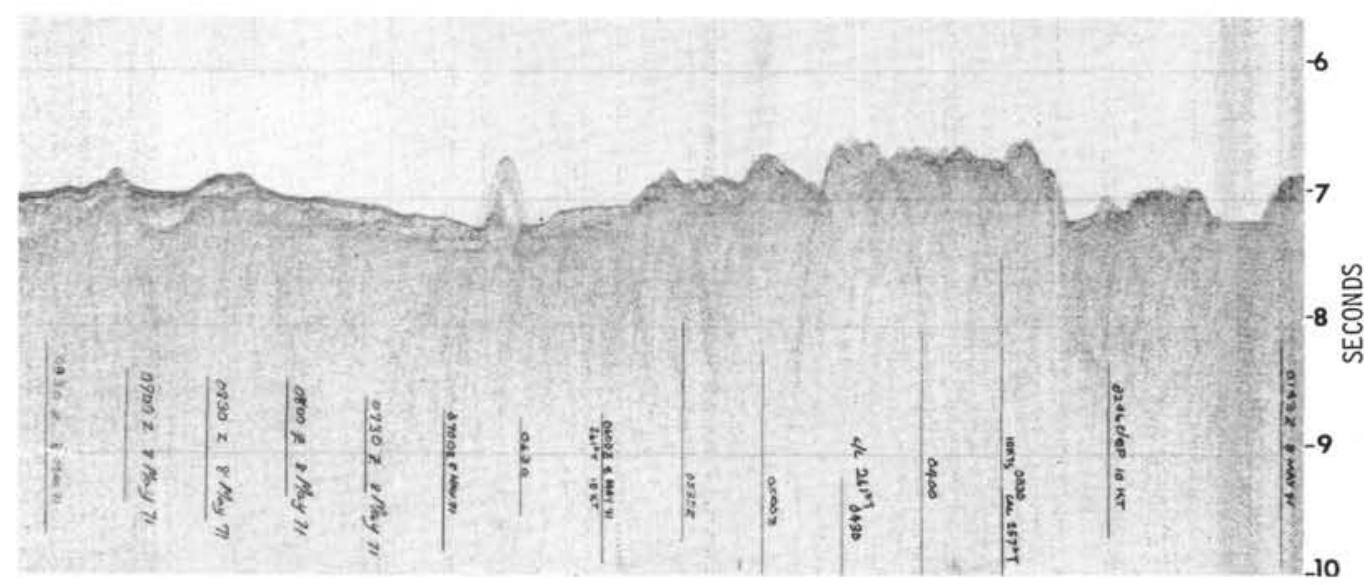

Figure 2. Seismic reflection profile of gentle deep basin topography south of the Hawaiian Ridge.

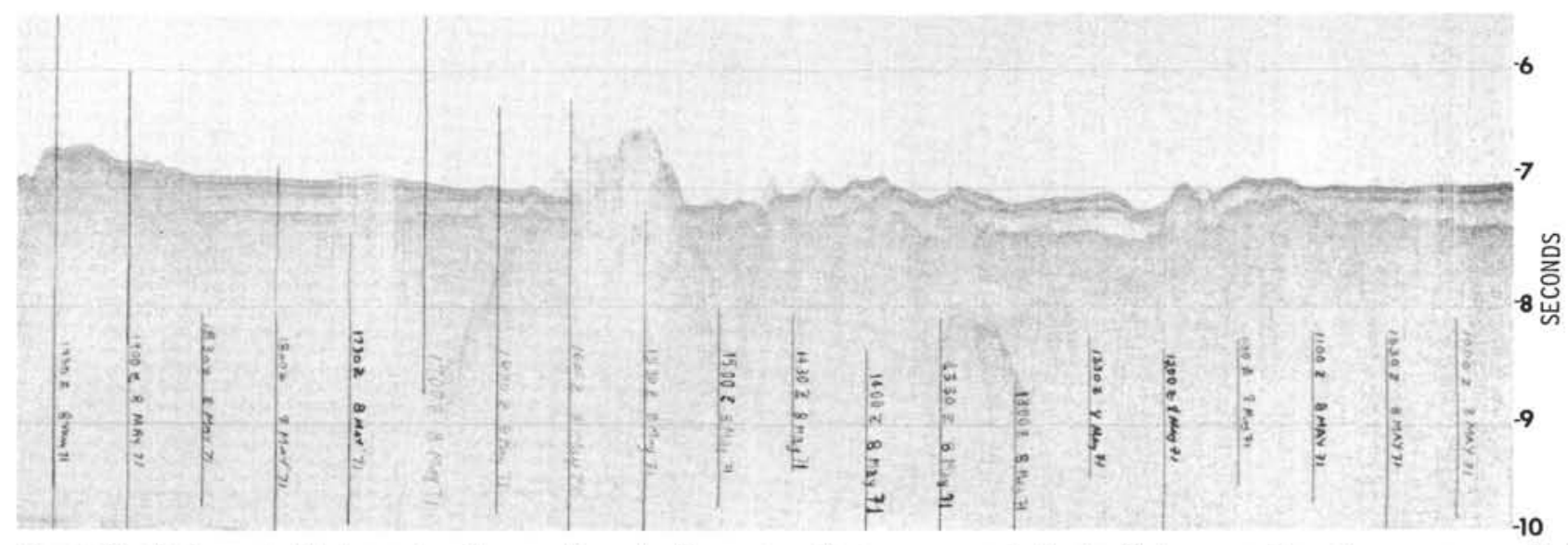

Figure 3. Sediment thickens to the southwest. Deepest reflectors are relatively flat suggesting the presence of deeper horizons. 


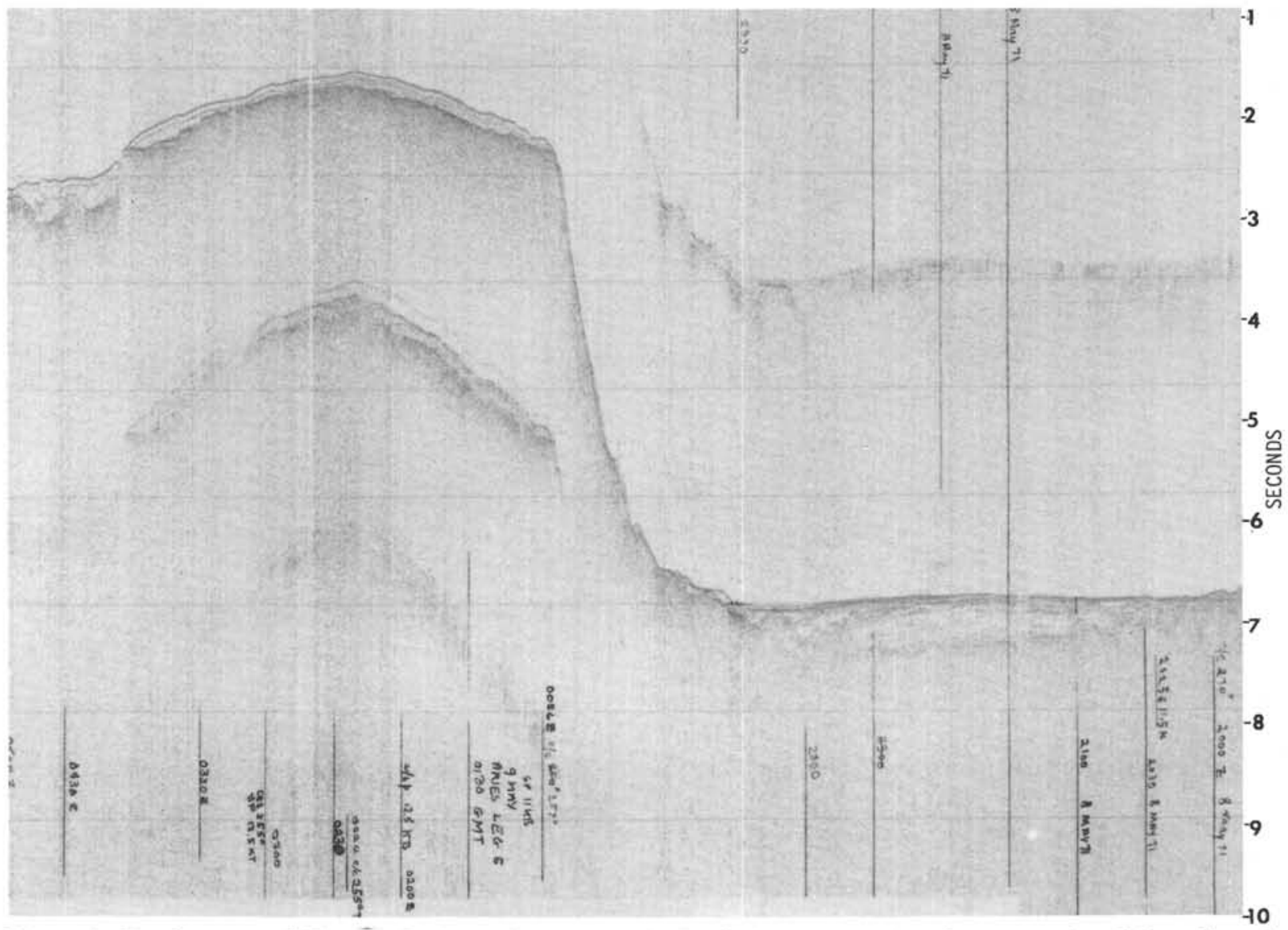

Figure 4. To the east of Horizon Ridge, sediments markedly thicken, suggesting the progressive tilting of ponded sediments. It is here that an undrilled Leg 17 prospect was located. The saddle between the two beveled summits of Horizon Ridge is the location of Leg 17 Site 171.

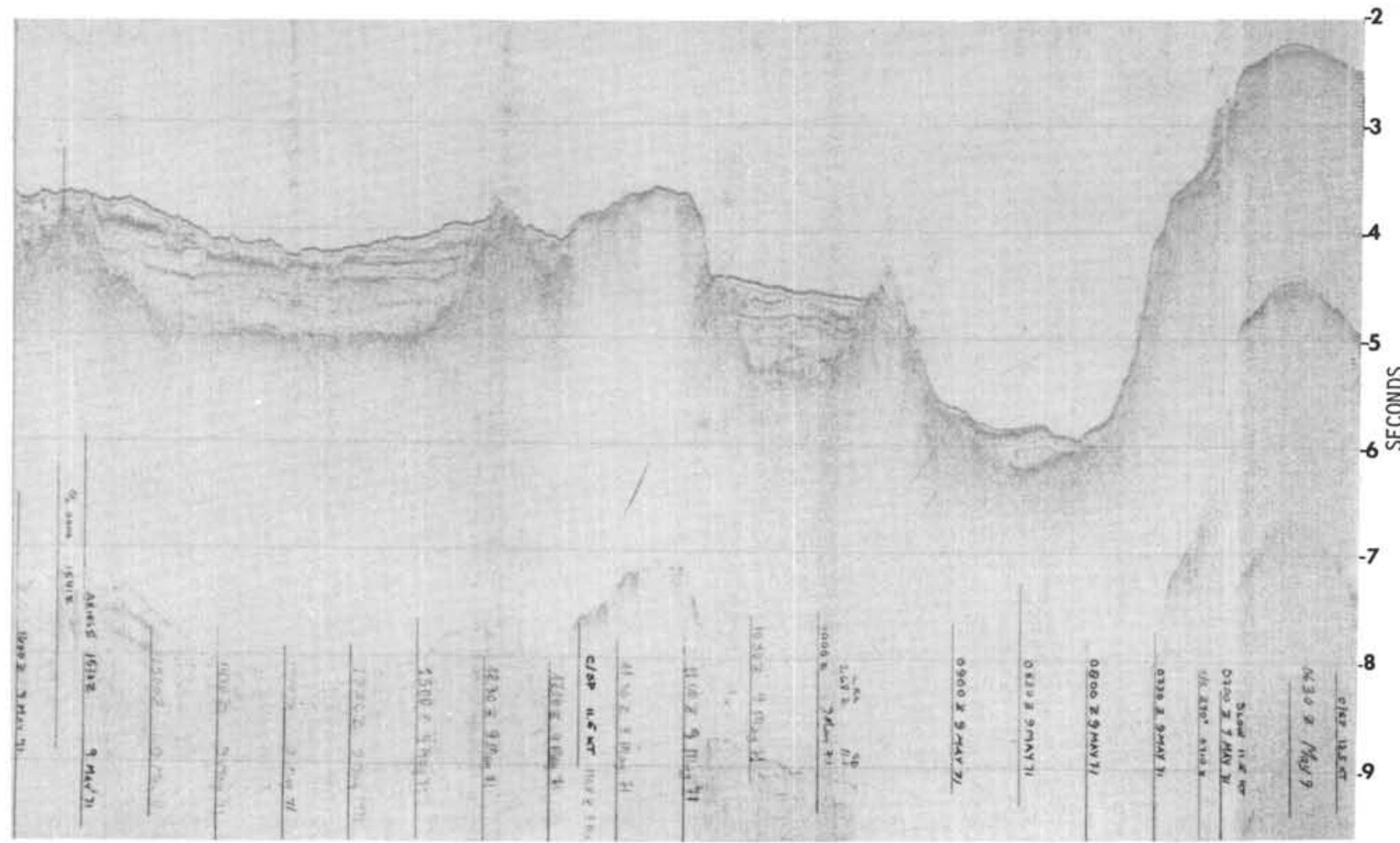

Figure 5. The west flank of Horizon Ridge is bare of sediment, but the relatively shoal area of the Mid-Pacific Mountains, which lies further west, is covered by more than $1 \mathrm{~km}$ of well-stratified sediments. 


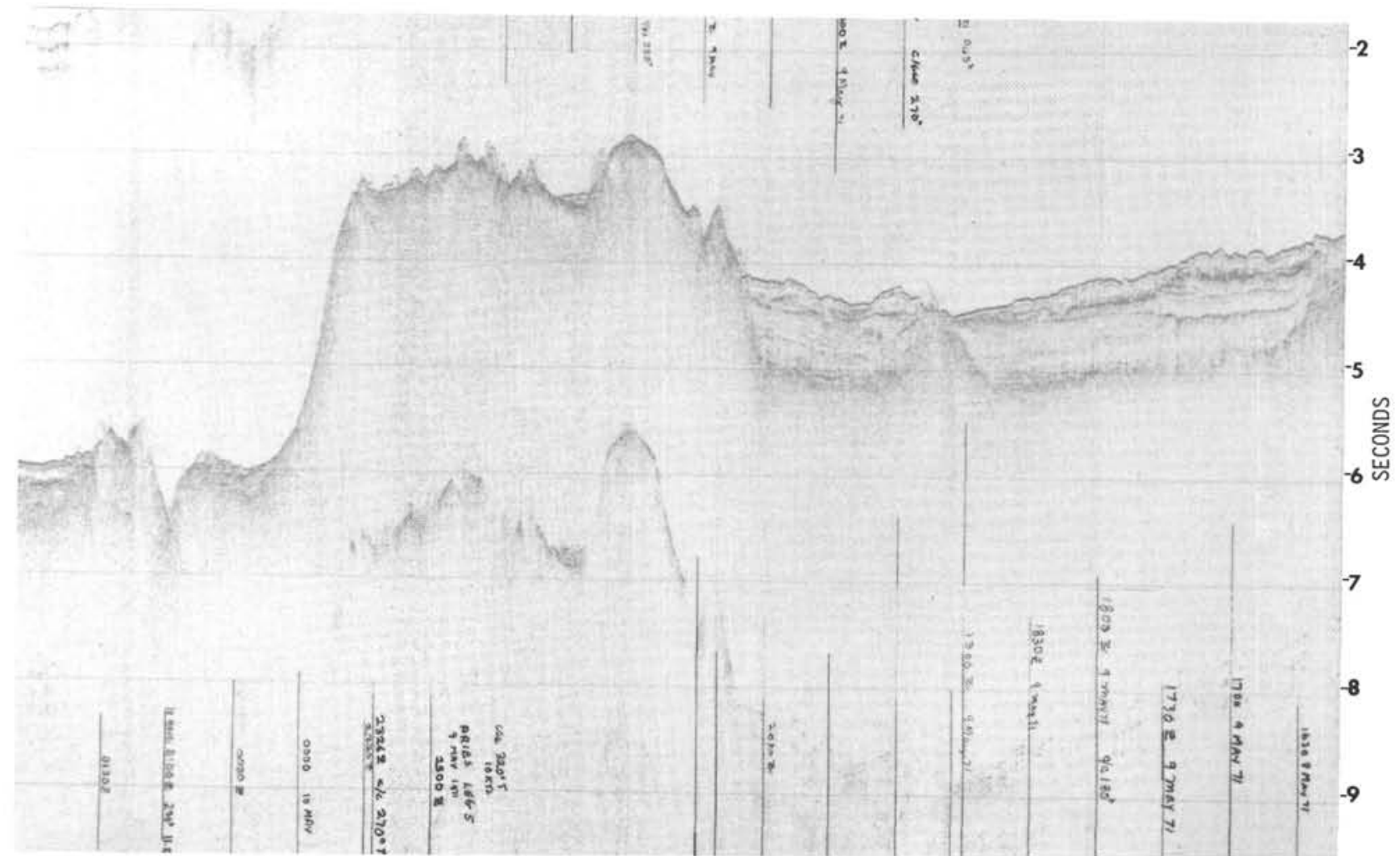

Figure 6. The elevated sediment pond which also appears on Figure 5 is banked against a nearly sediment free ridge. The sediment pond was the object of ARIES V DSDP Site investigation No. 1. See Figure 10.

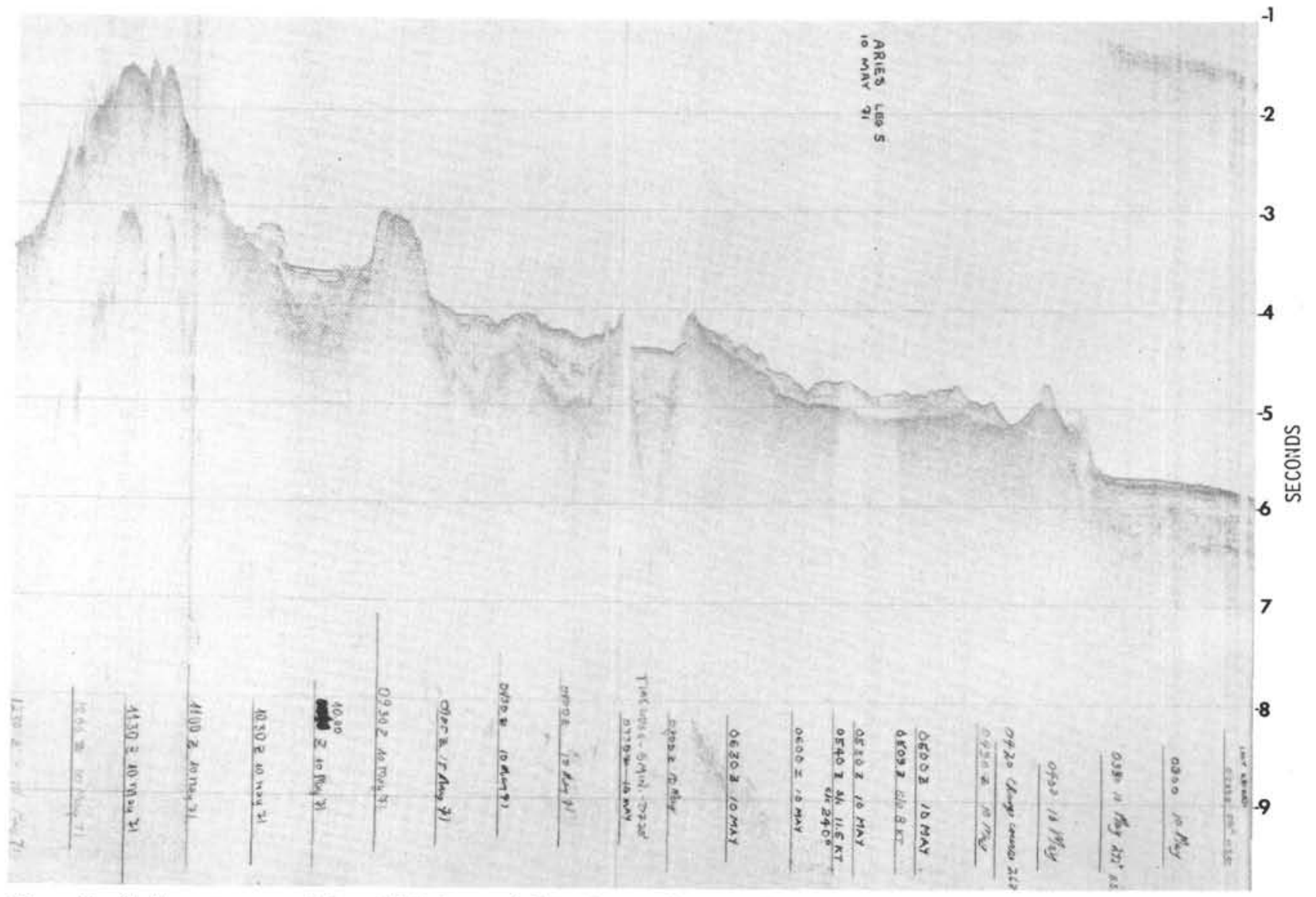

Figure 7. Sediment, up to $1 \mathrm{~km}$ thick is ponded in deep valleys on the eastern approach to a regular topped seamount of the Mid-Pacific Mountains. 


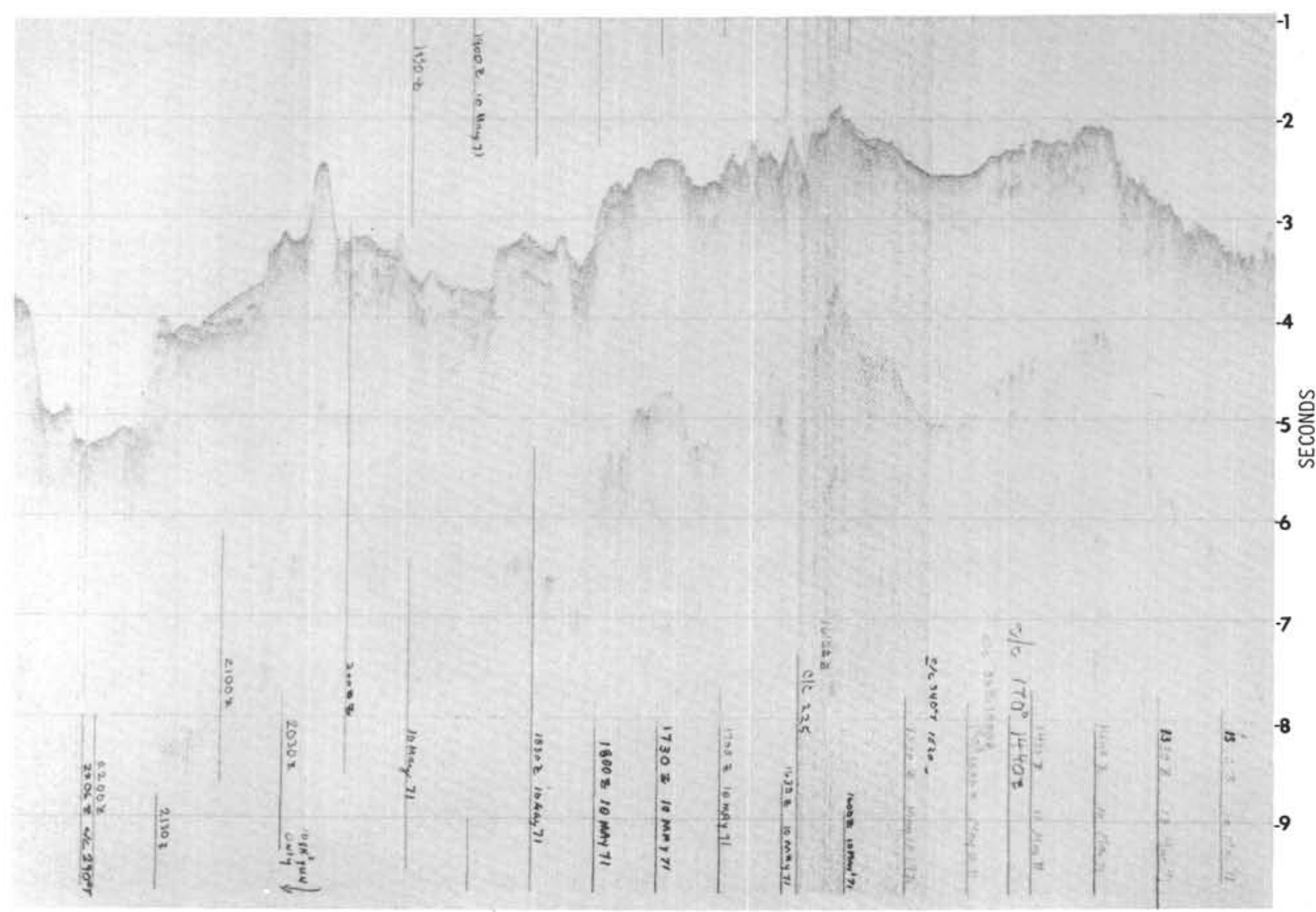

Figure 8. Sediment 0.5 to $1 \mathrm{~km}$ thick fills deep valleys on an irregular basement elevation within the Mid-Pacific Mountains. Deeper escarpments, as at left, appear bare of sediment.

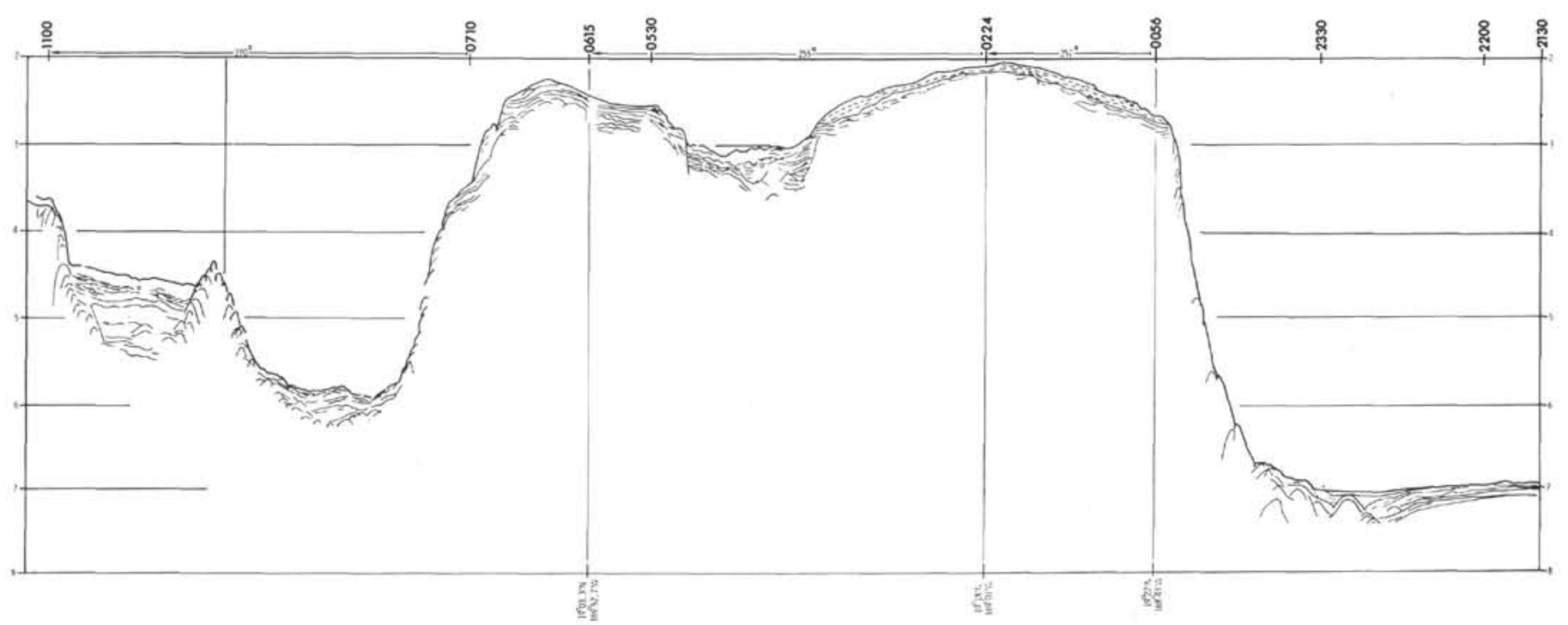

Figure 9. Tracing of seismic reflection record of Horizon Ridge showing location of DSDP Site 171. 


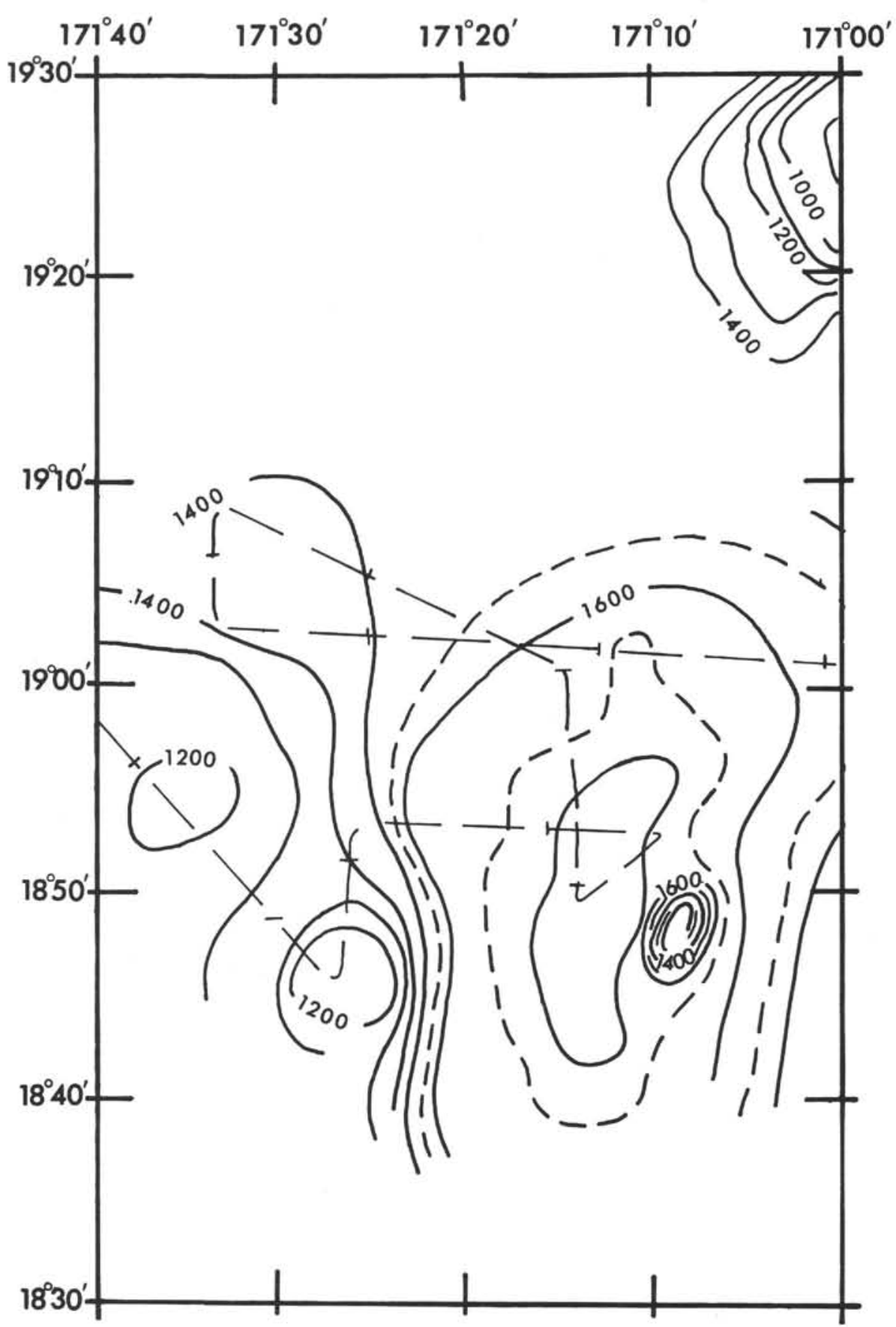

Figure 10. Navigation and bathymetry at ARIES V DSDP site investigation No. 1.

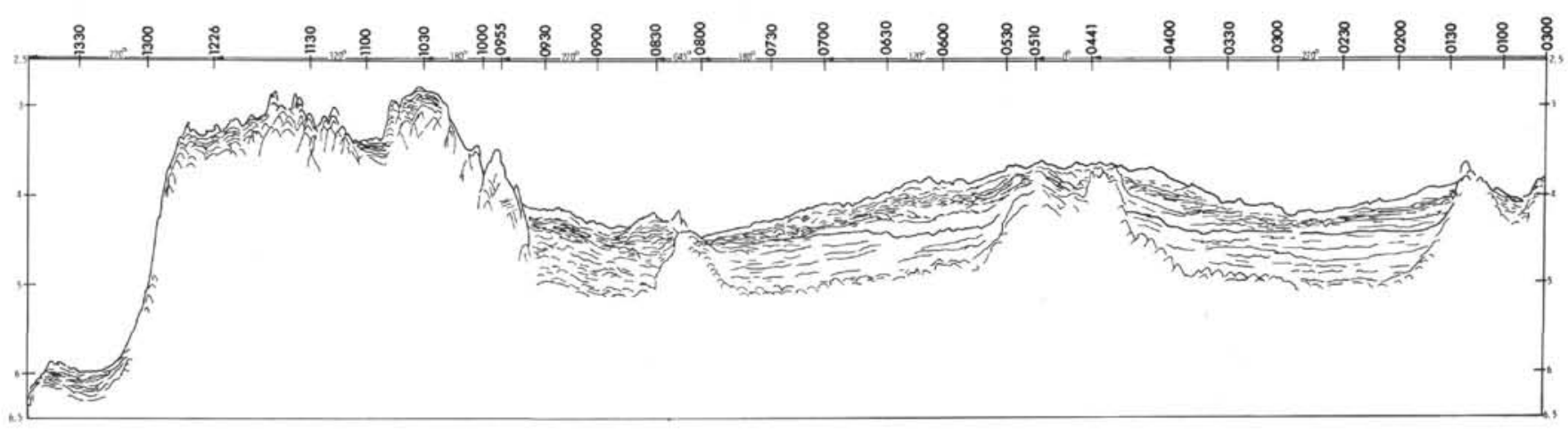

Figure 11. Line drawing of seismic reflection profile obtained at ARIES VDSDP site investigation No. 1 . 


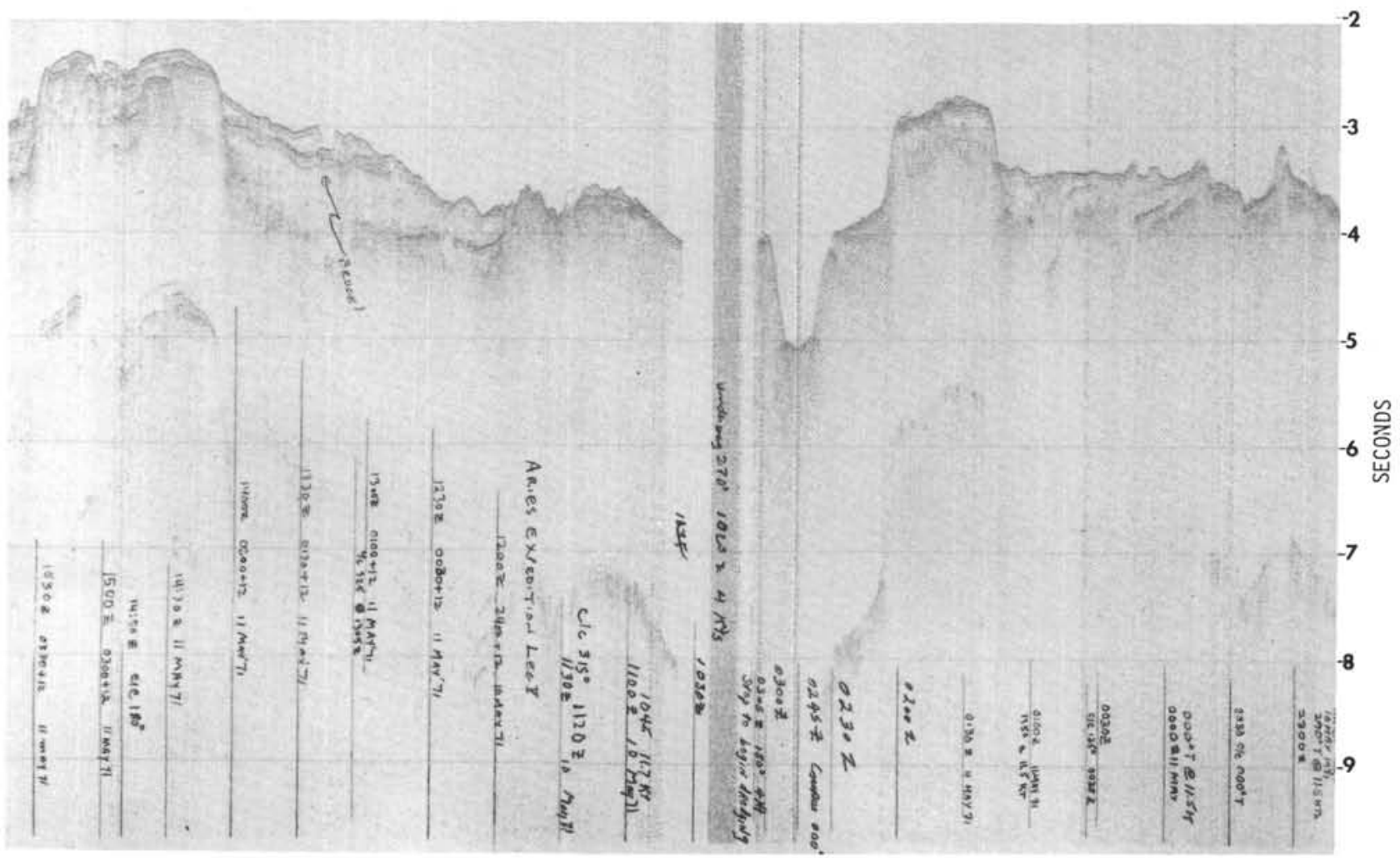

Figure 12. Seismic reflection record showing sediment accumulation banked against guyots of the eastern Mid-Pacific Mountains. Deeper escarpments and slope breaks at the summits of guyots appear to be the only prospective dredging sites.

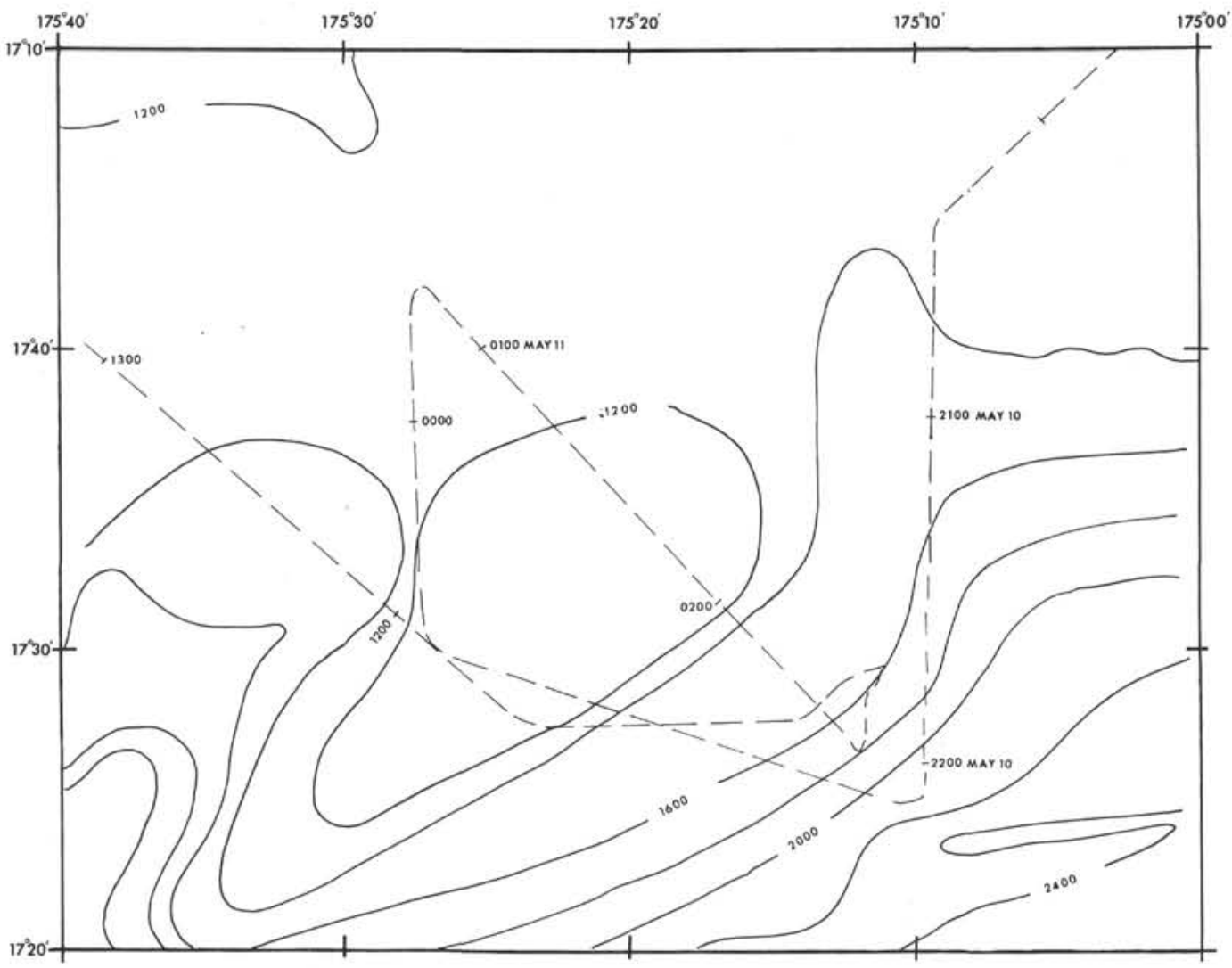

Figure 13. ARIES V DSDP site investigation No. 2, track and bathymetric sketch. 


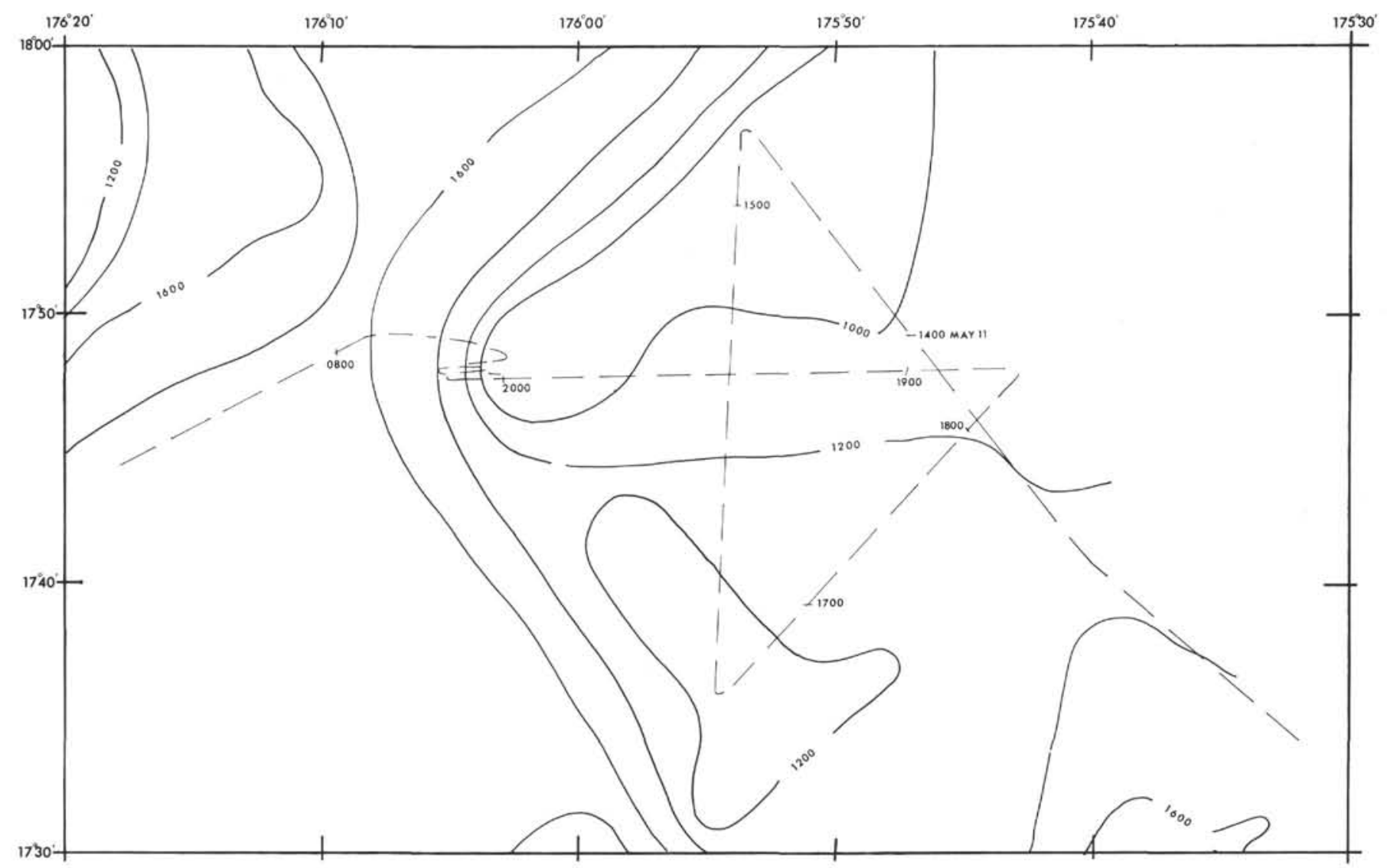

Figure 14. Track and bathymetric sketch ARIES V DSDP site investigation No. 3. 


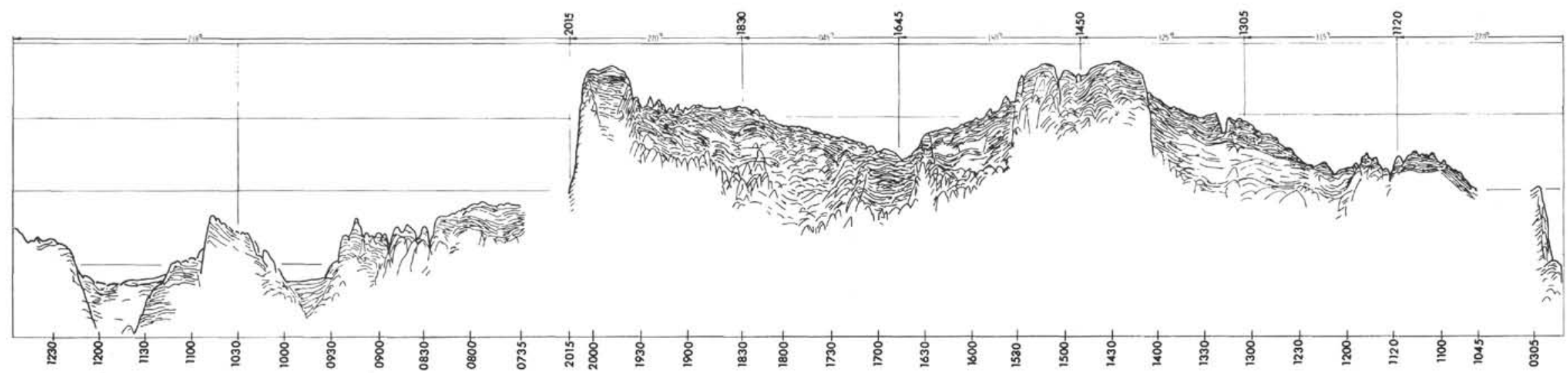

Figure 15. Tracing of reflection record obtained at DSDP site investigation No. 3 .

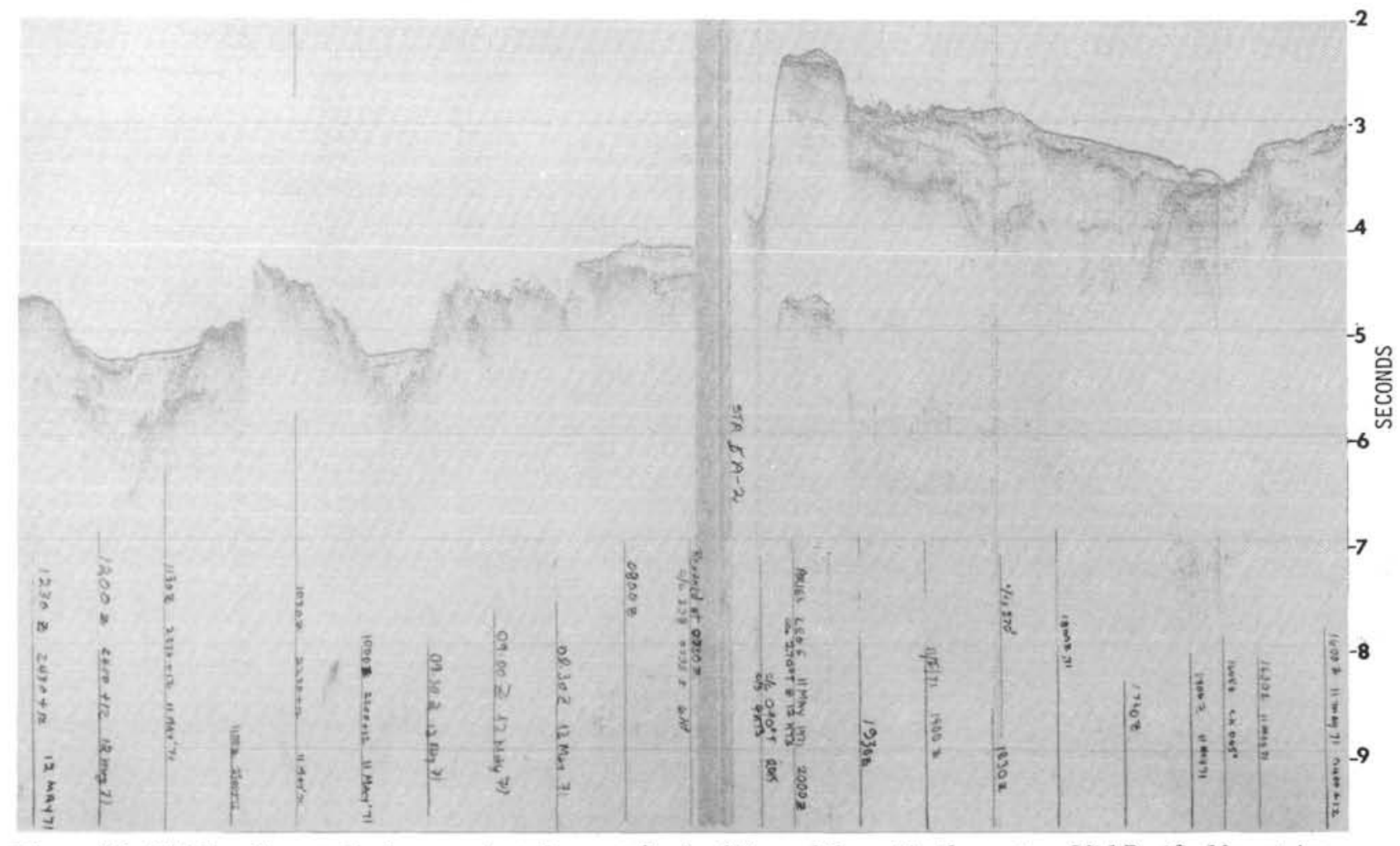




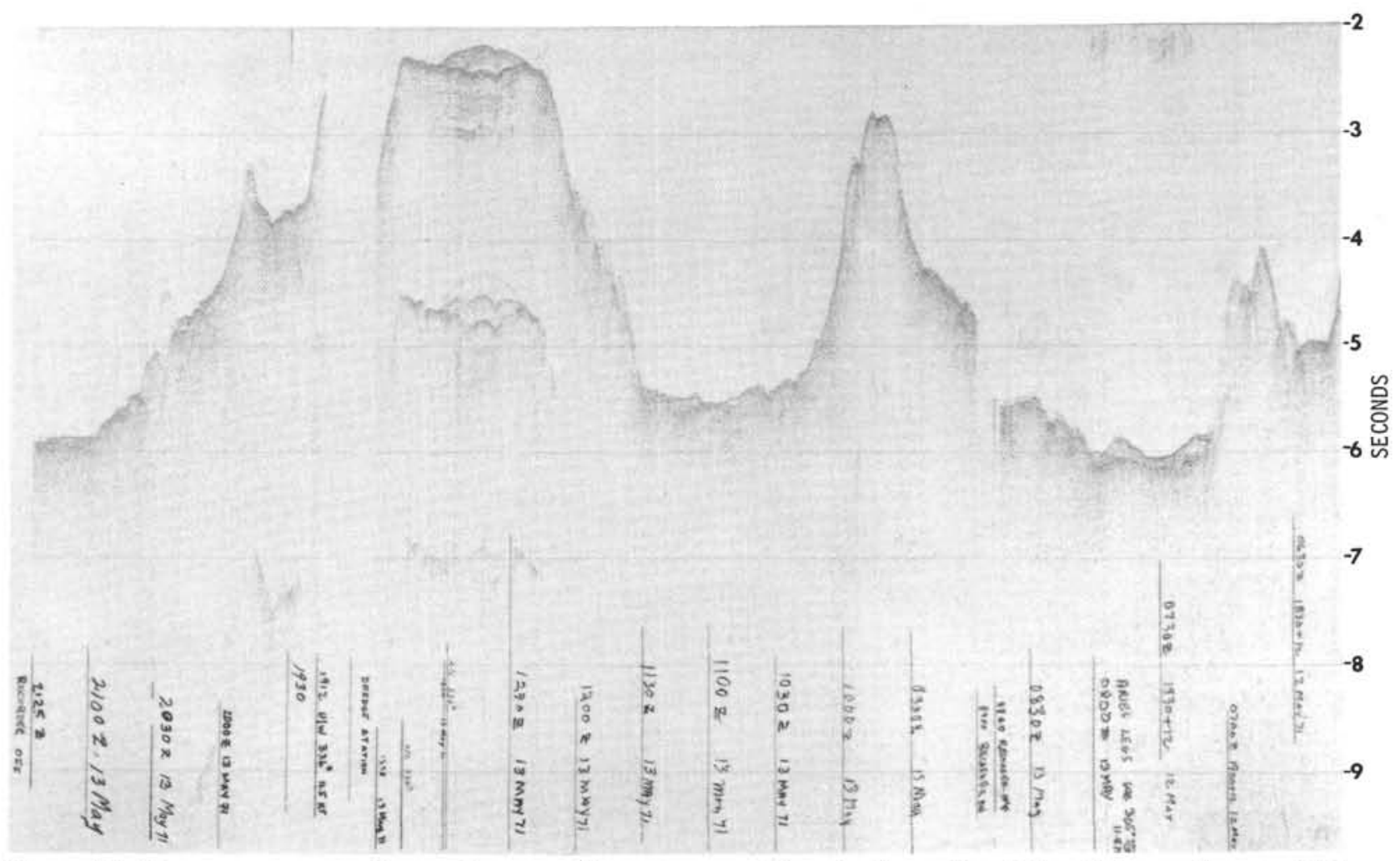

Figure 17. The transparent sediments become thin to the west. The seismic profile of Cape Johnson Guyot, which was obtained between the records shown in Figures 17 and 18, is found in Chapter 31. Sediment embankments observed on the flanks of the guyots become thinner and eventually disappeared as the cruise passed from east to west through the Mid-Pacific Mountains. The transparent sediment caps are still very thick on Navoceano Guyot, shown in this figure.

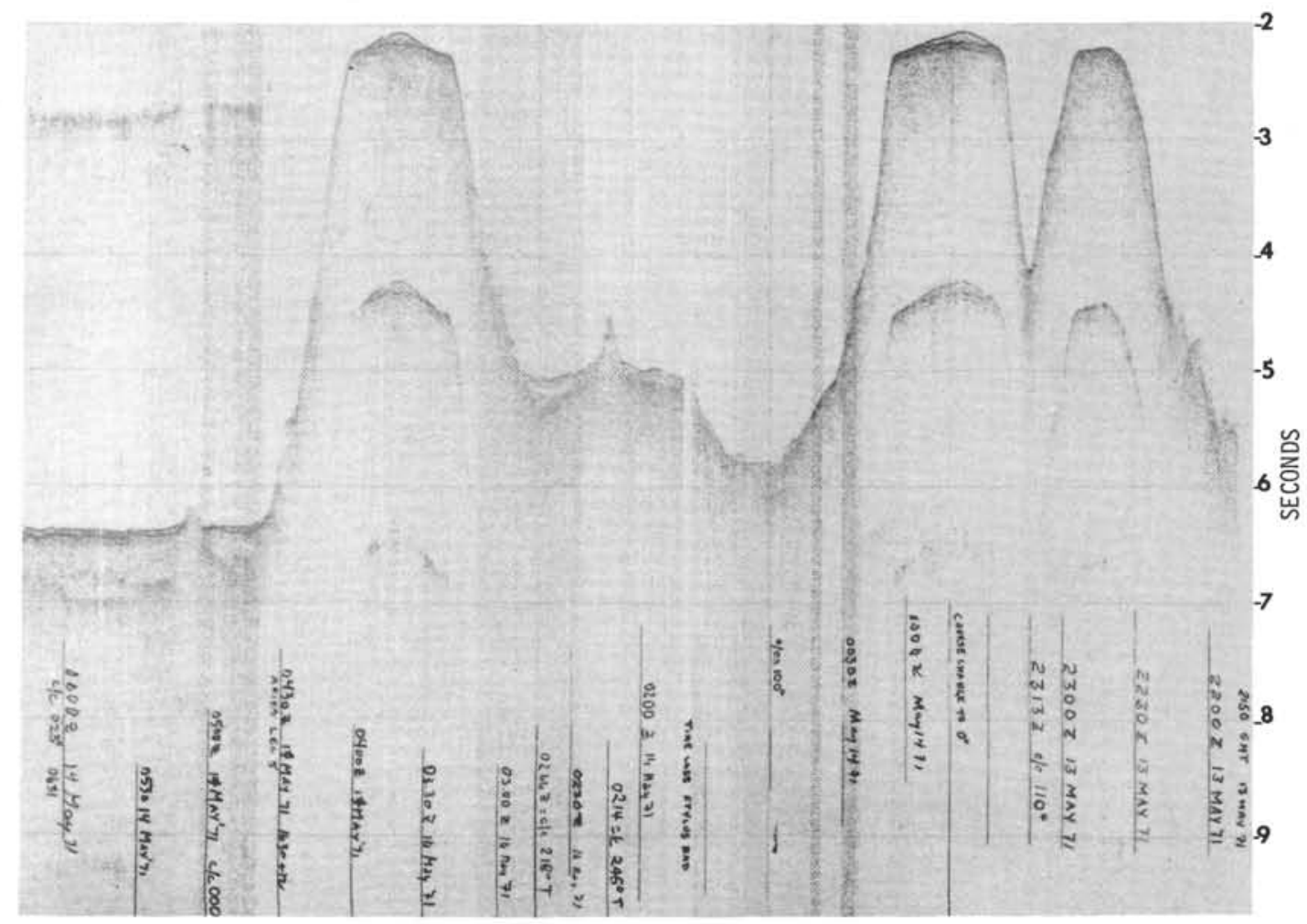

Figure 18. Seismic profile of Shepard Guyot showing a decrease in sediment embankments. Note, however, the thick ponded sediment of the interior basin. 


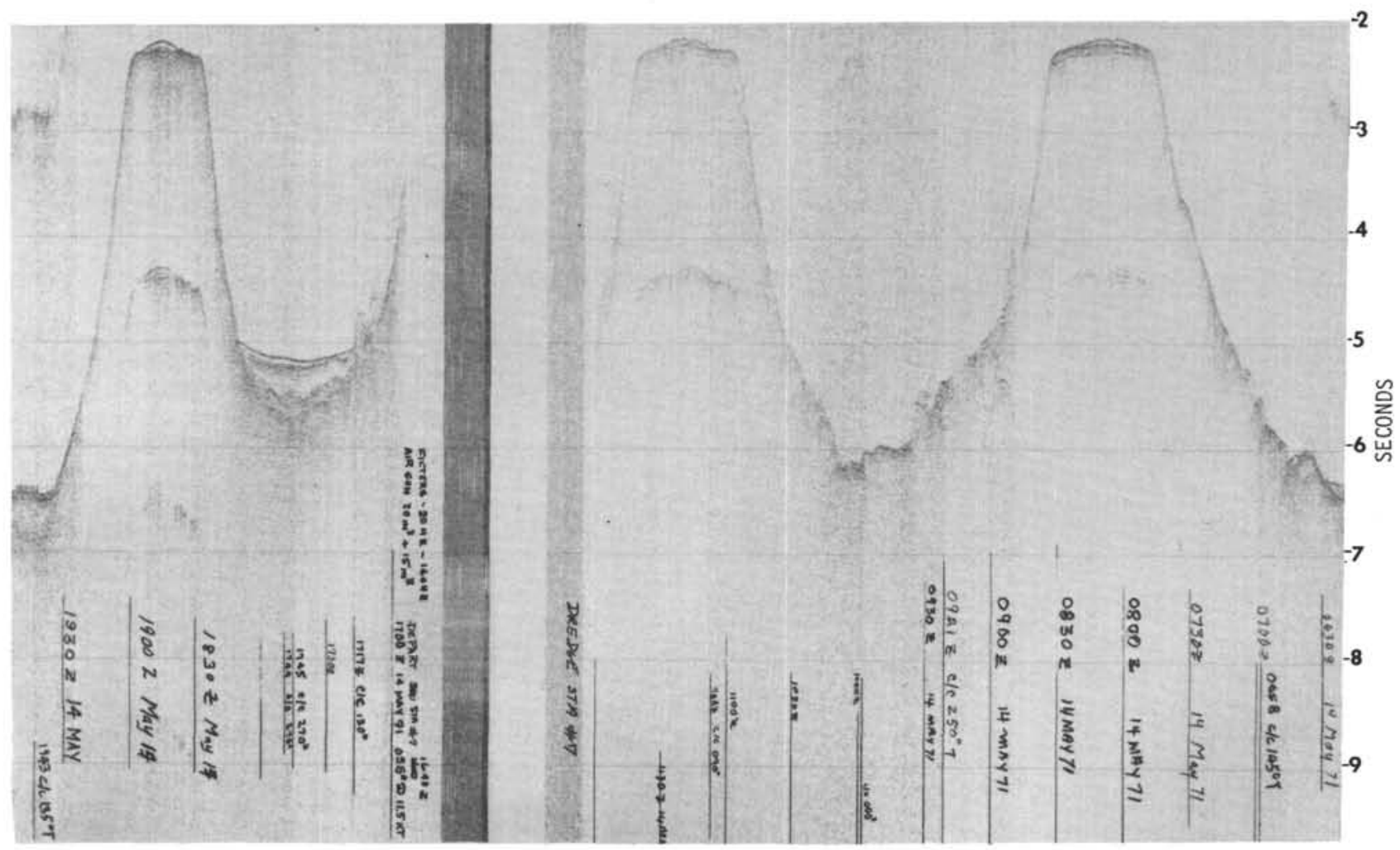

Figure 19. Seismic reflection profiles of Shepard Guyot.

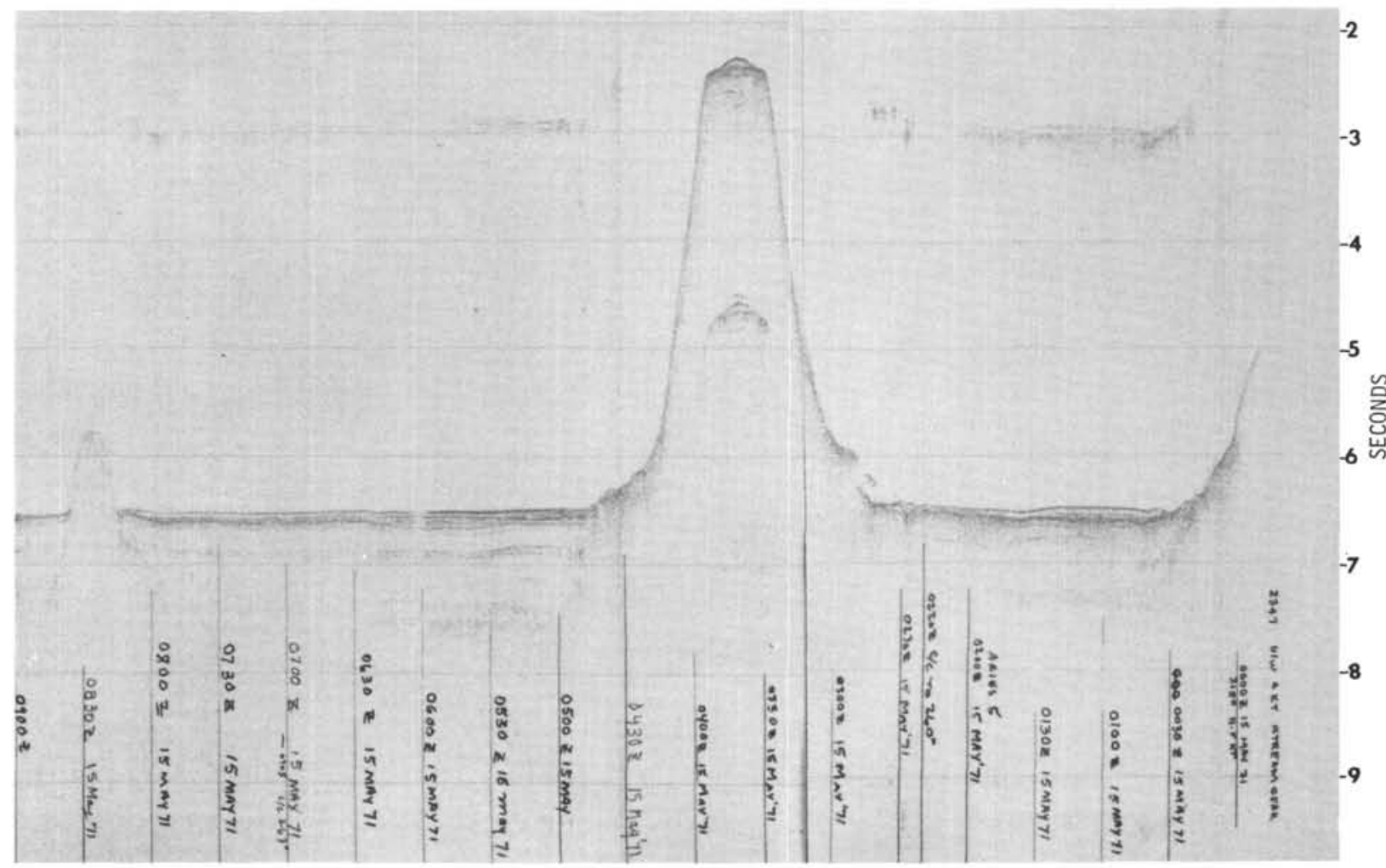

Figure 20. The ARIES $V$ seismic reflection profile records a thick sediment pond west of Shepard Guyot. Revelle Guyot in the center of this figure possesses a thick transparent cap. 


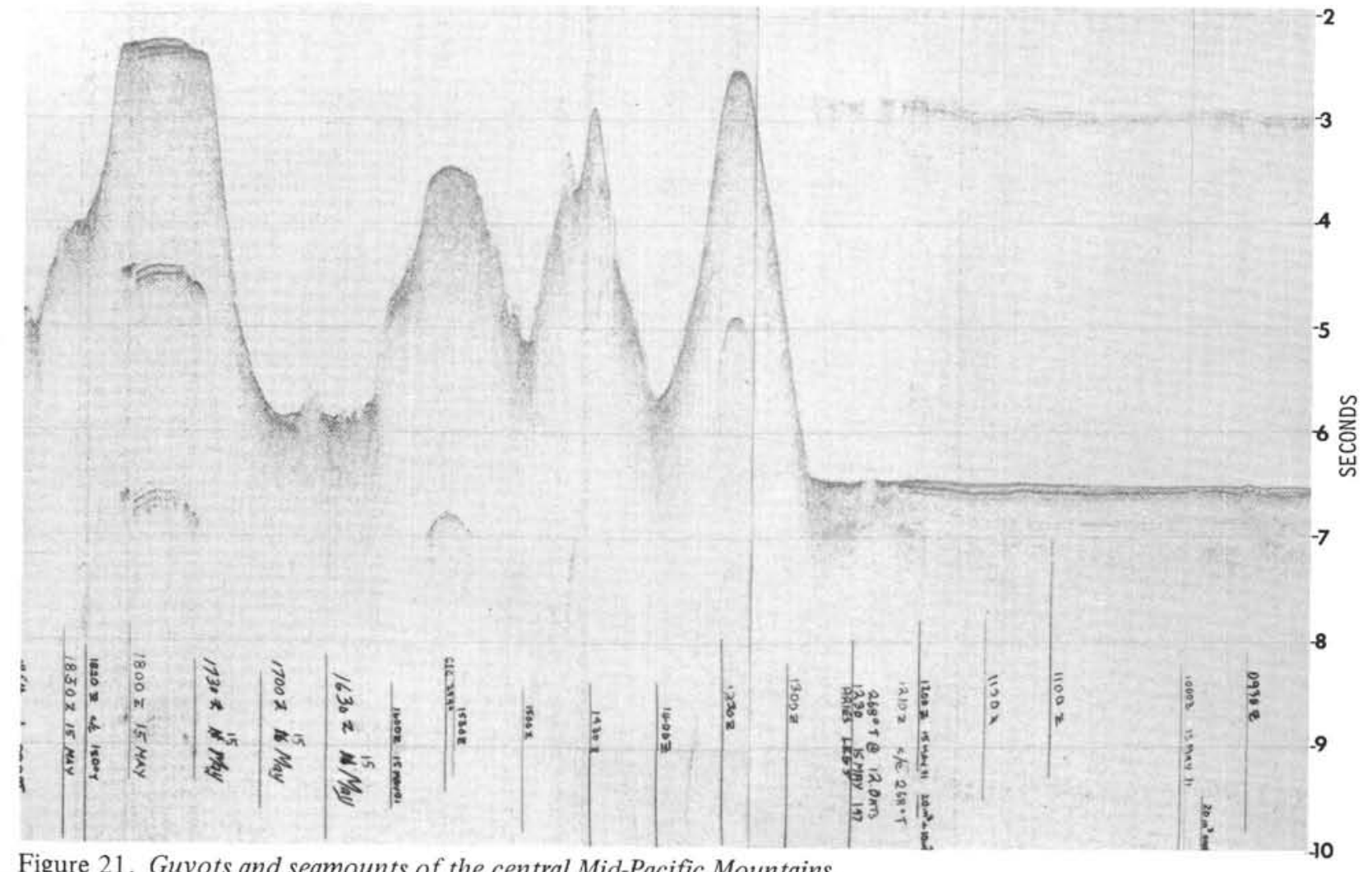

Figure 21. Guyots and seamounts of the central Mid-Pacific Mountains.

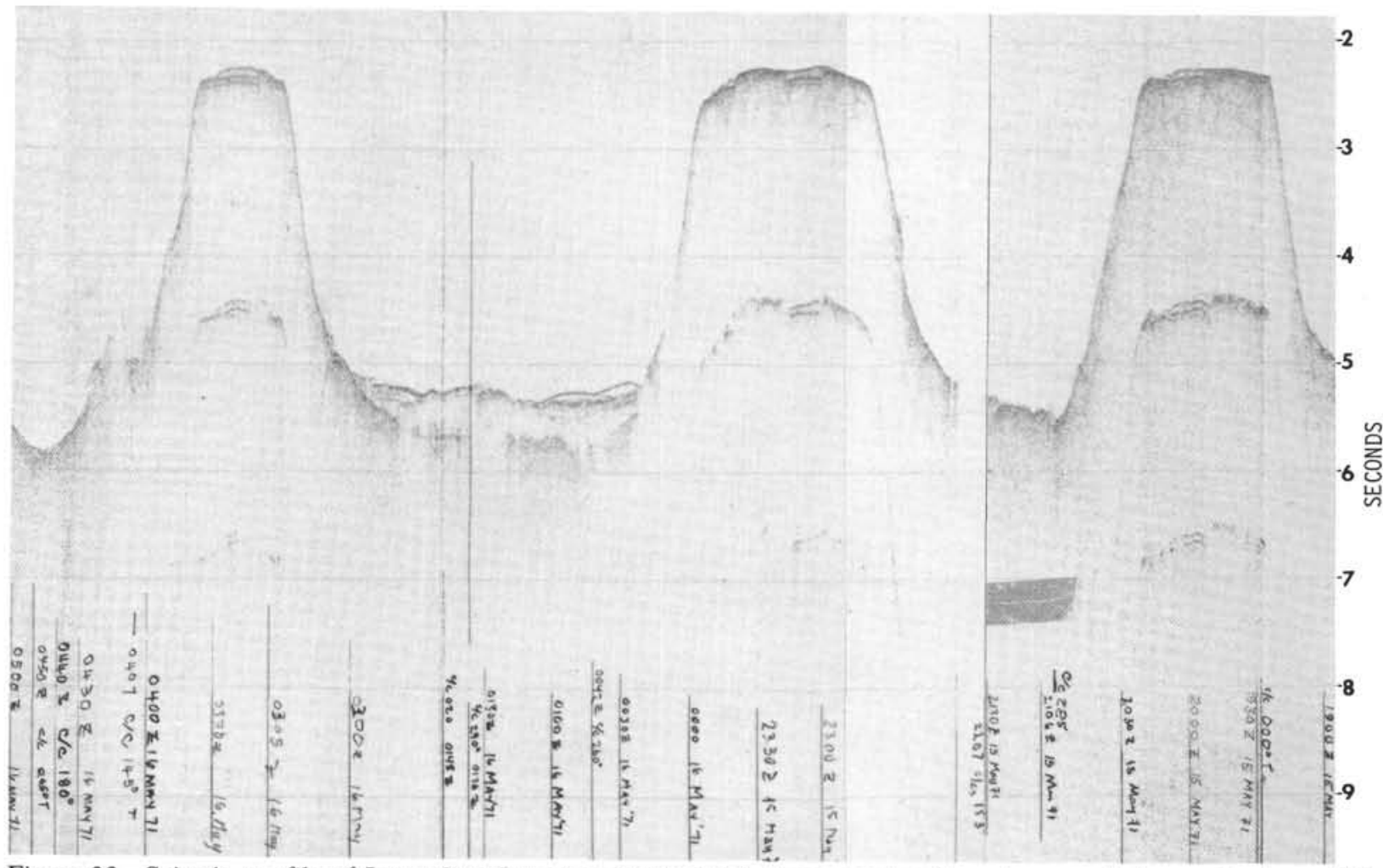

Figure 22. Seismic profile of Jacqueline Guyot: note the thick transparent sediment accumulation at the base of the seamount. 


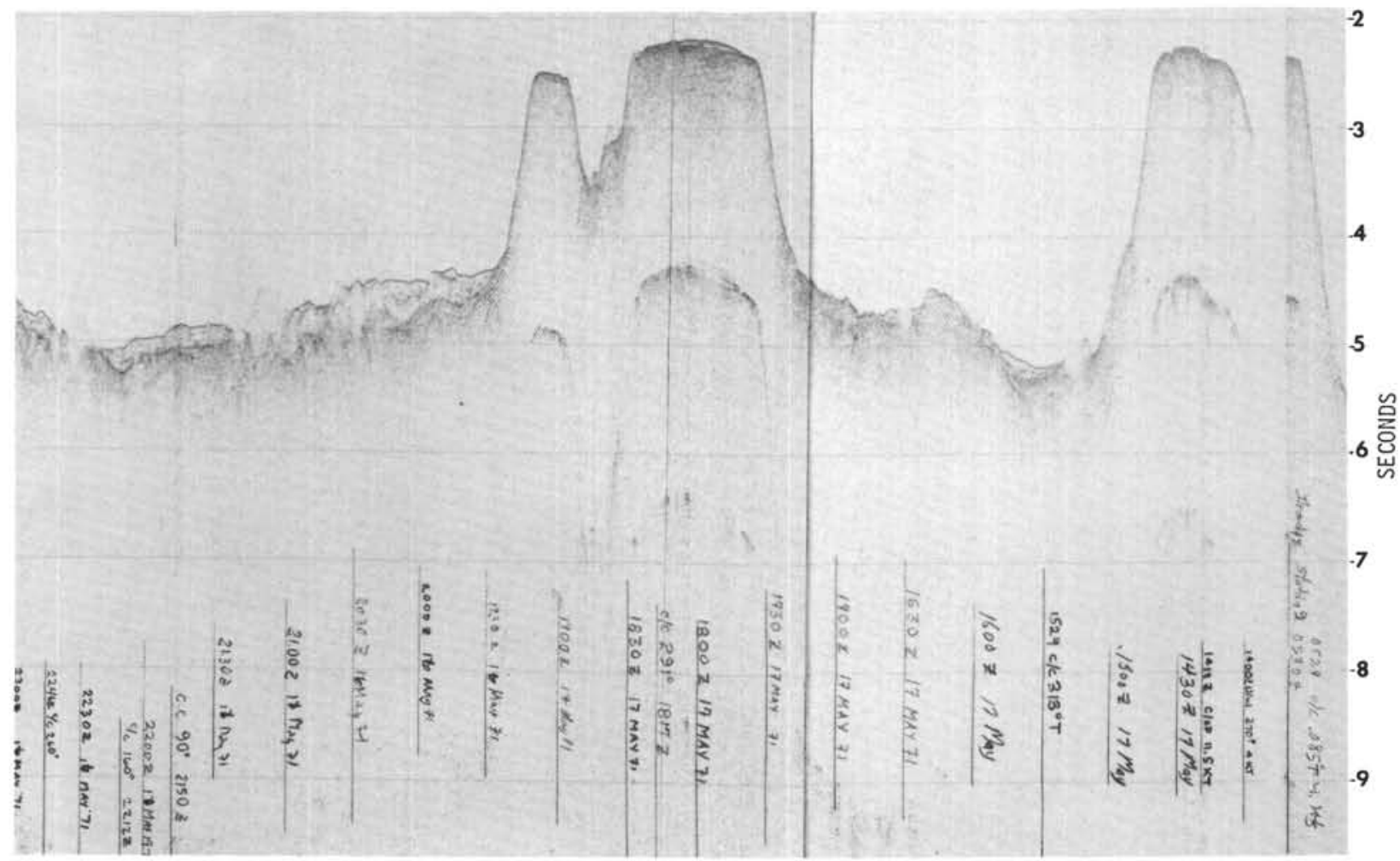

Figure 23. Lying west of Jacqueline Guyot, the unequal twin Stetson-Hill Guyots possess even thinner transparent caps, and the deeper layers, if present, are much thinner than on those guyots further to the east. The disturbed sediment lying west of the guyots may be related to a semi-active fracture zone.

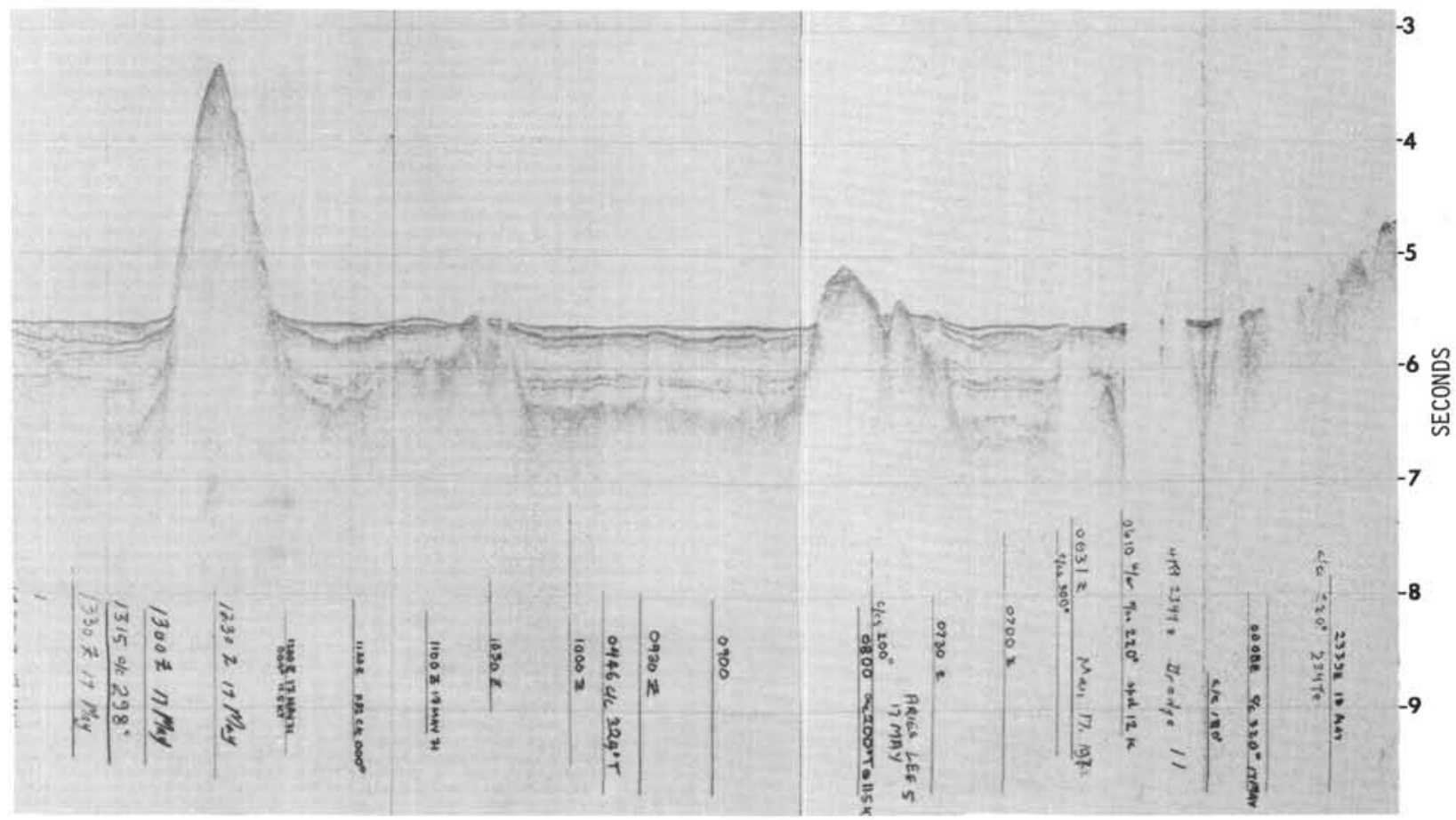

Figure 24. Thick even layers of sediment fill the depressions between the guyots and seamounts of the western Mid-Pacific Mountains. Capping of transparent sediment is much diminished but the ponded basin sediments are as well developed as in the east. 


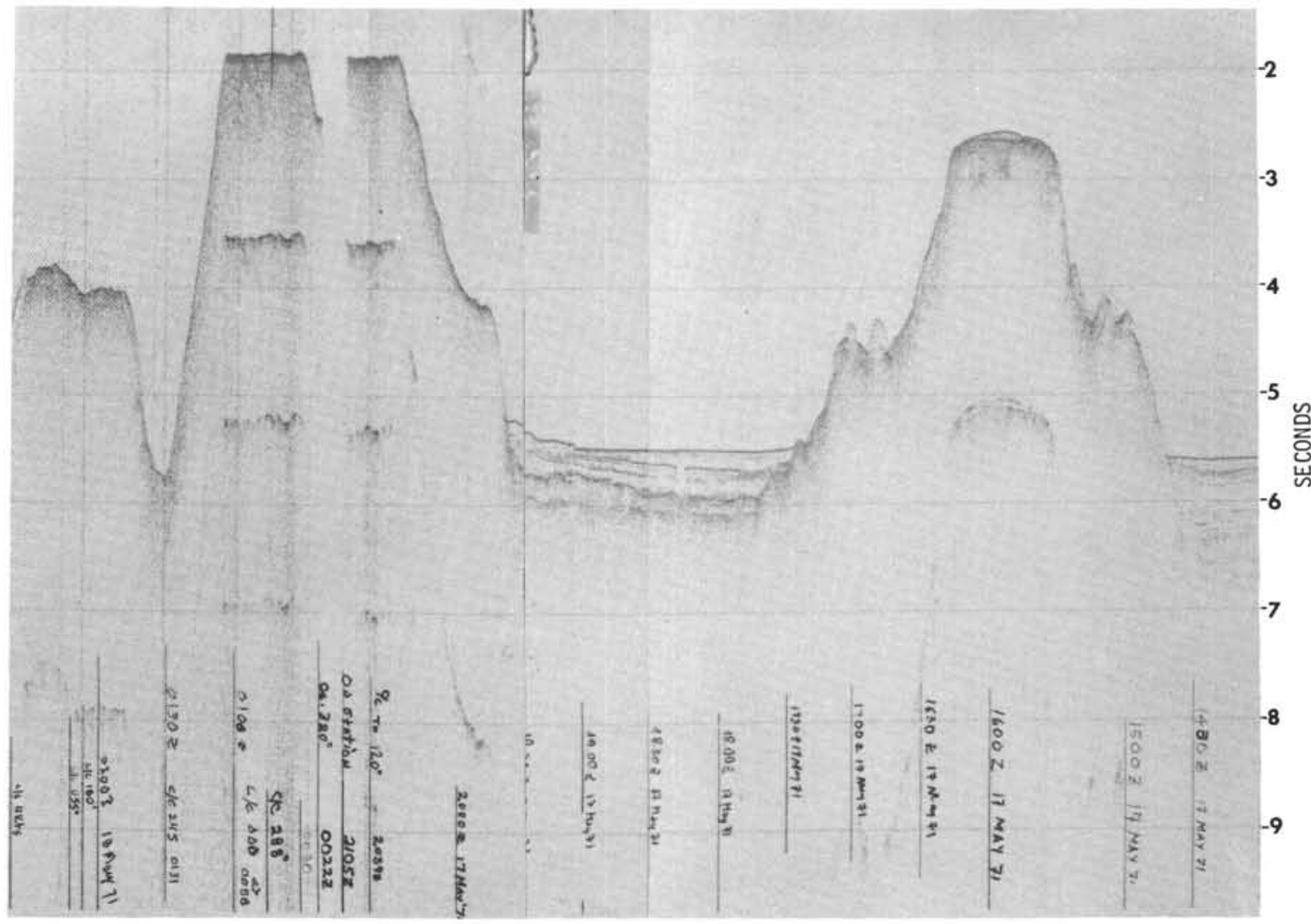

Figure 25. The basin between the 1200 fathom Ewing Guyot and the 800 fathom Menard Guyot, at the western limit of the Mid-Pacific Mountains, is filled with ponded sediment. Menard Guyot stands higher, is flatter, and lacks a transparent accumulation on its summit.

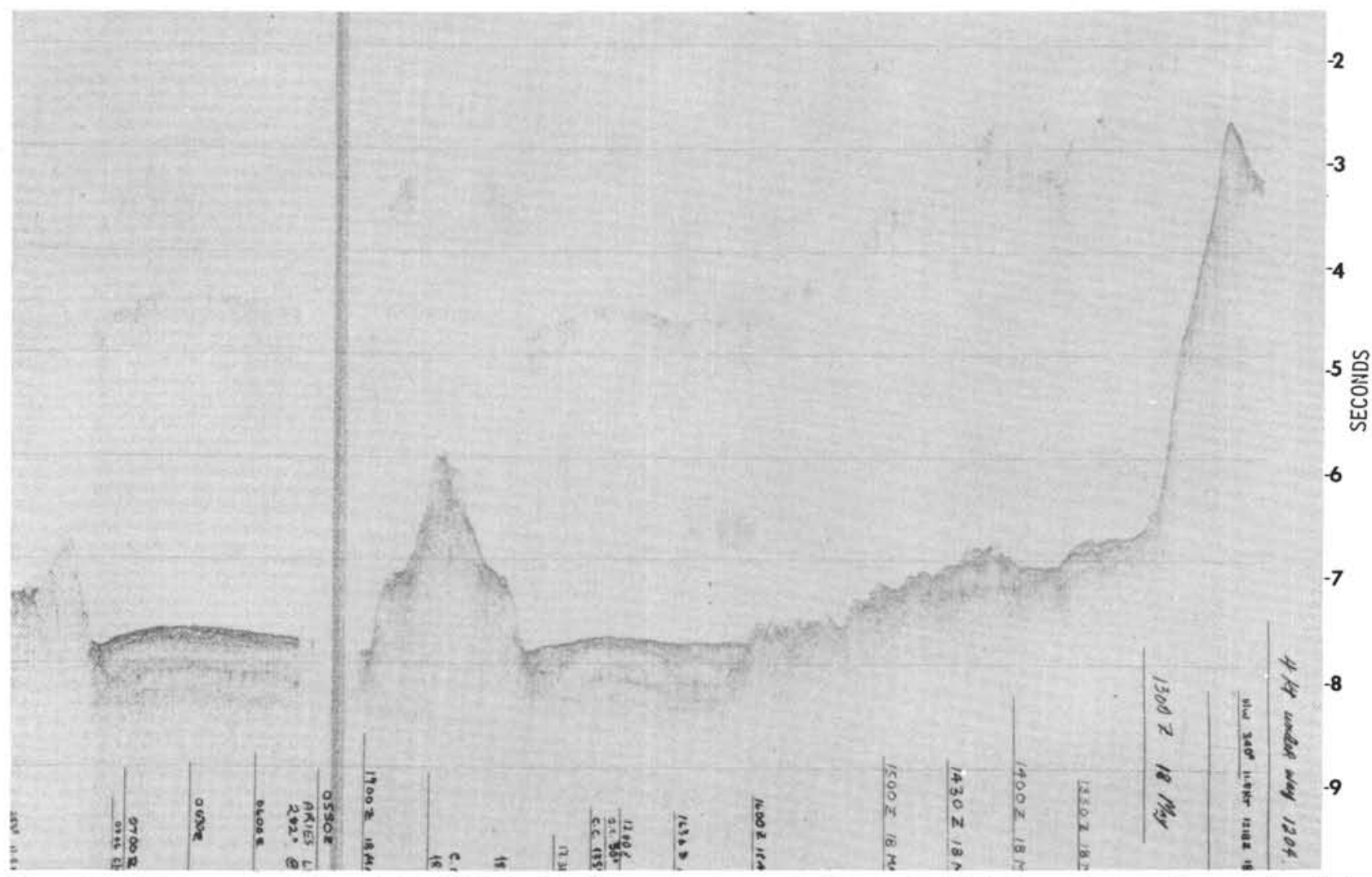

Figure 26. The western edge of the Mid-Pacific Mountains is marked by a decided deepening at the margin of the adjacent basin and an abrupt thinning of the transparent sediments. The relatively steep slope between the Mid-Pacific Mountain platform and the deep northwestern Pacific basin is shown in this profile. 


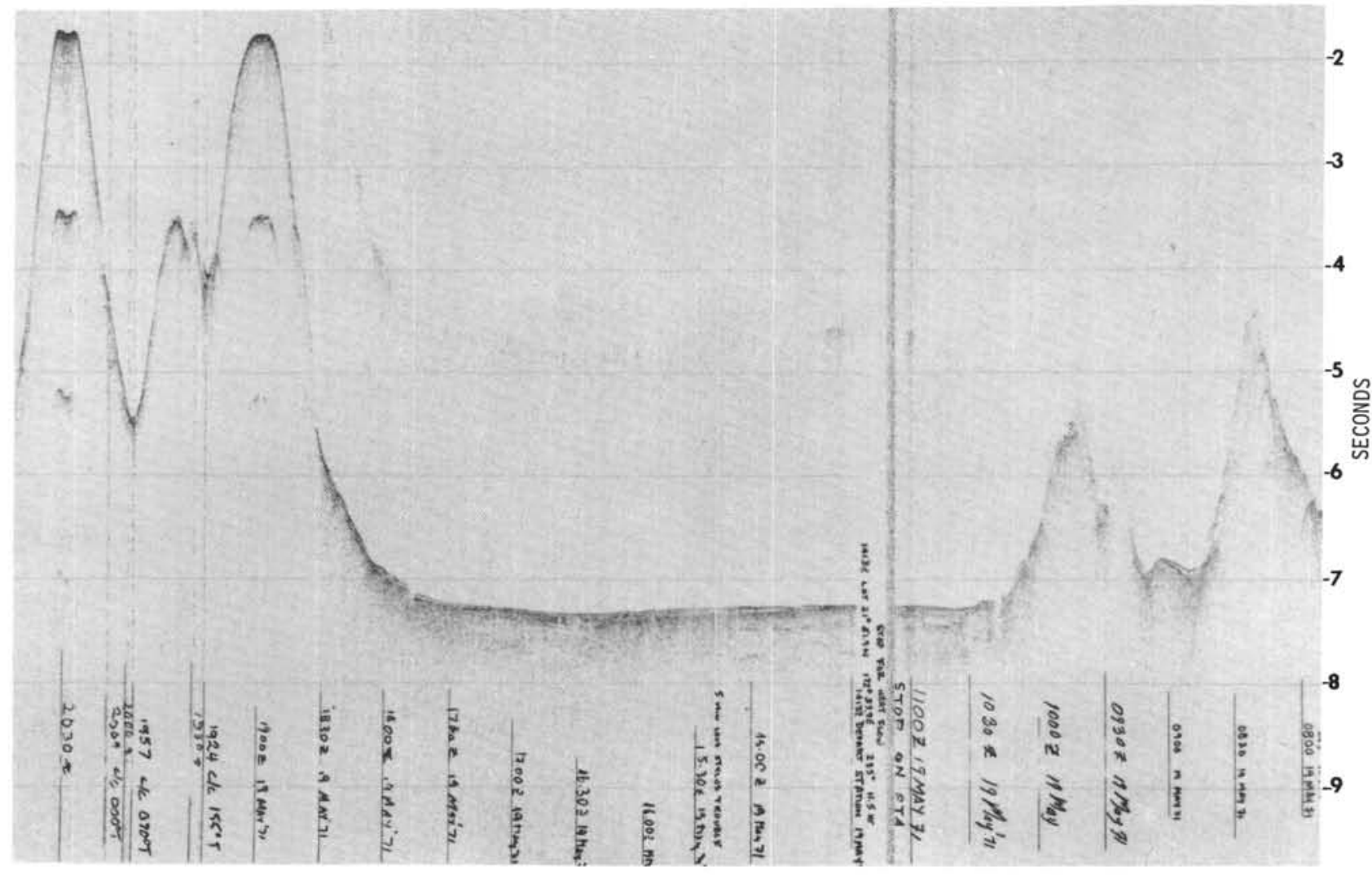

Figure 27. The floor of the deep western Pacific basin between the western margin of the Mid-Pacific Mountains and Darwin Guyot is underlain by a thick sequence of sediments which are apparently less transparent than those which fill the basins between the Mid-Pacific Mountains.

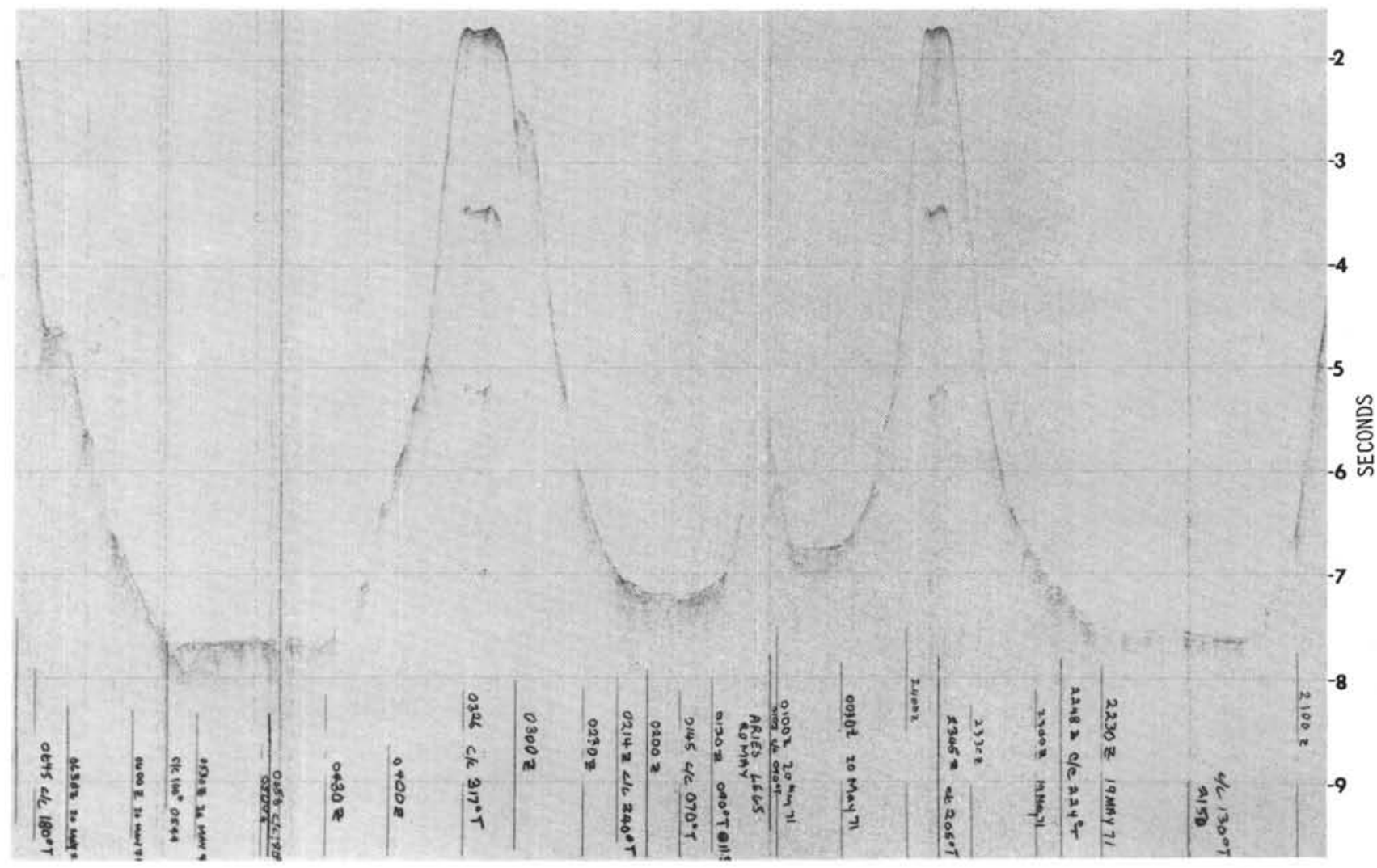

Figure 28. Darwin Guyot appears to have little or no sediment cap on its small summit. 


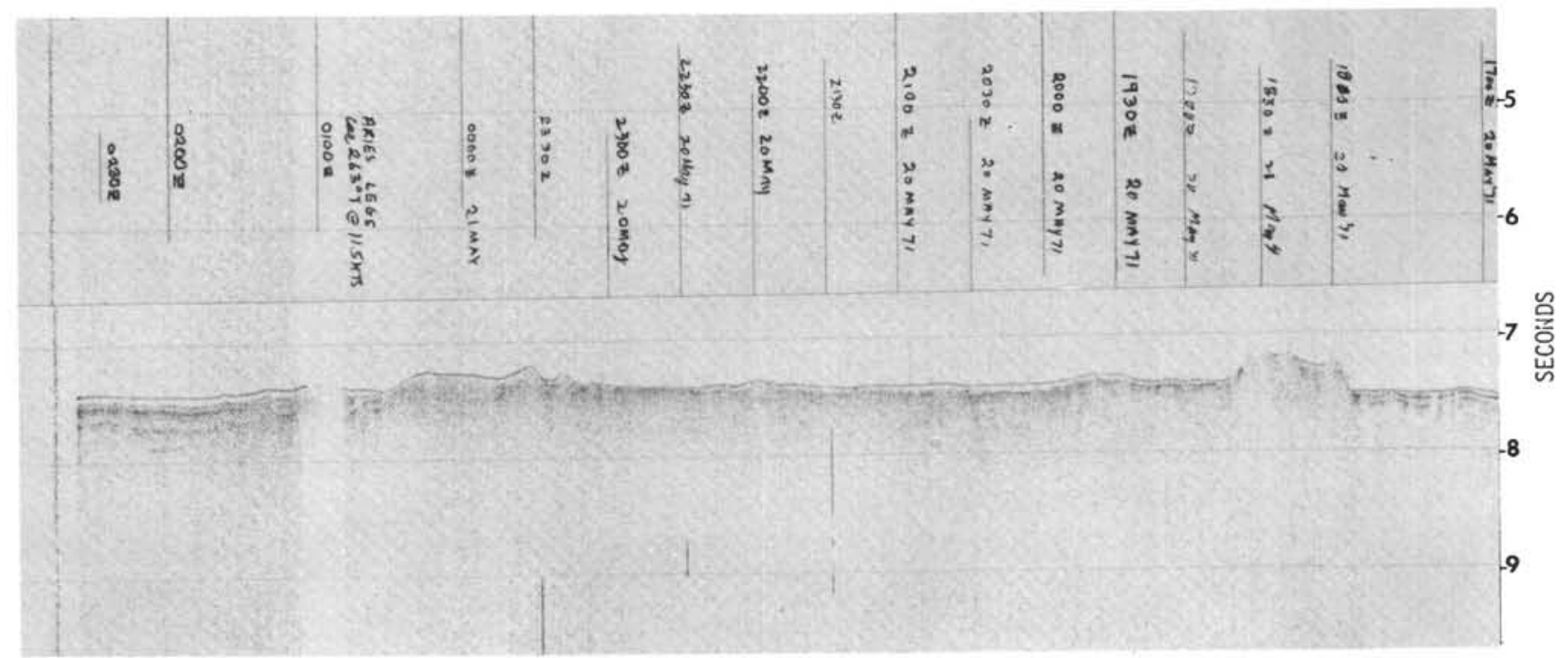

Figure 29. In the deep Pacific basin between the Mid-Pacific Mountains and the Wake Guyot group, sufficient sediment for spudding-in are locally present over an attractive sequence of deeper reflectors.

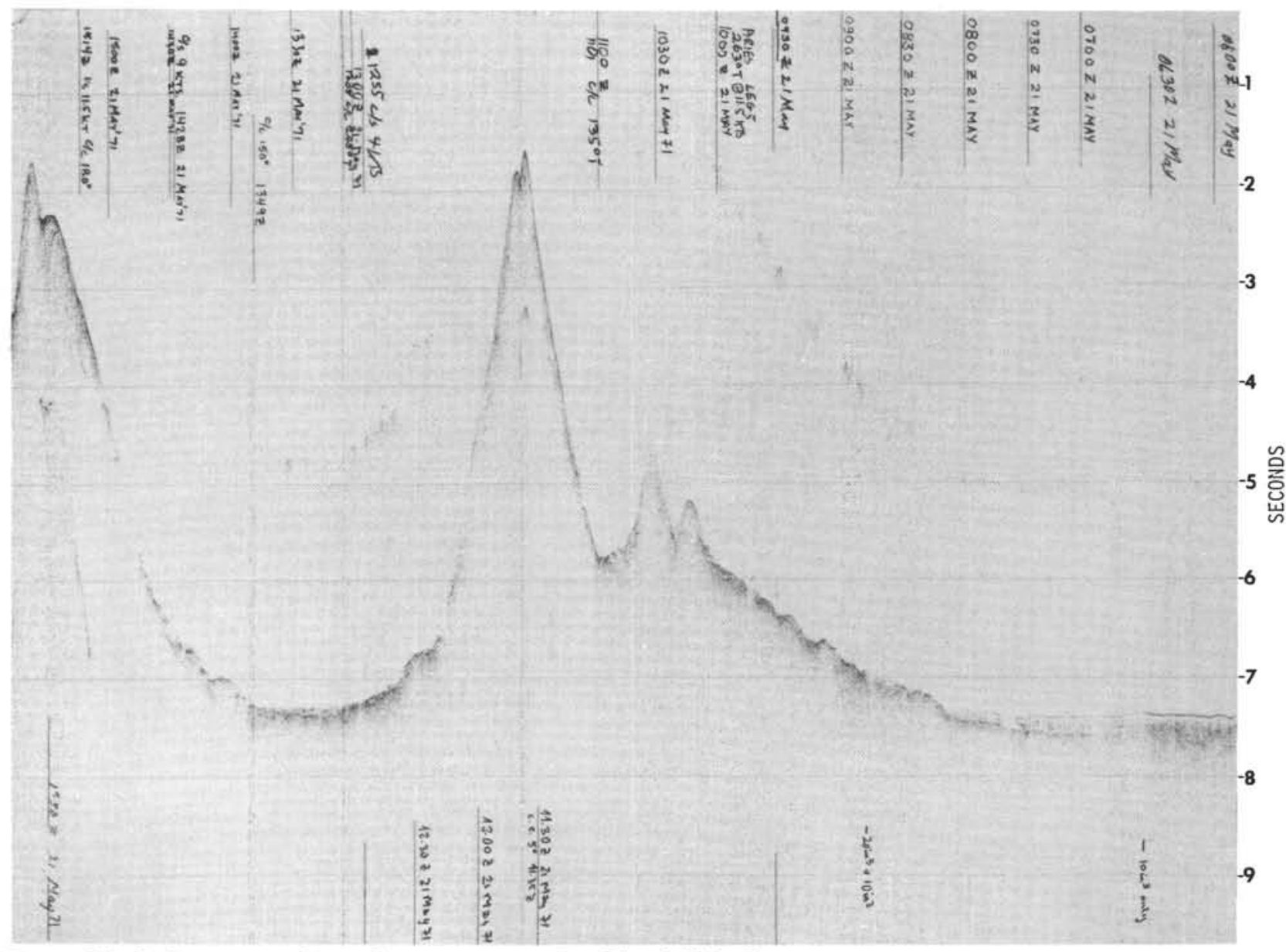

Figure 30. Sediments are thin in the areas surrounding Woods Hole Guyot. 


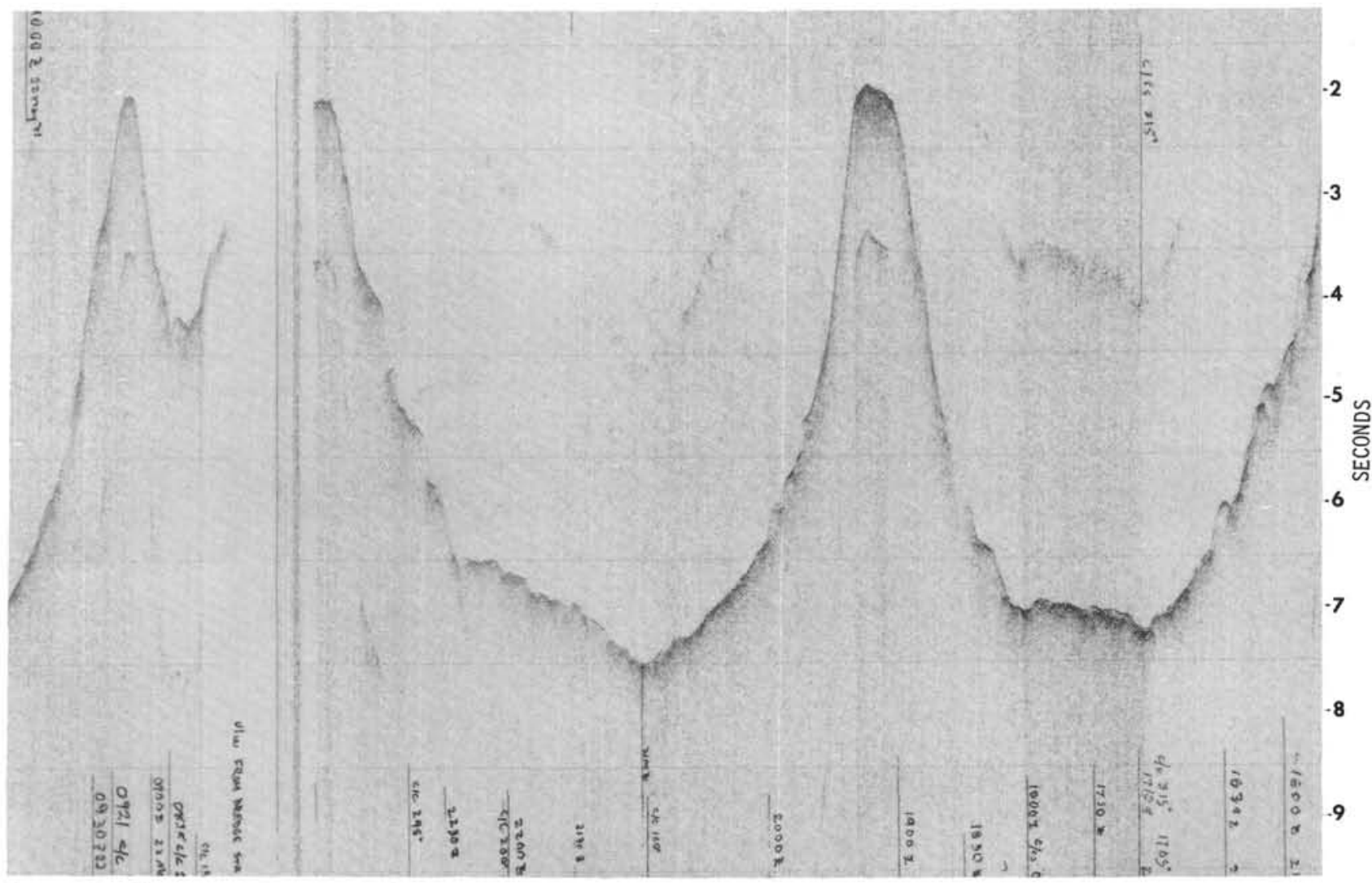

Figure 31. Seismic reflection profile across Woods Hole Guyot.

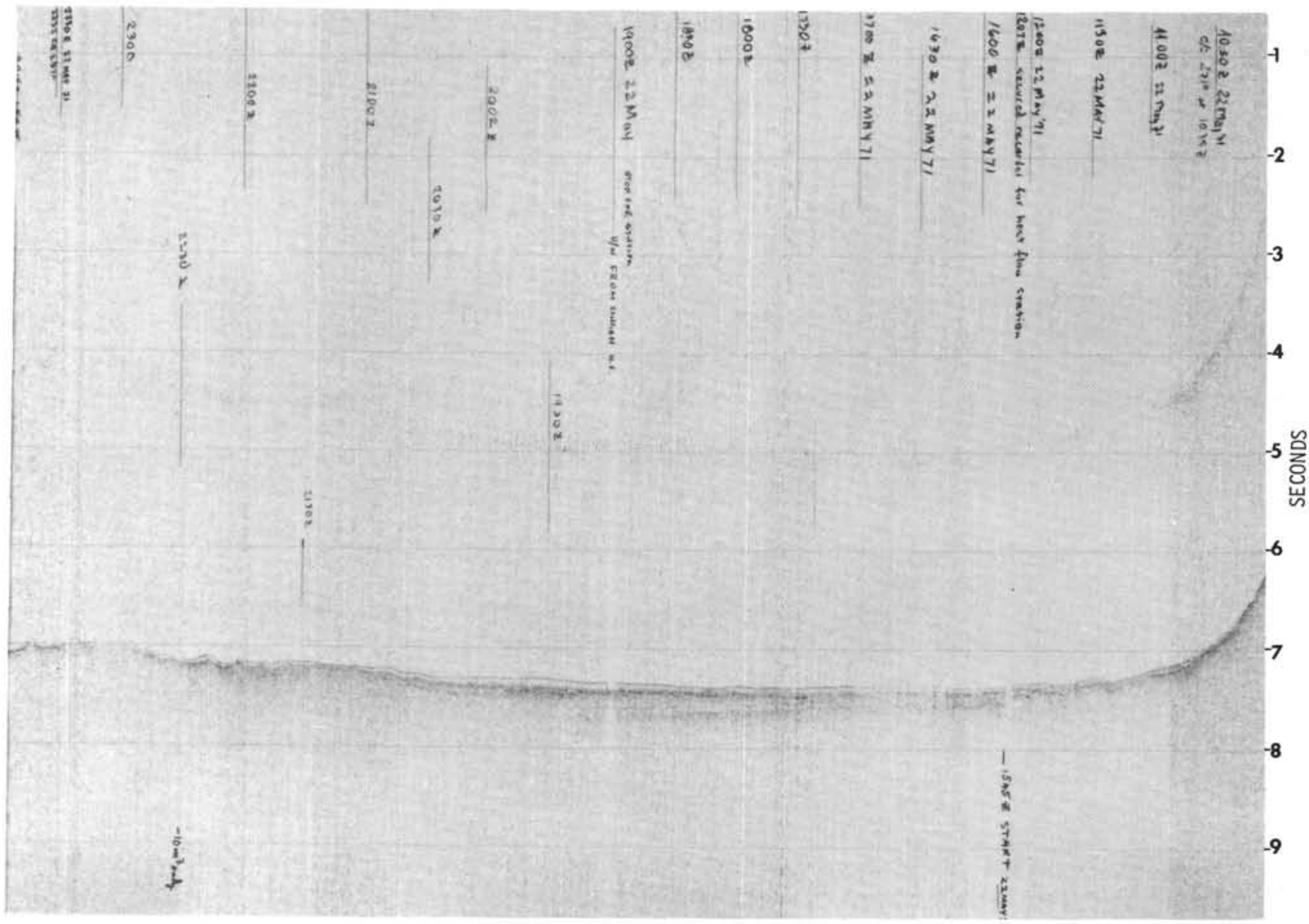

Figure 32. The deepest reflector in the deep basin between Woods Hole Guyot and Wilde Guyot is smooth and suggests the presence of still deeper strata. 


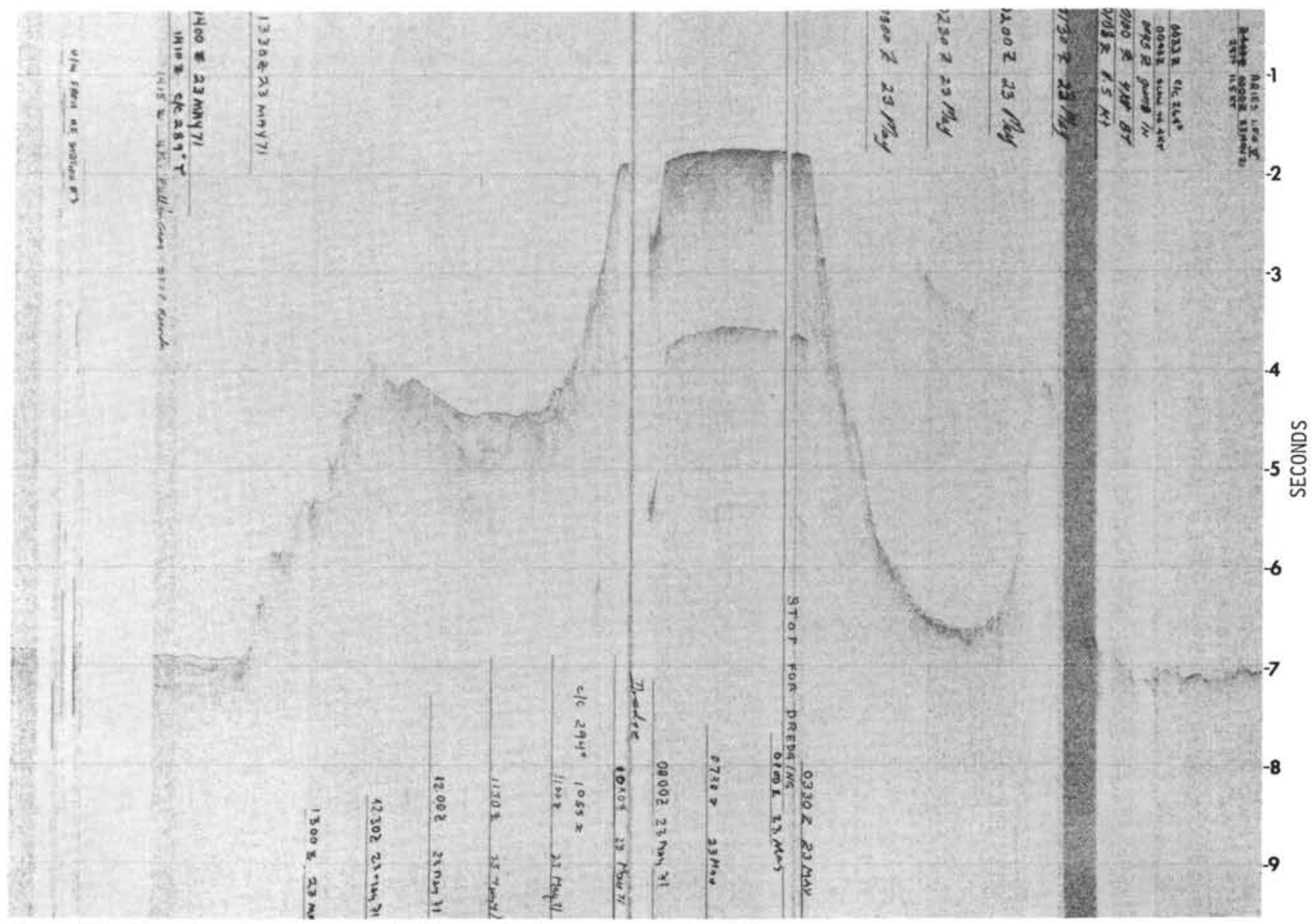

Figure 33. No reflections are recorded beneath the even summit of this guyot.

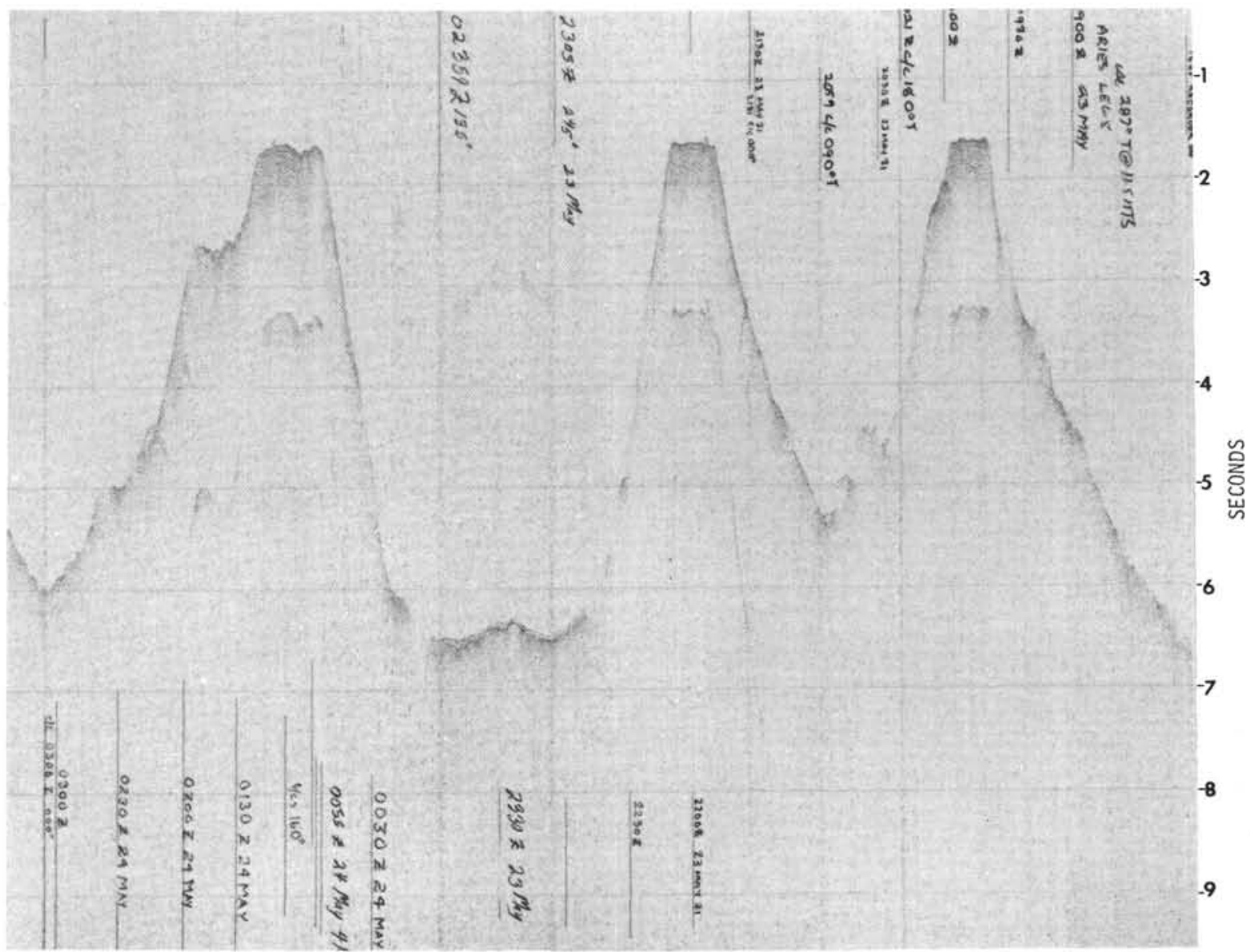

Figure 34. Small pinnacles protrude from the summit of a guyot in the Wake group. 


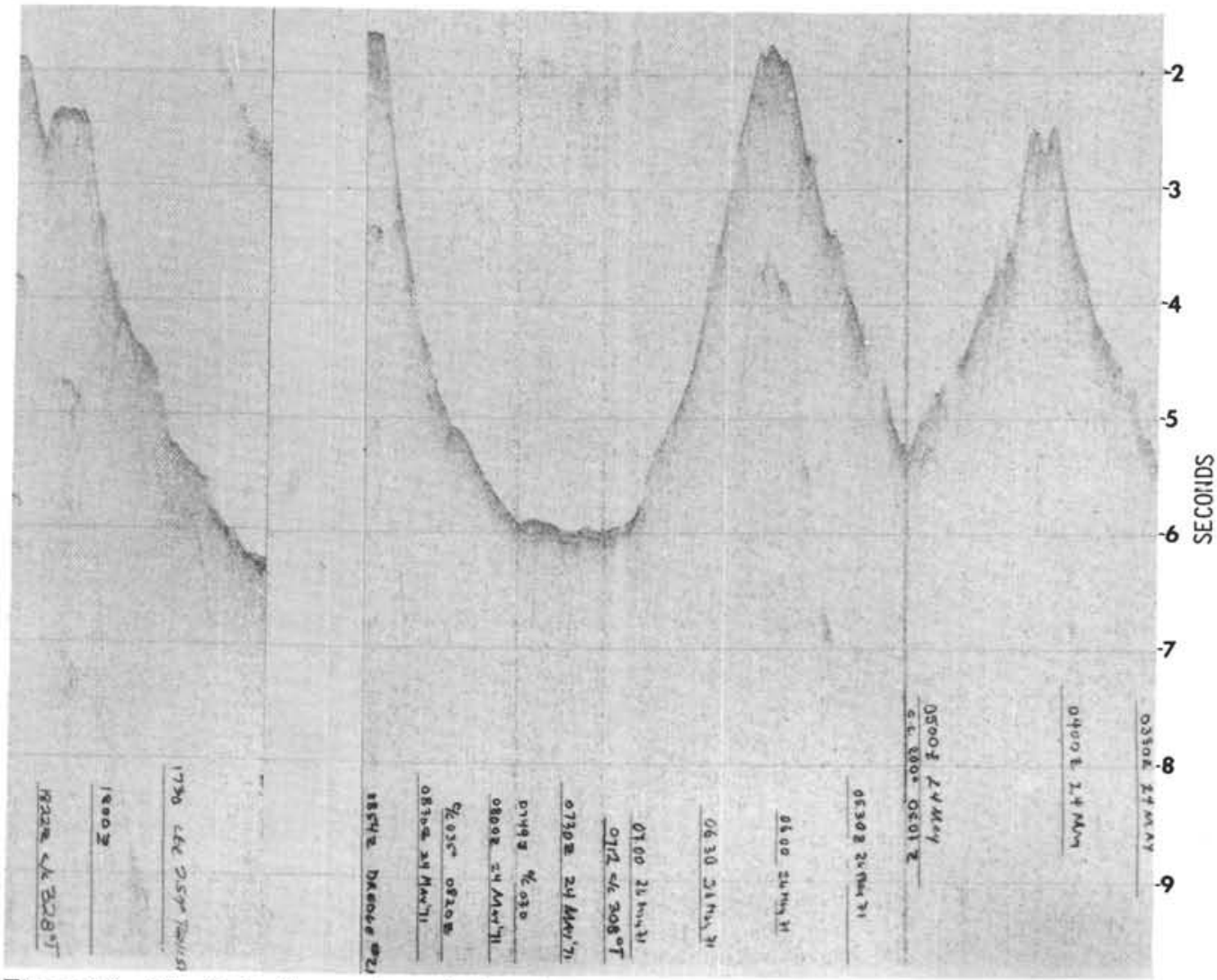

Figure 35. The Wake Guyots have little sediment cover and relatively small summits.

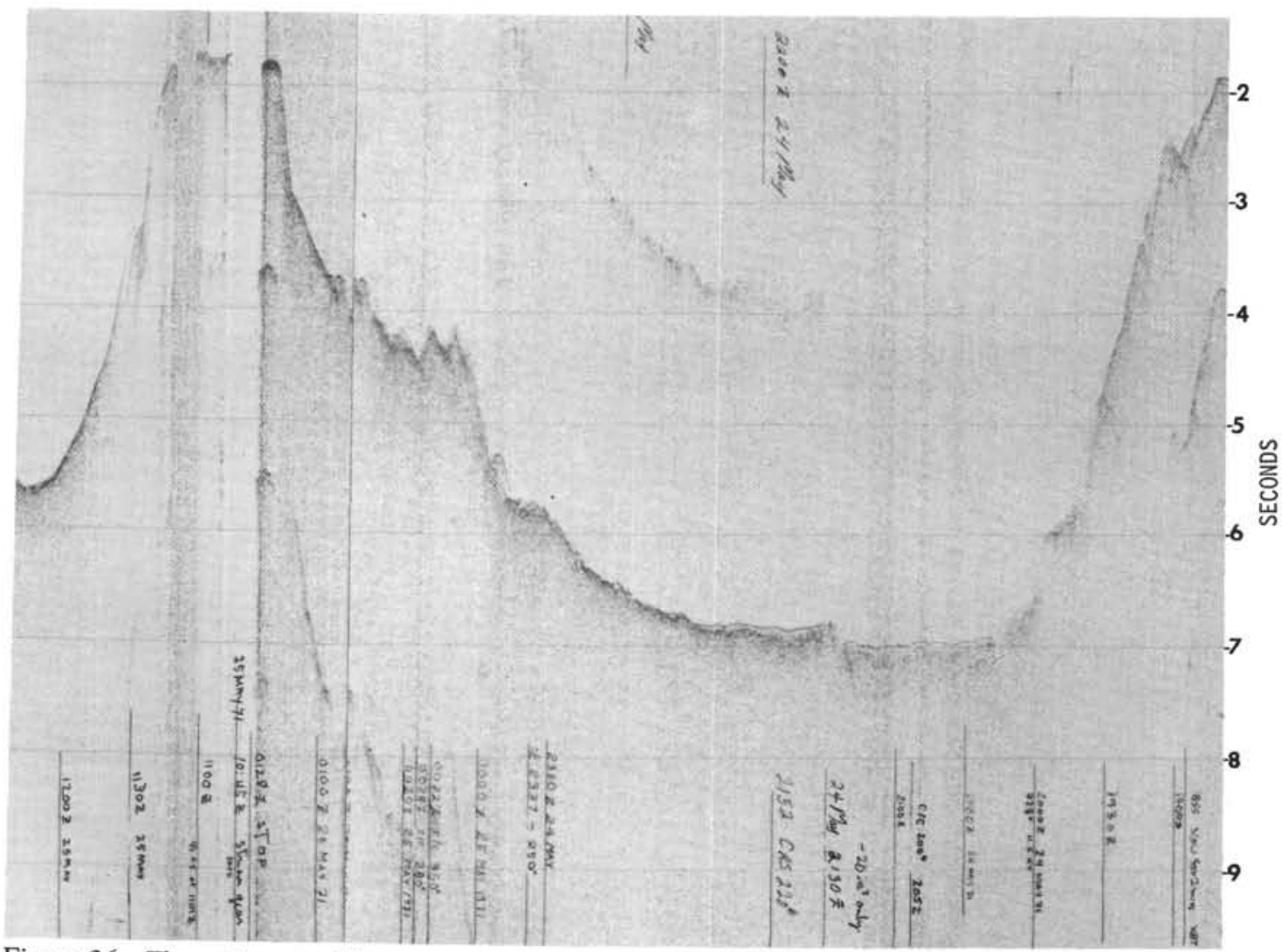

Figure 36. The sediments filling the basin between these Wake Guyots possess complex stratification. 


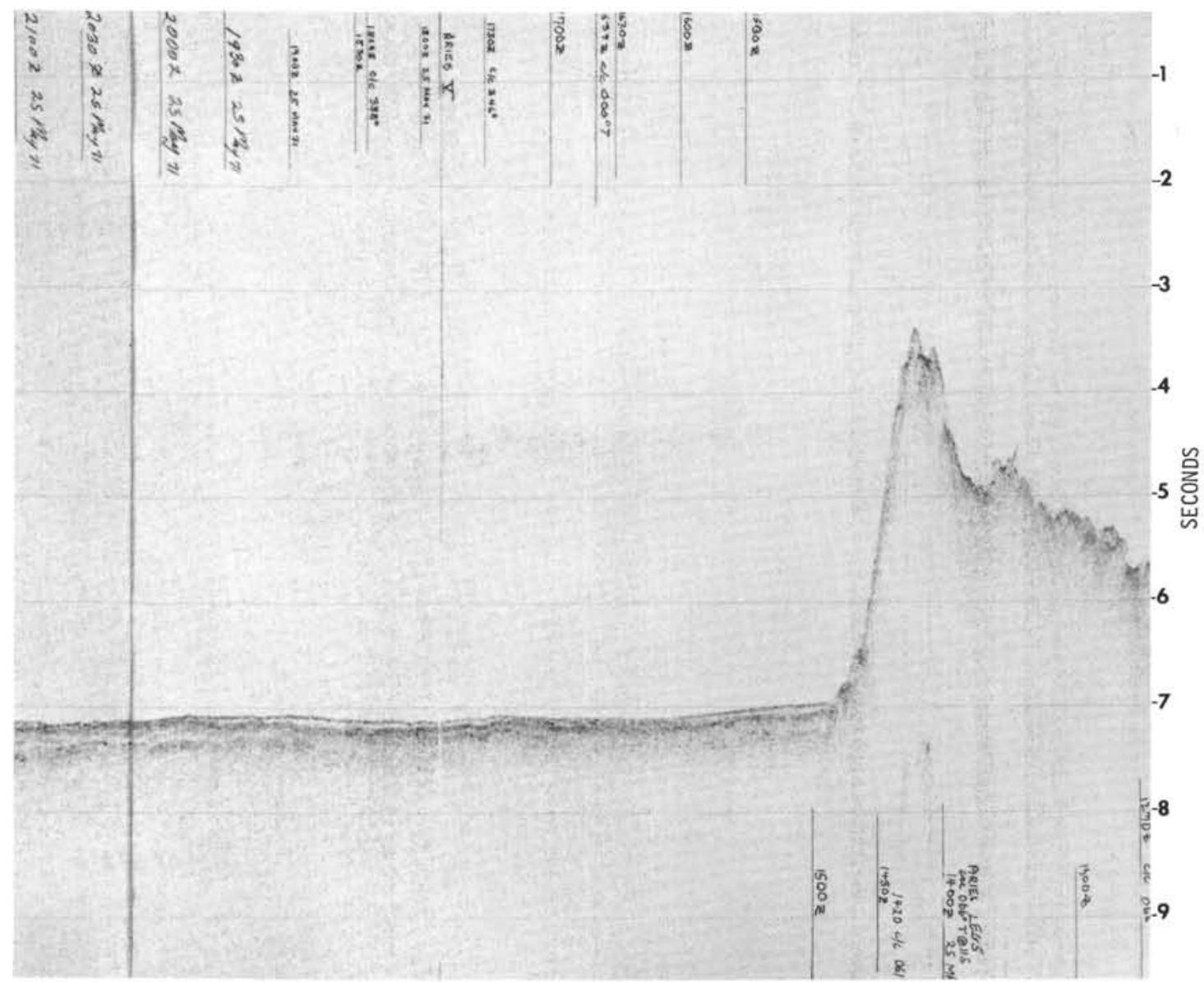

Figure 37. Basin between Lamont Guyot and Scripps Guyot is underlain by a relatively thick sequence of sediments. Local thickening of the transparent layer gives promise of spudding-in. 


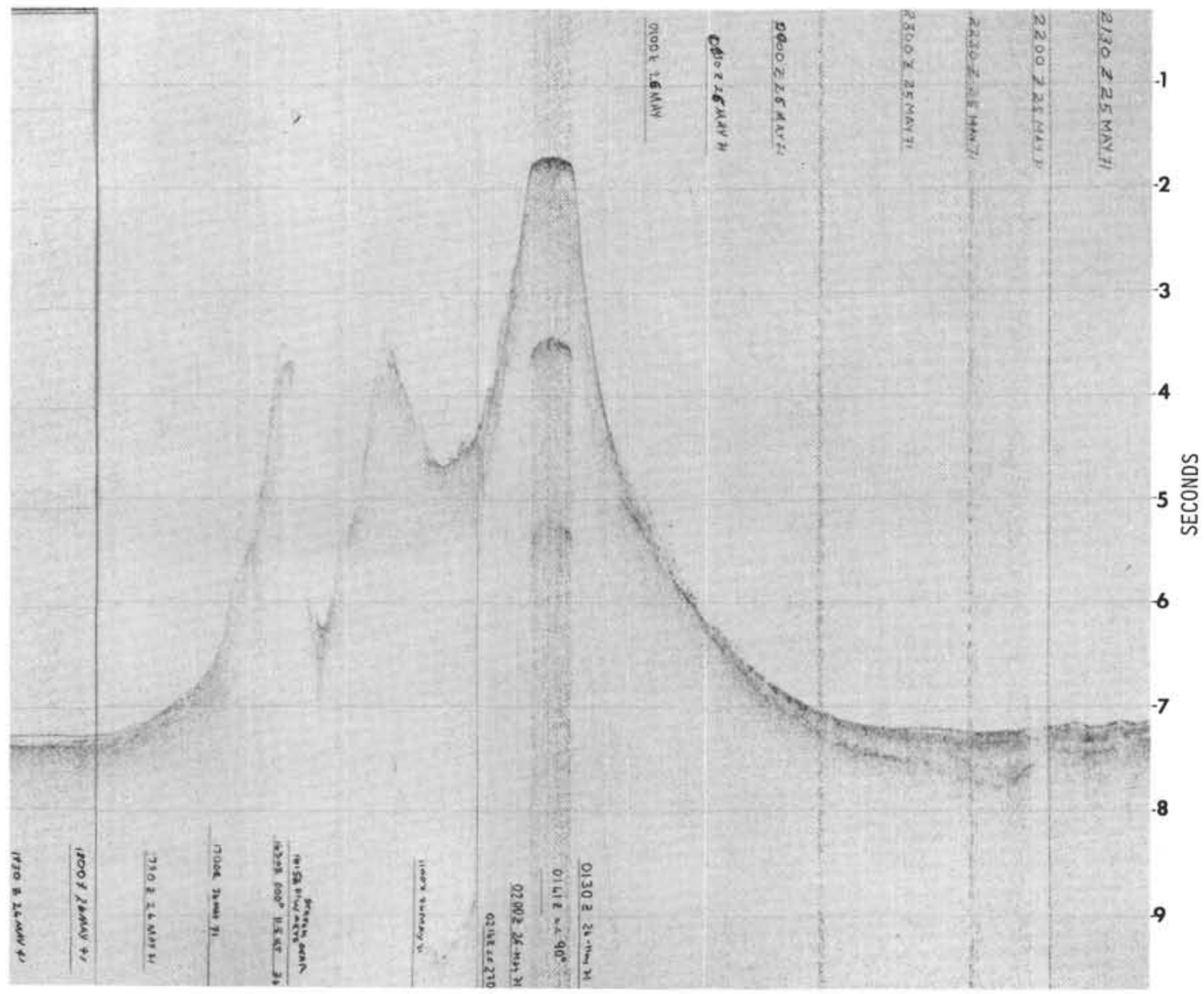

Figure 38. Sediments of the basin lap up on the pedestal of Scripps Guyot.

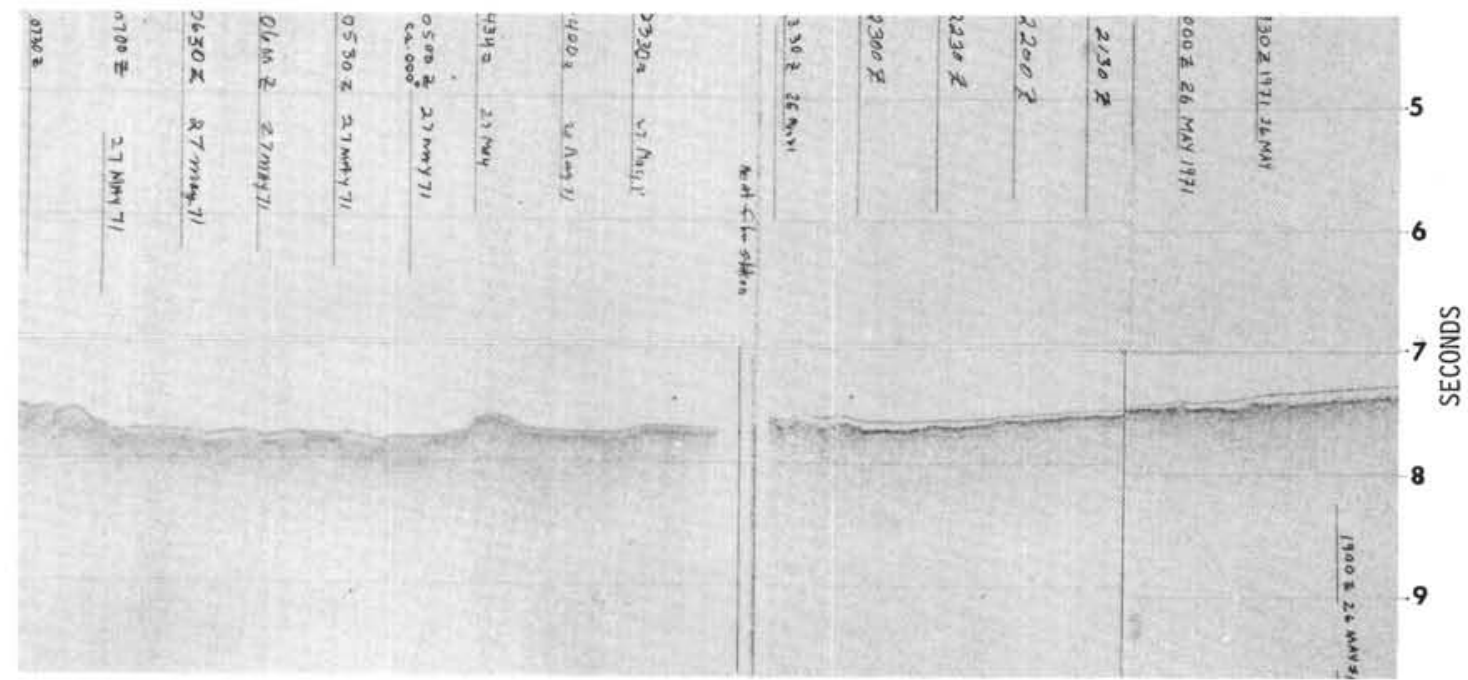

Figure 39. This profile which runs north along $160^{\circ} \mathrm{E}$ indicates a gradual thinning of the upper transparent layer. With the exception of occasional peaks, basement reflectors are not recorded. 


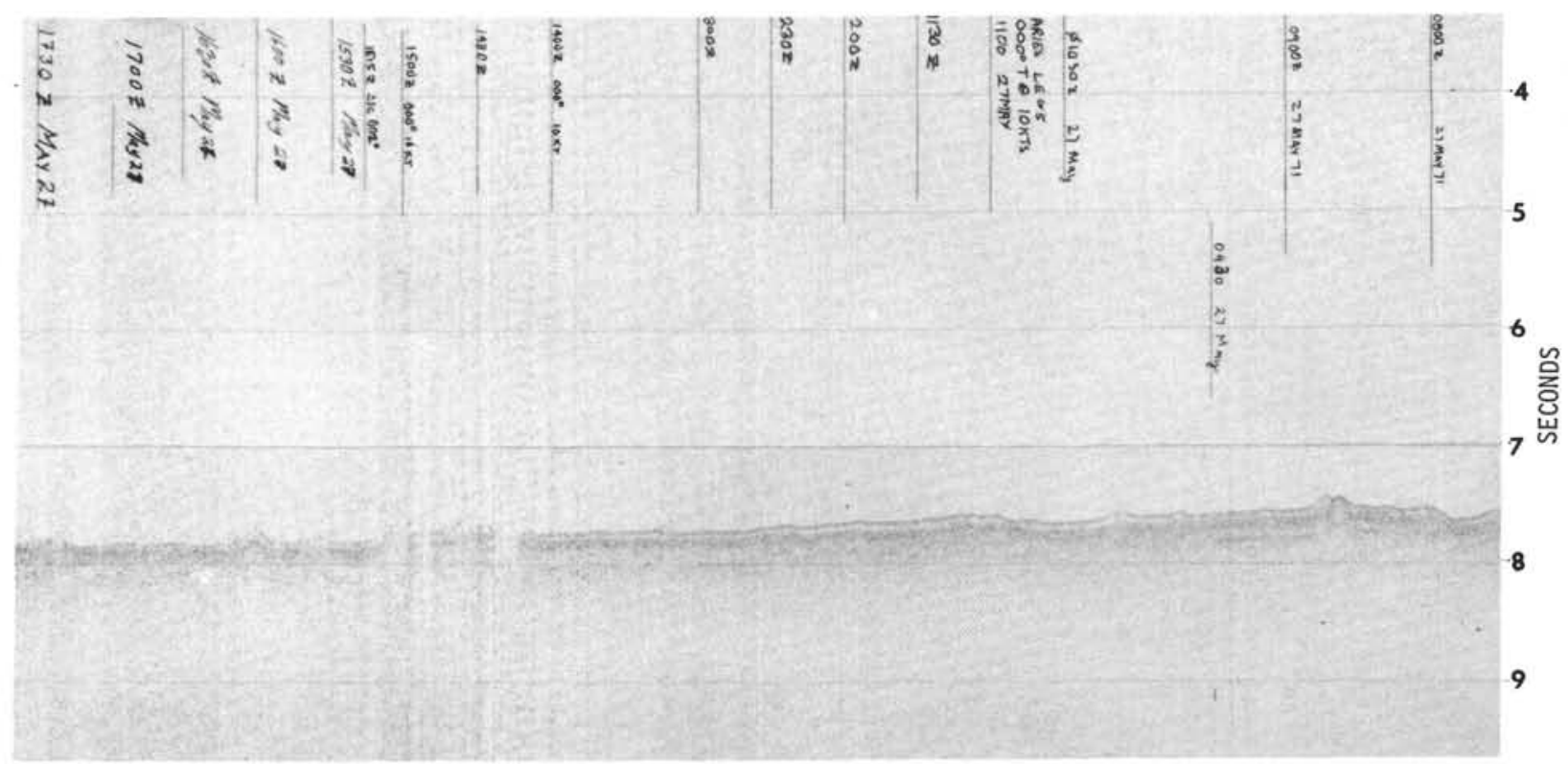

Figure 40. The upper transparent layer is apparently much too thin for spudding-in over most of the smoothly rolling basin floor.

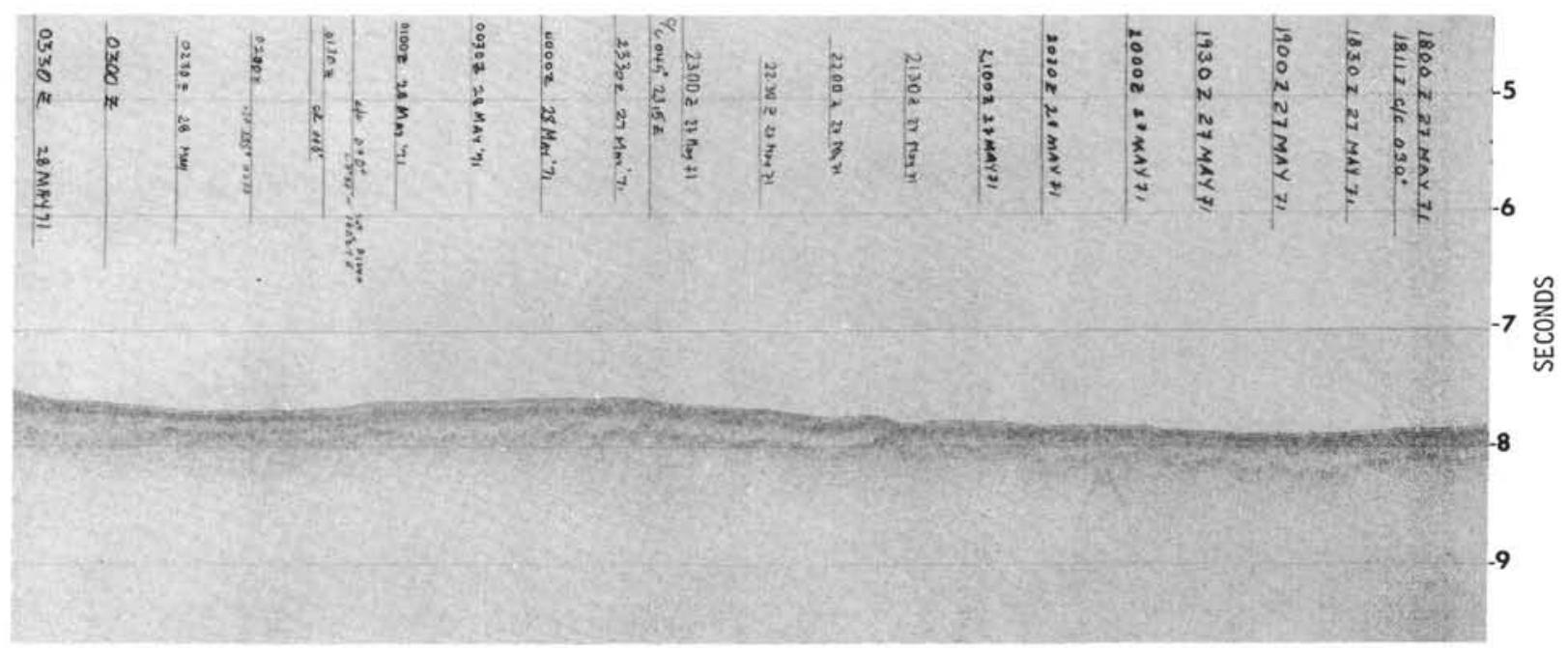

Figure 41. The deepest reflector seems almost too irregular for a sedimentary horizon. 


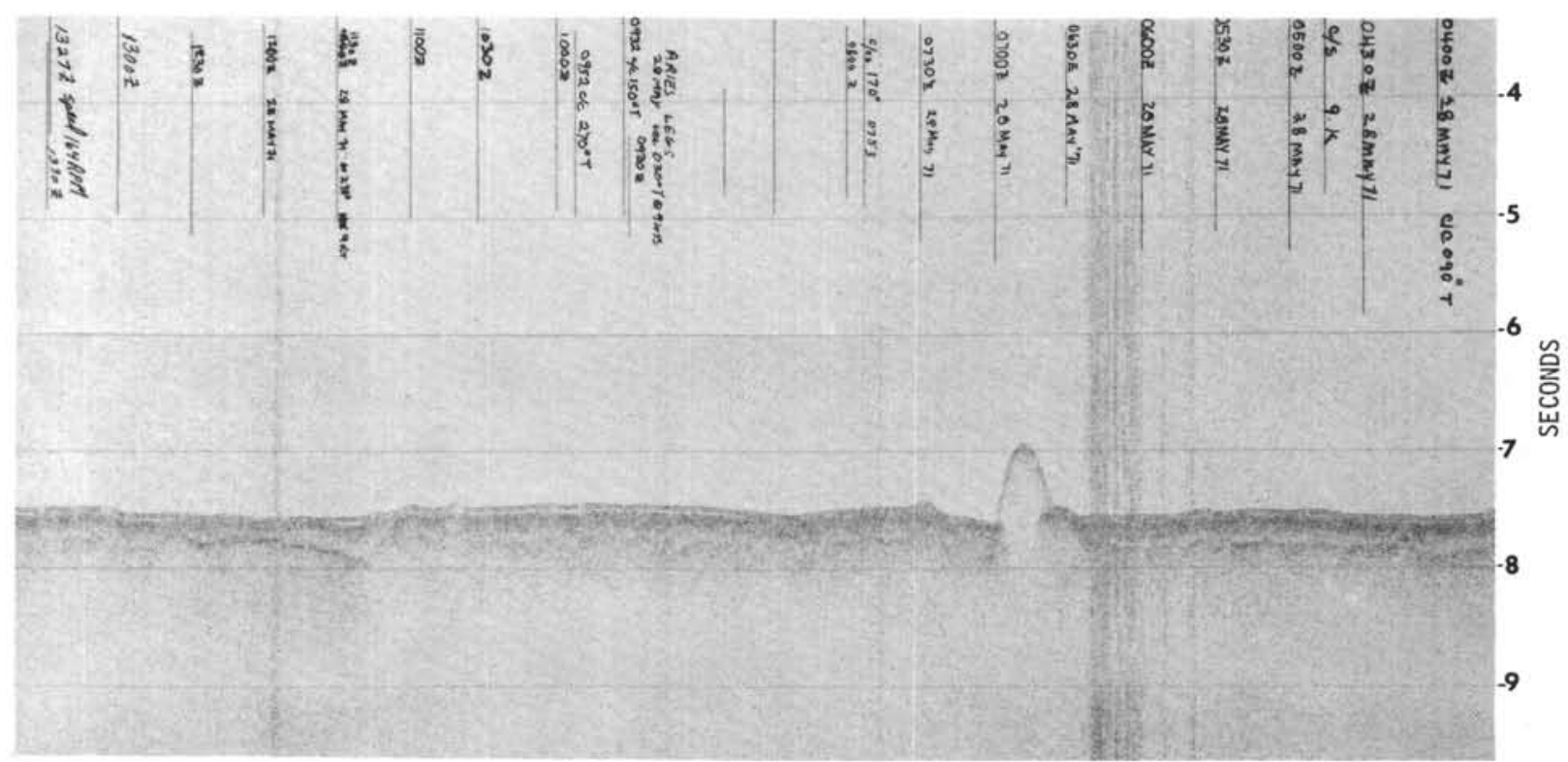

Figure 42. The upper transparent layer thickens sufficiently in this area and presents a marginal opportunity to spud-in.

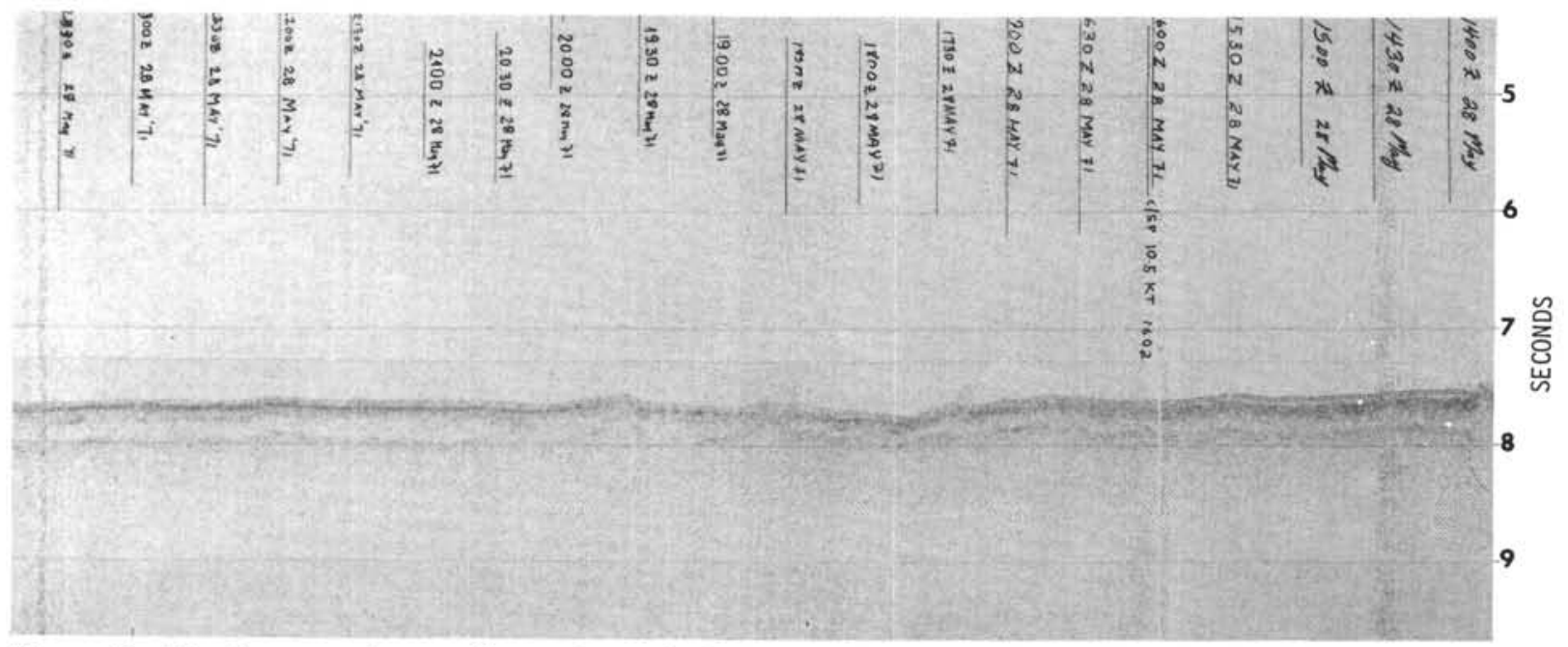

Figure 43. The first prominent reflector beneath the bottom deepens as the southern flank of the Shatsky Plateau is approached. 


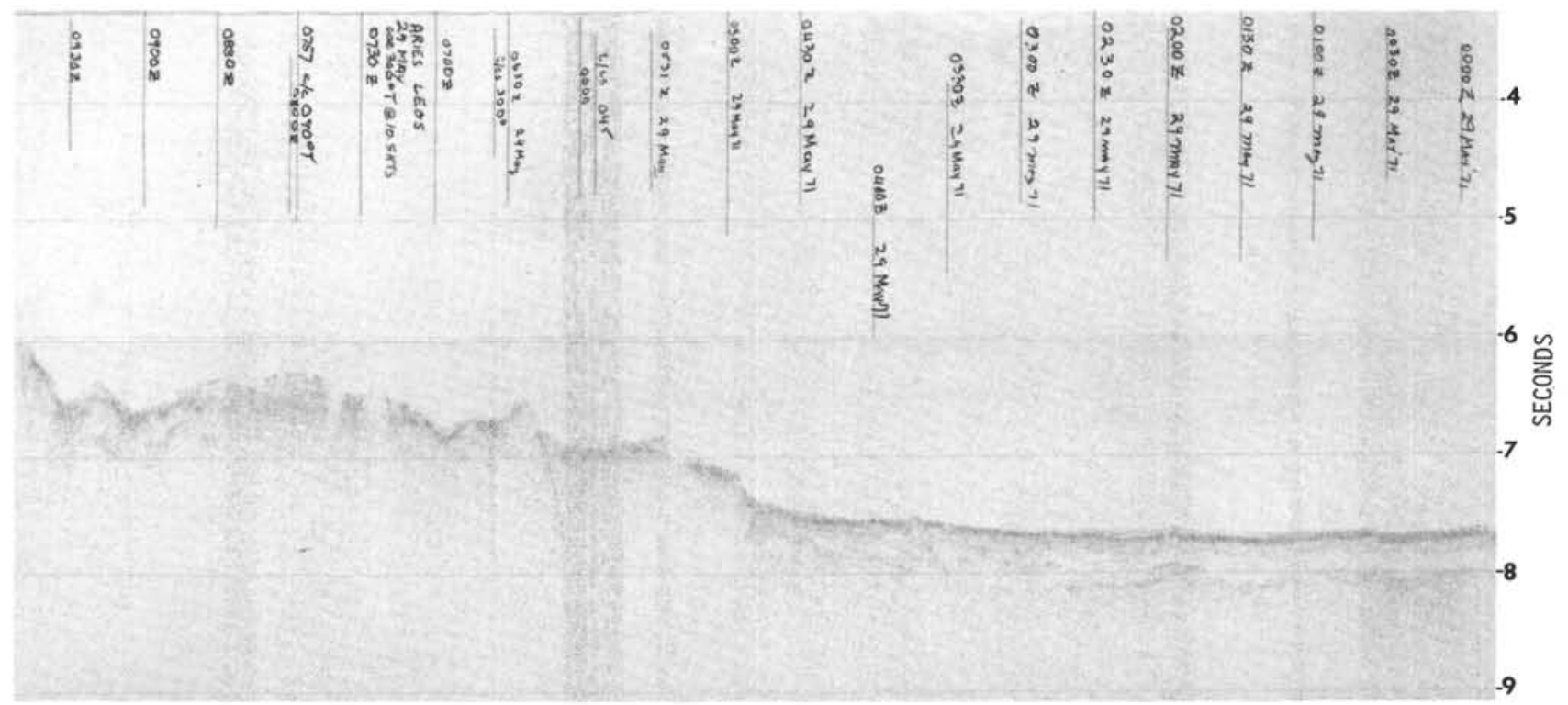

Figure 44. Sediments thicken along the southern margin of the Shatsky Plateau.

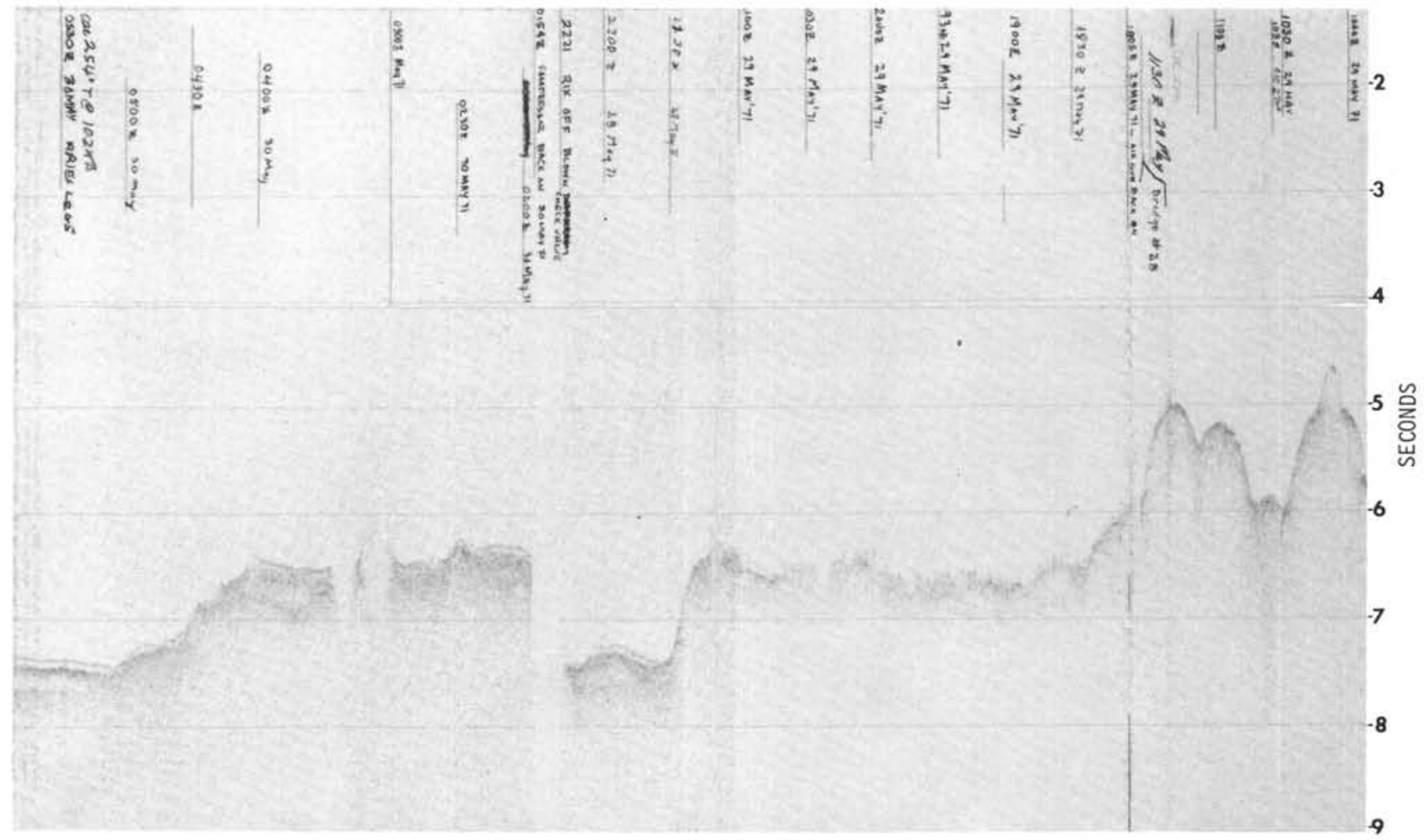

Figure 45. Sediment is draped along the irregular topograpny of the soutnern flank of the Shatsky Plateau. 


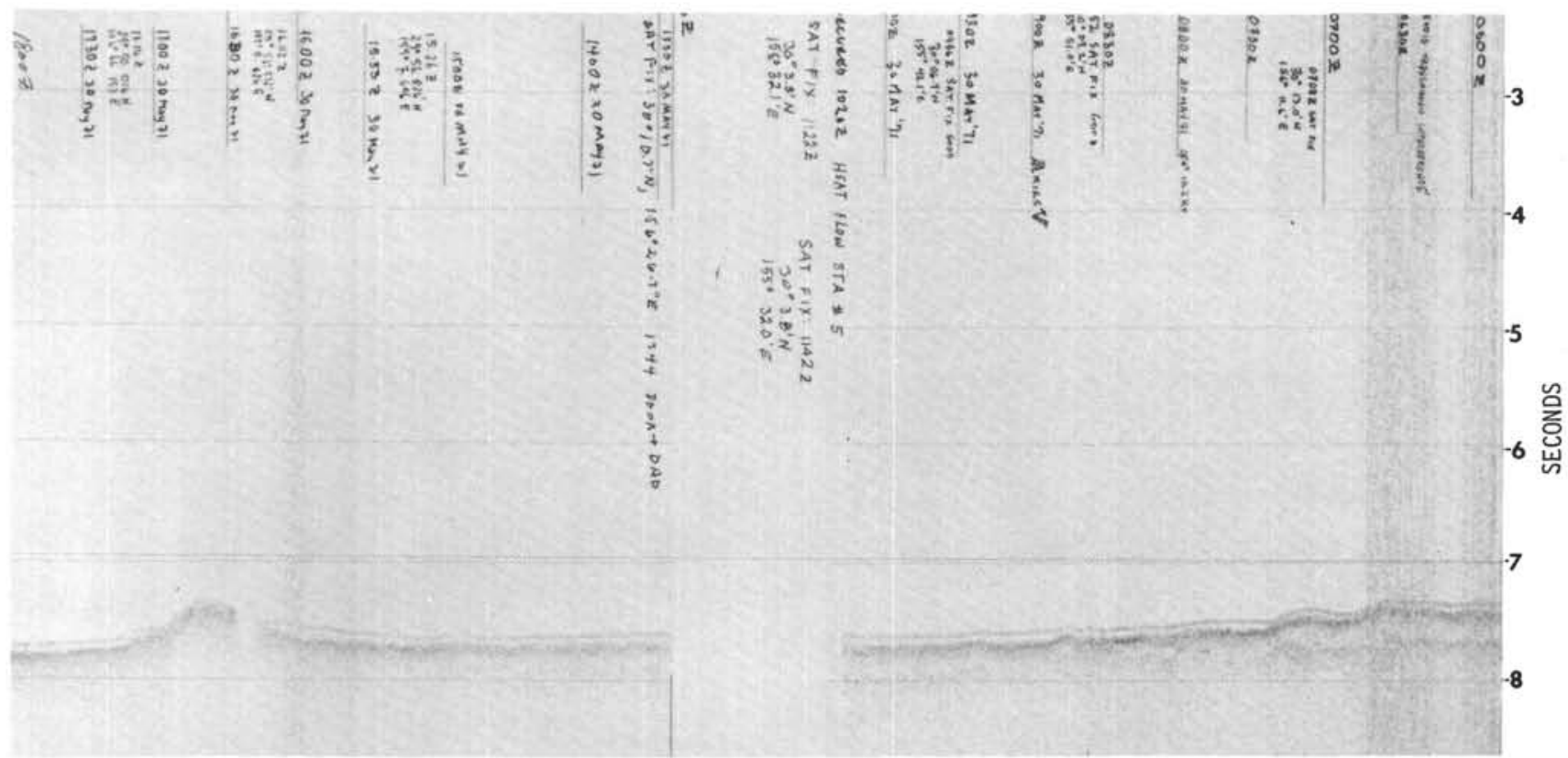

Figure 46. The seismic reflection profiler does not show the basement surface beneath apparently thick sediments which fill the basin between the Shatsky Plateau and Makarov Guyot.

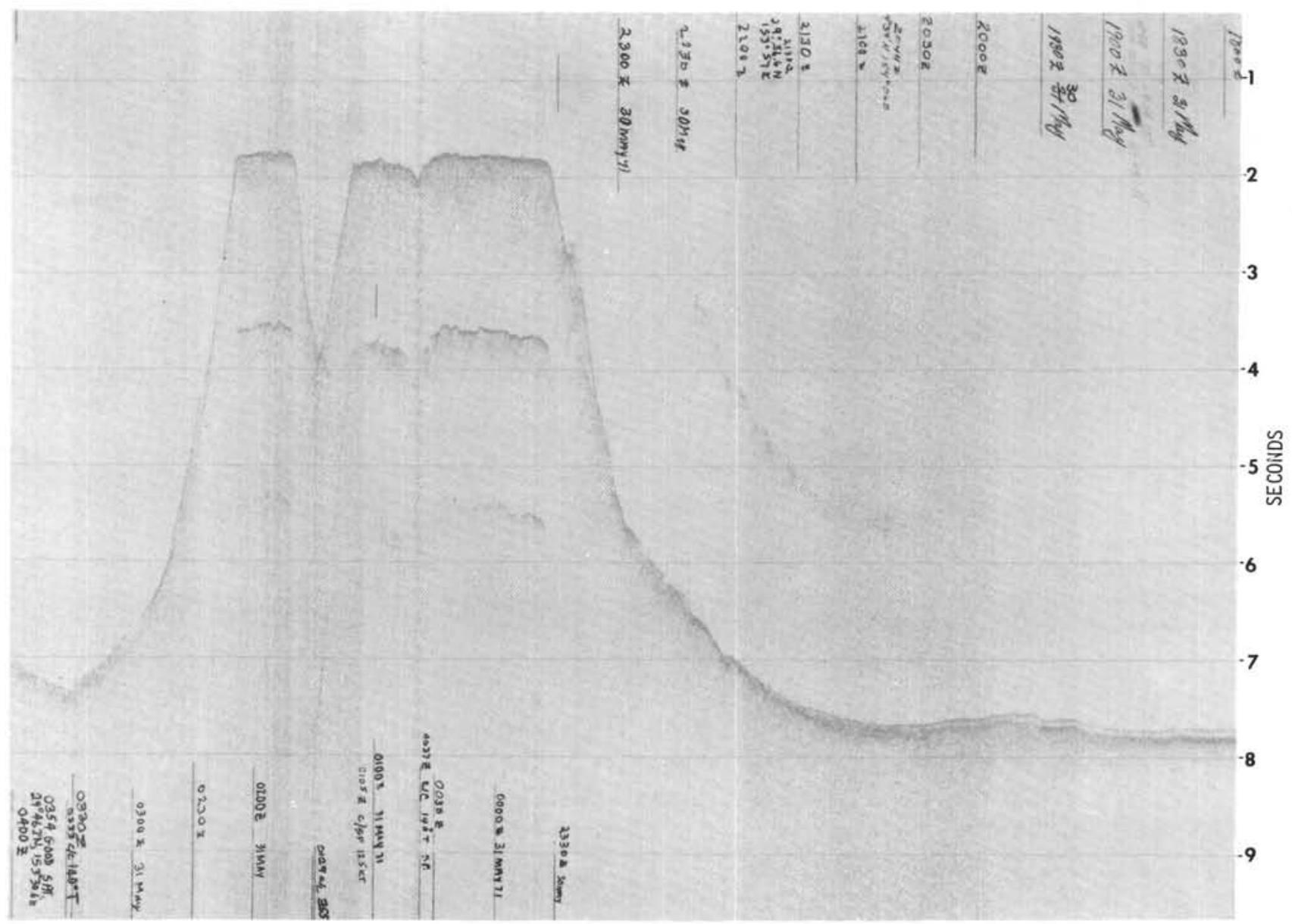

Figure 47. Seismic reflection profile across Makarov Guyot. To the northeast of the seamount (right side of record), the upper transparent layer is maybe thick enough to allow spudding. The lowest horizon is rather irregular and may represent either basement outcrop or volcanic erupted during the volcanic episode which created the seamount. 


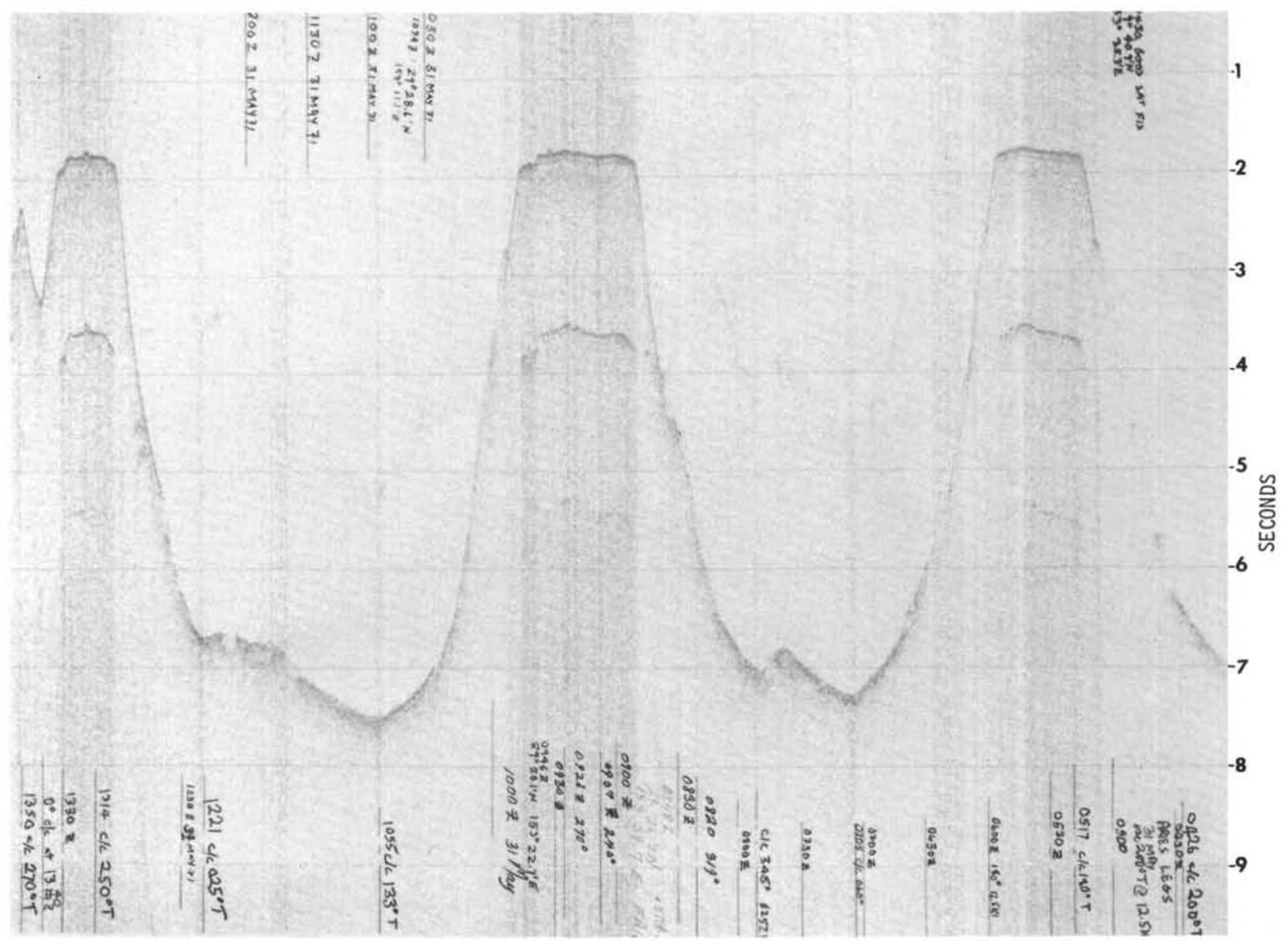

Figure 48. Seismic reflection profiles obtained during the survey of Makarov Seamount. Note the small topographic irregularities which mark the summit of the seamount. The seismic reflection record gives no hint of deeper layers on the summit. 


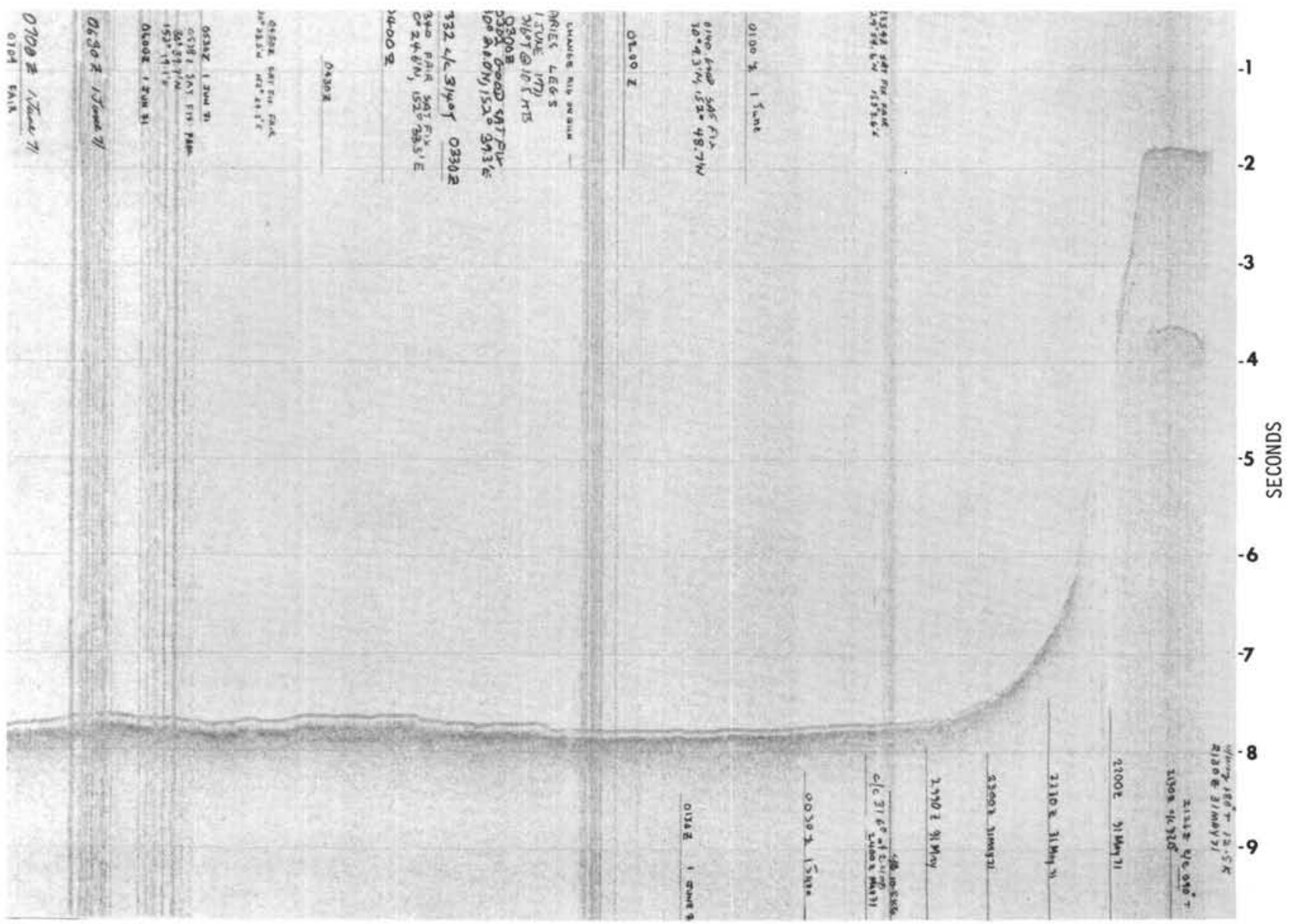

Figure 49. Seismic reflection profile from Makarov Seamount northwest across the deep basin towards Isakov Guyot. The upper transparent layer in this area becomes thick enough to spud-in nearly everywhere. The cruise having by this time reached within $1000 \mathrm{~km}$ of Japan has come into the area where volcanogenic sediments have created a wedge of soft sediment. The reflector beneath the upper transparent appears rather irregular although it is undoubtedly a sedimentary horizon. 


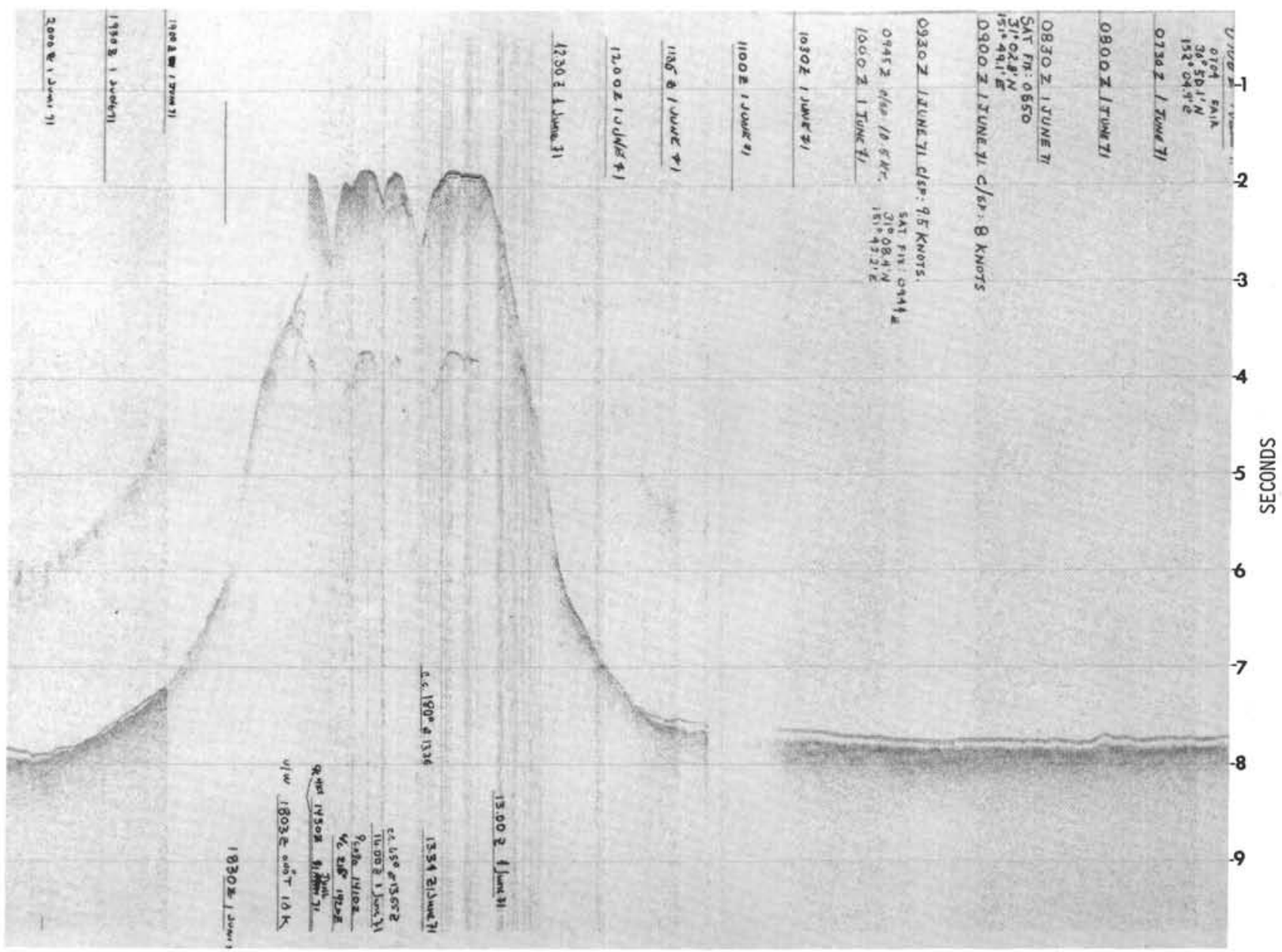

Figure 50. Seismic reflection profile of Isakov Guyot and its approaches. The upper transparent layer is abruptly terminated near the base of Isakov Seamount, apparently as a result of sedimentary processes which inhibit the accumulation of soft sediment on the steep slopes of the seamount. 


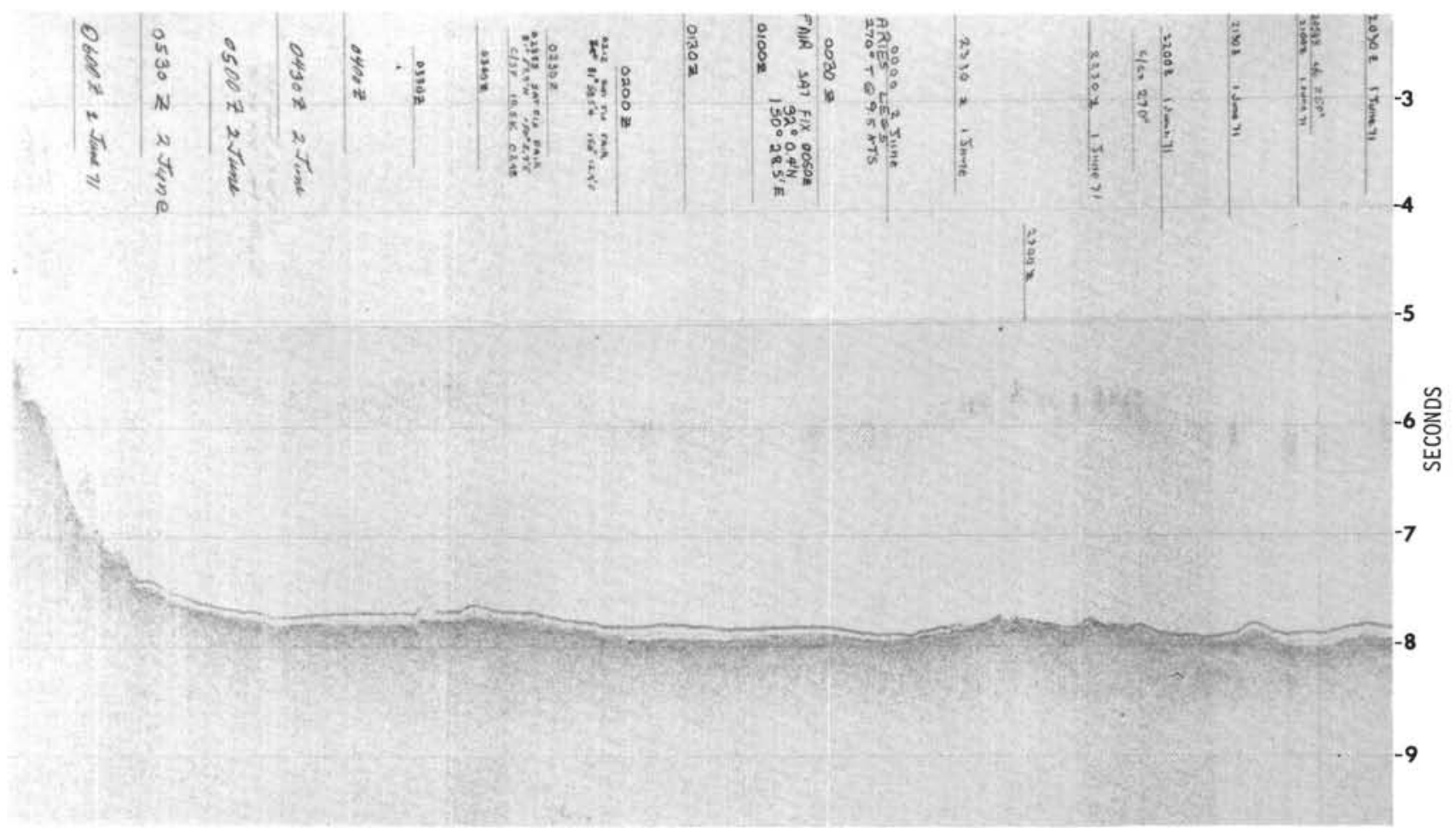

Figure 51. Seismic reflection profile north and northwest of Isakov Seamount shows an increasing thickness of upper transparent material and fails to indicate any definable horizon within the opaque layer. 


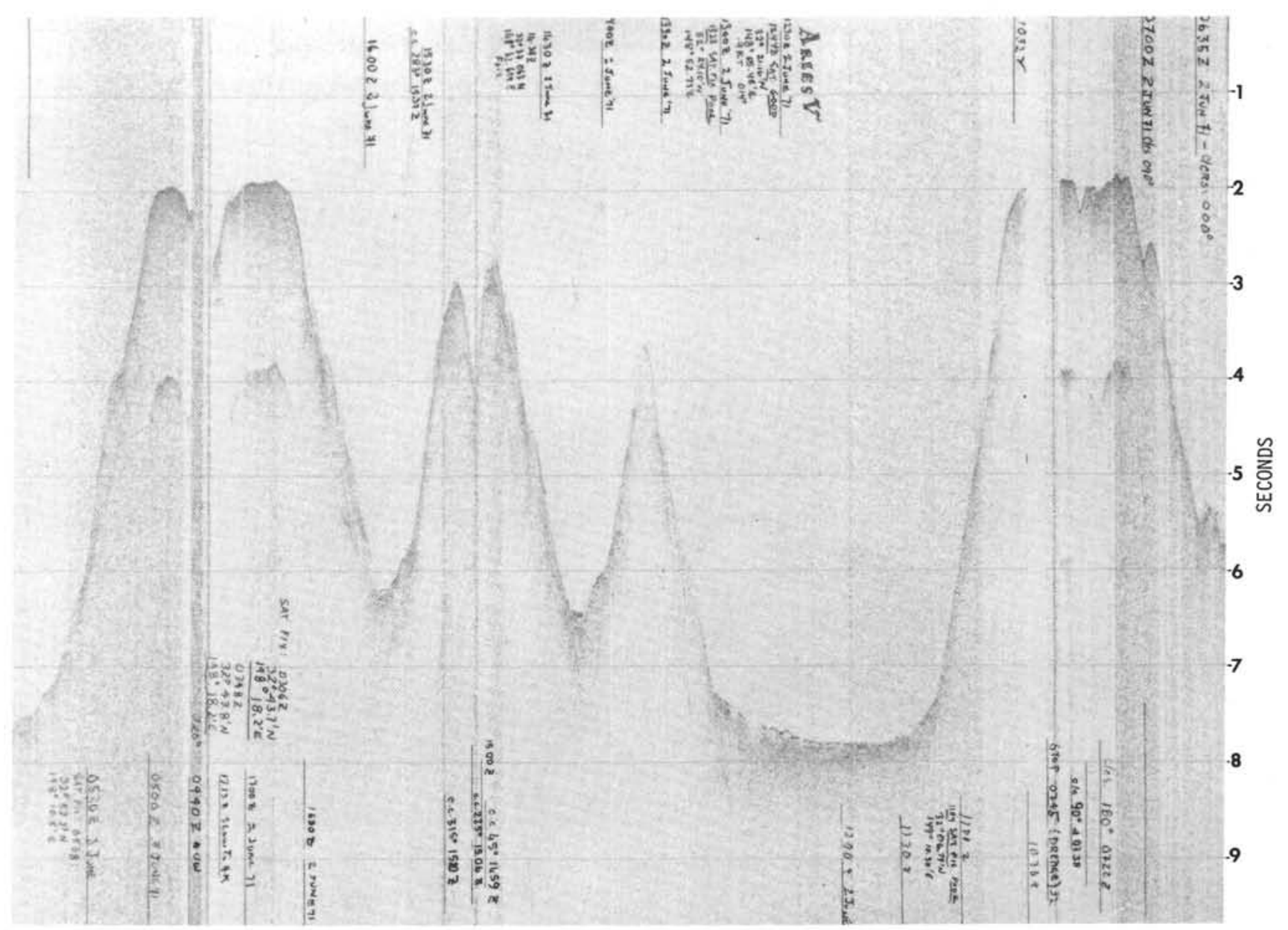

Figure 52. Seismic reflection profile of Thomas Washington and Winterer Guyots in the Geisha Guyot group. There is no indication of sedimentary horizons on the top of either guyot. In the regions between the two guyots the upper transparent layer is absent suggesting the action of currents in this very deep passage.

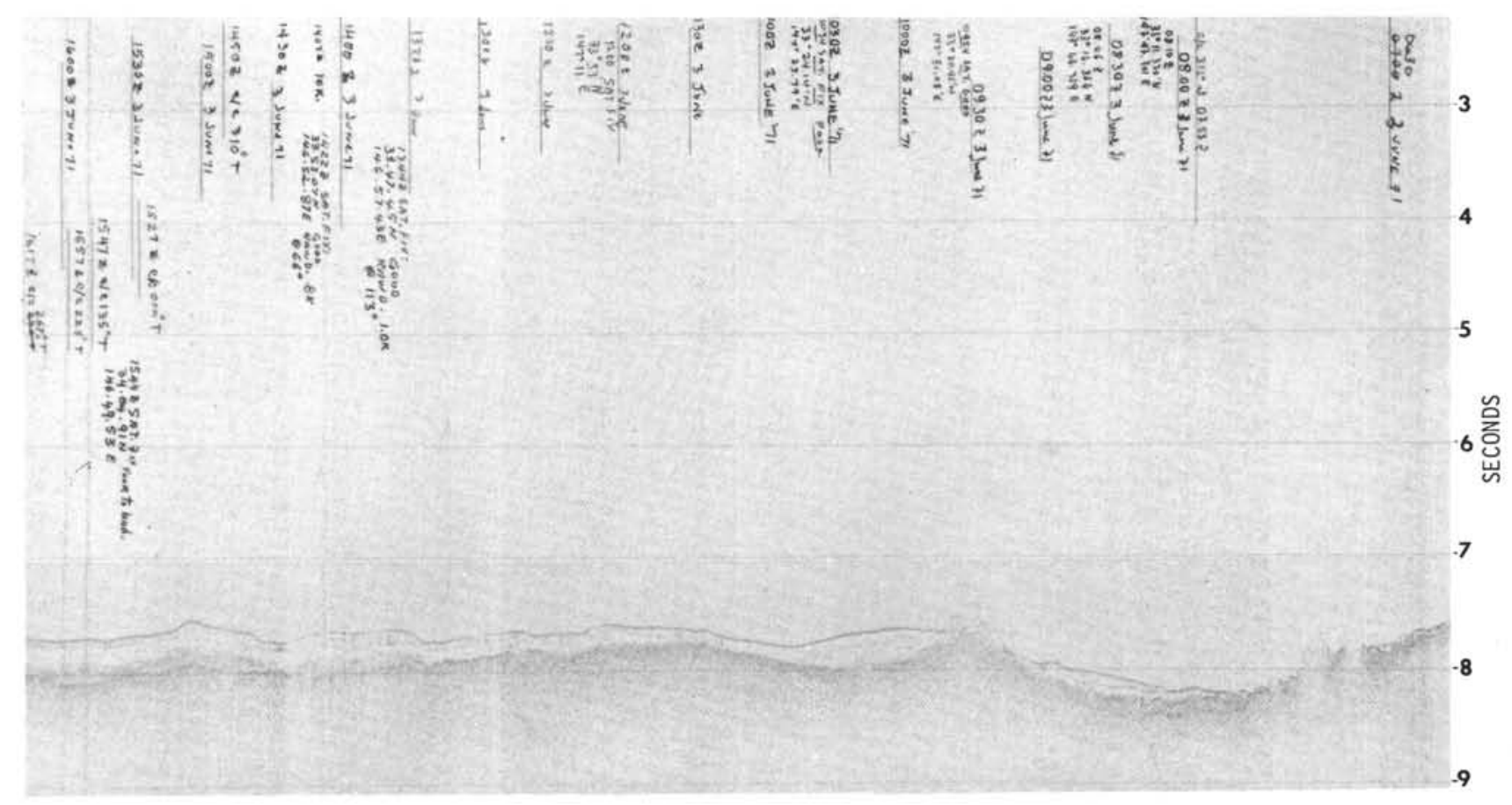

Figure 53. On this profile between Winterer Guyot and Maiko Seamount the upper transparent layer dramatically thickens to the west. 


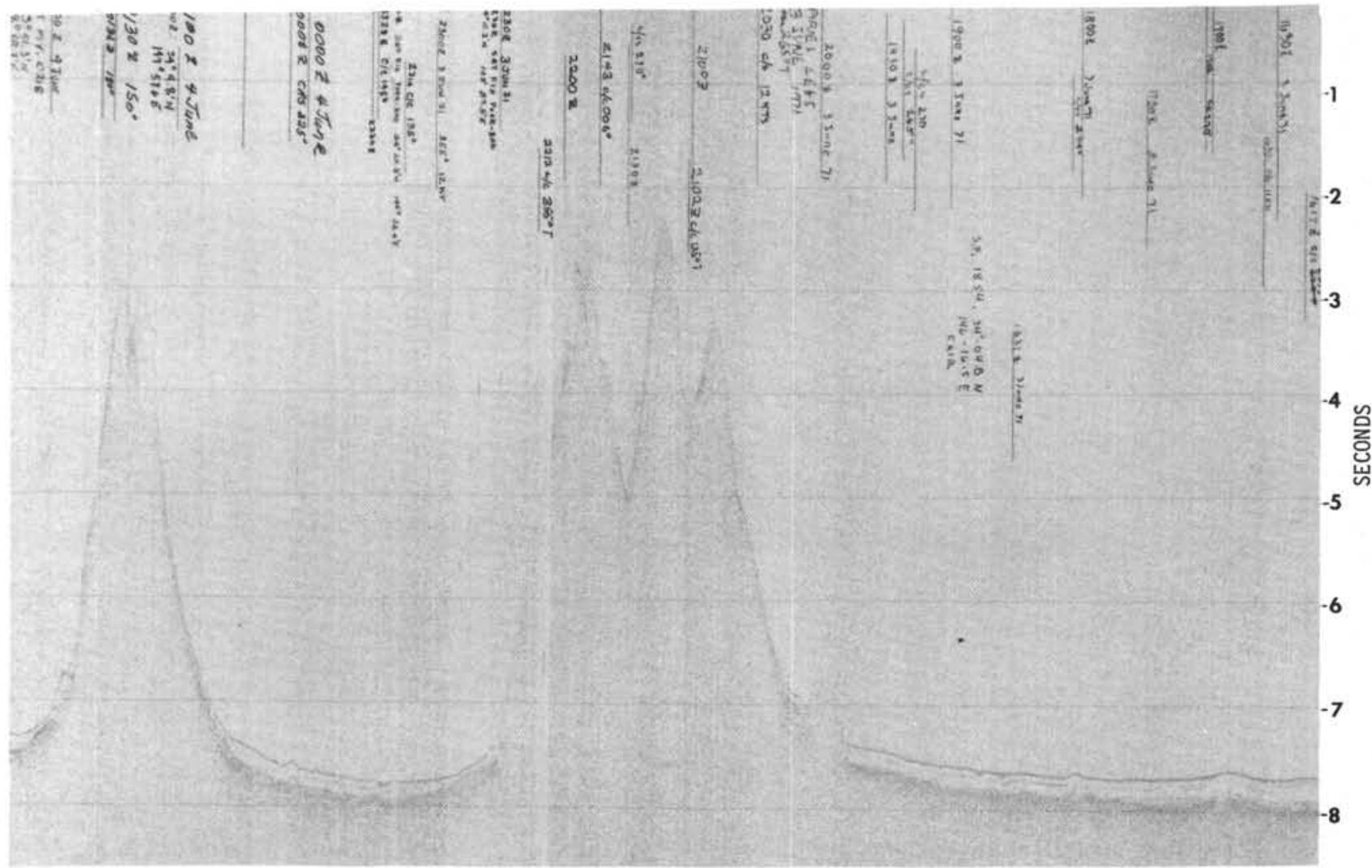

Figure 54. Seismic reflection profile of Maiko Seamount.

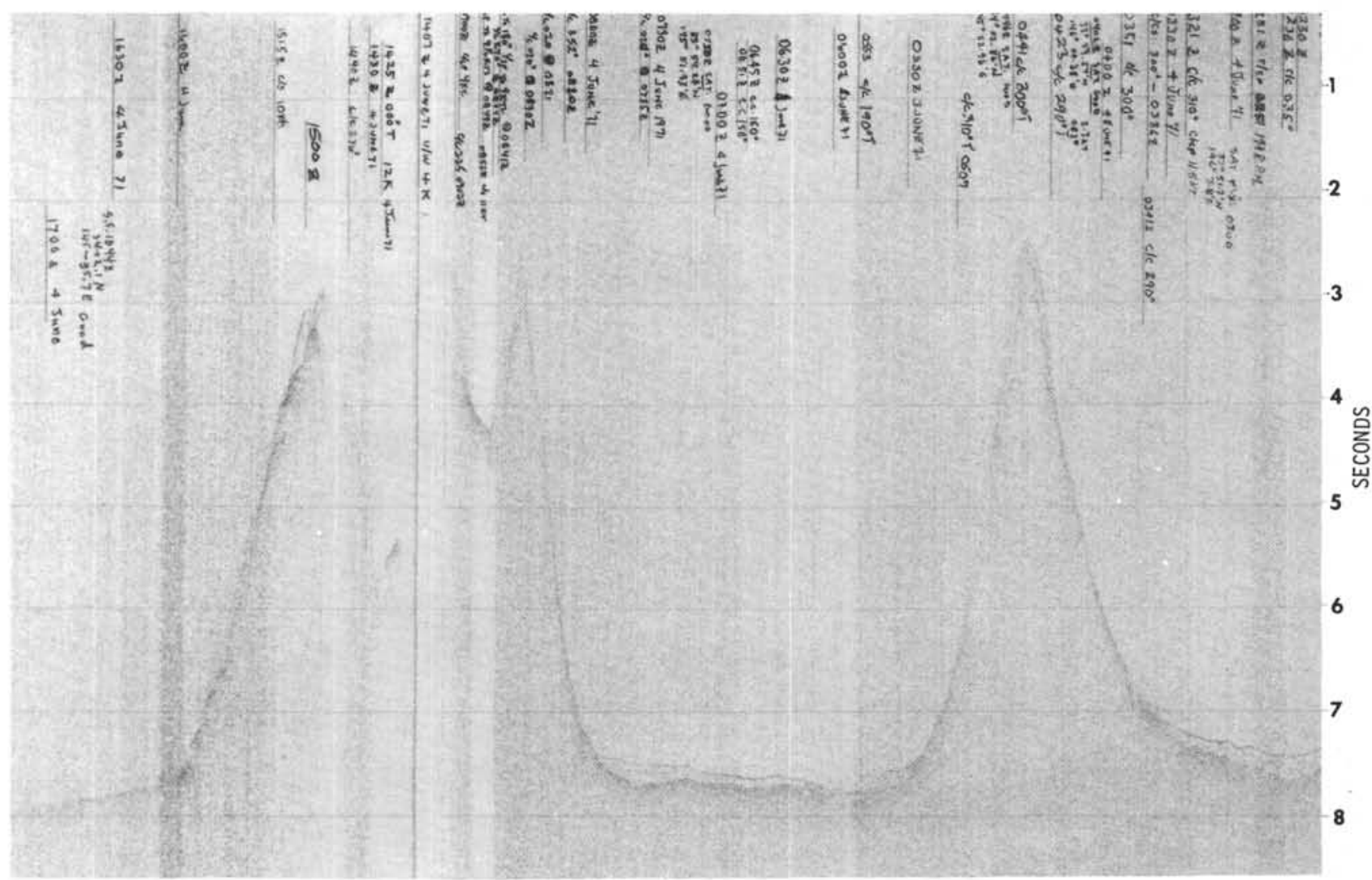

Figure 55. Seismic reflection profile of Maiko Seamount. 


\section{B. HEEZEN, M. THARP}

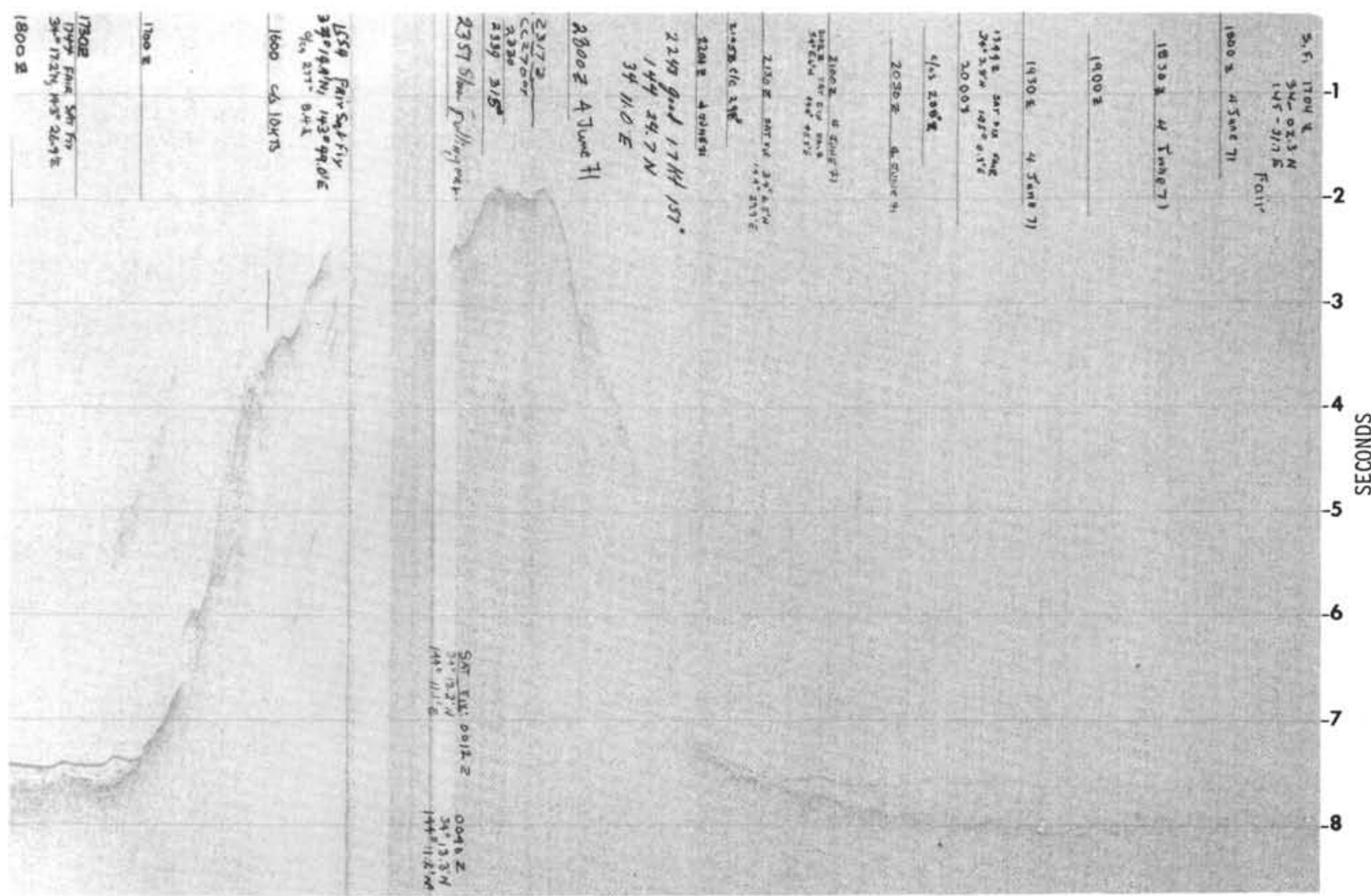

Figure 56. Seismic reflection profile of the Seiko Twin Seamounts. The seismic reflection profiler was not operated between 2300 and 1500 during a short run across the summit of the Seiko Twin Seamounts so an incorrect impression is given of this being a single mountain.

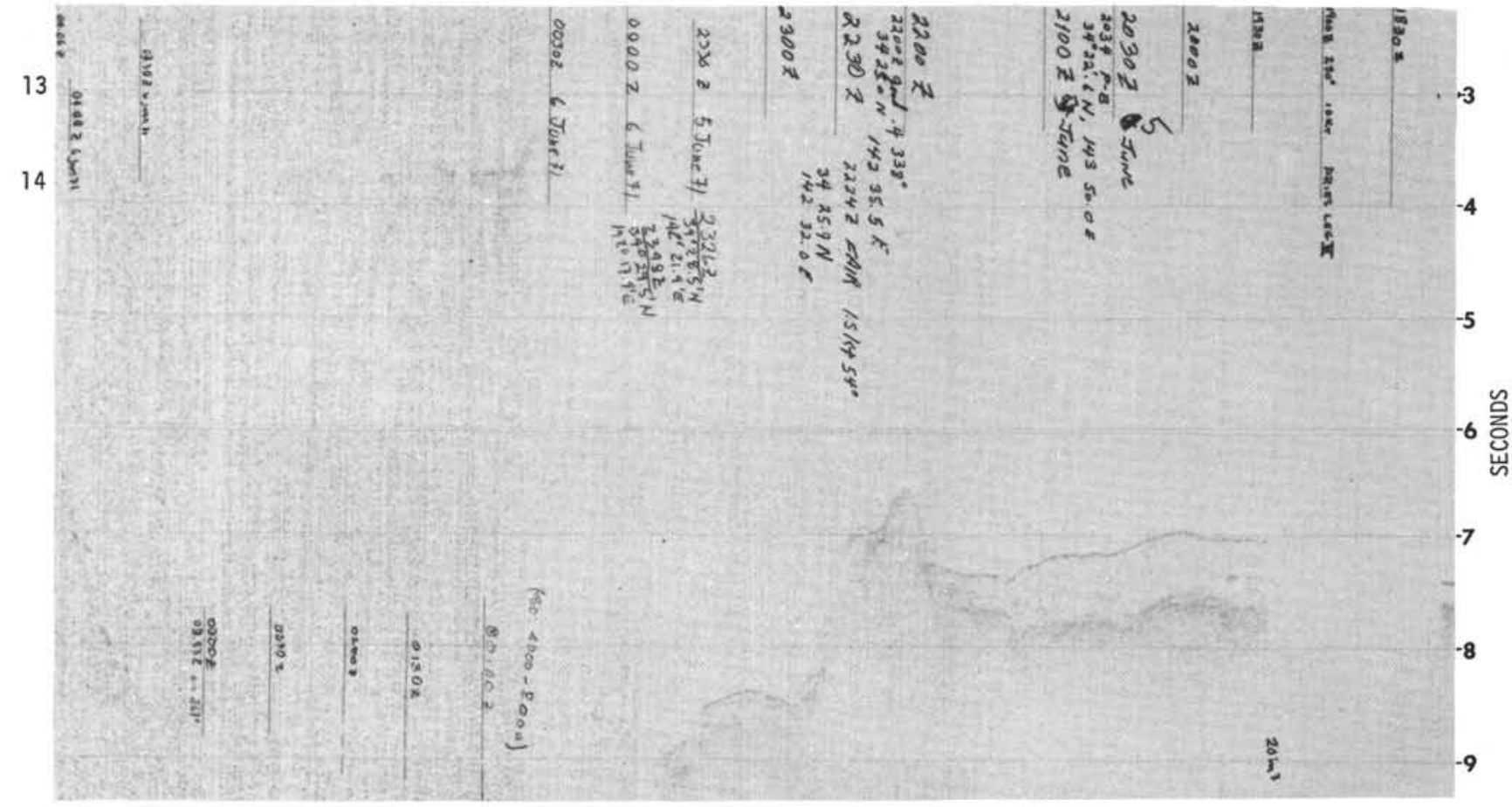

Figure 57. The volcaniclasic wedge of sediment reaches its greatest thickness at the crest of the outer wall of the Japan Trench. Somewhat heavy weather and the necessity of achieving good time to make port resulted in the sacrifice of the trench-crossing, however, the left third of the record (near the top) the flat floor of the trench in excess of 4600 fathoms is shown. 


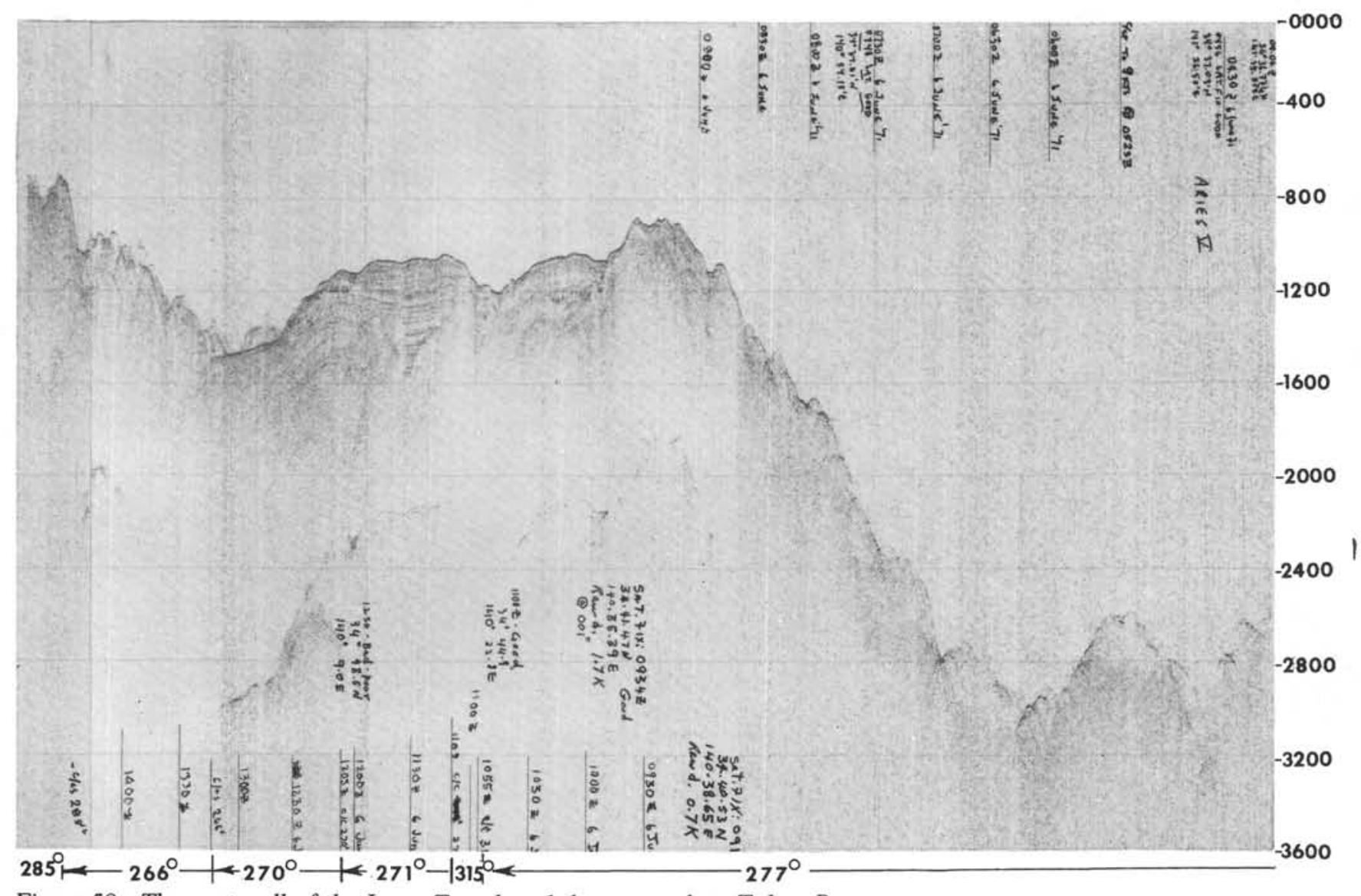

Figure 58. The west wall of the Japan Trench and the approach to Tokyo Bay. 


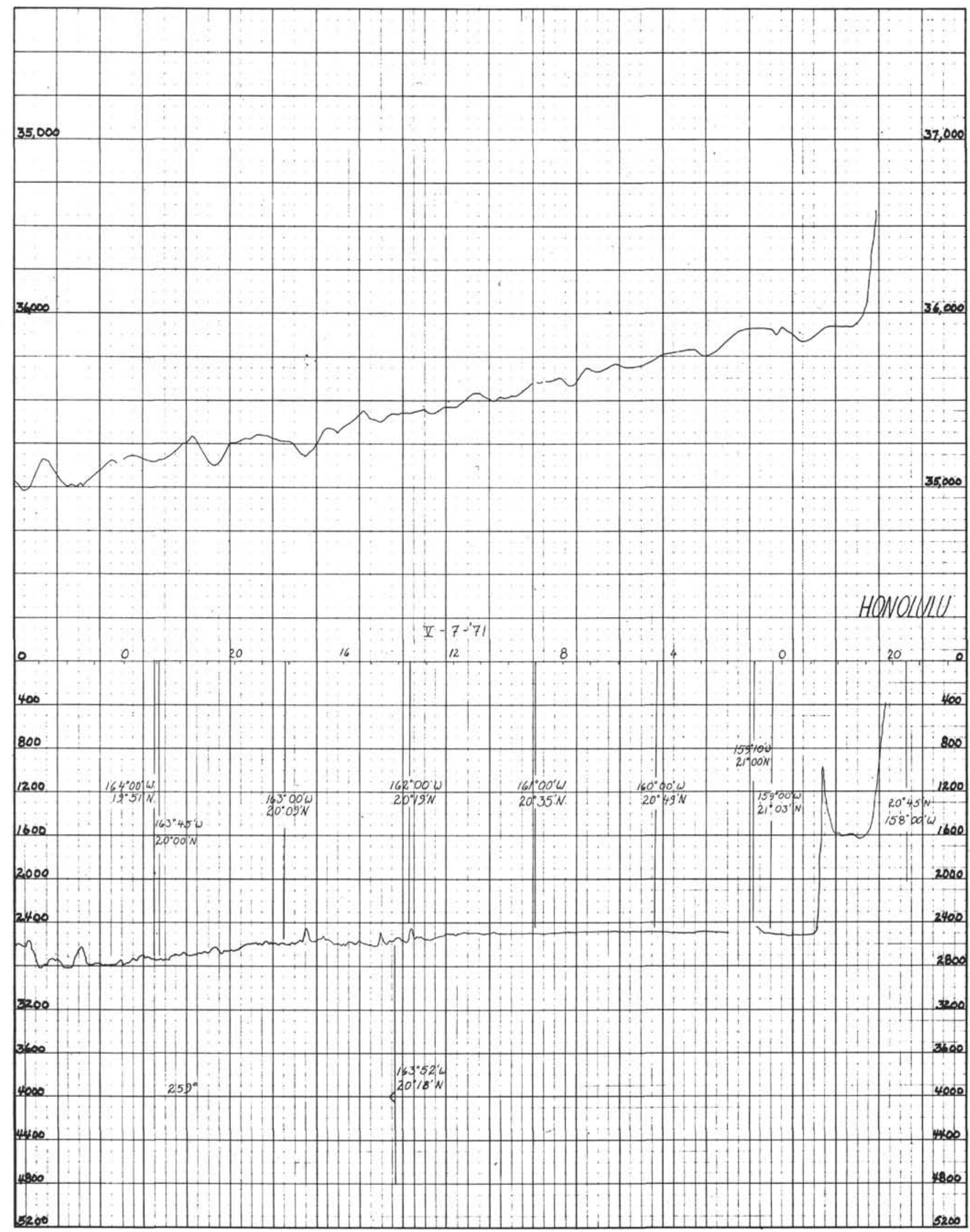

Figure 59. Topographic and total magnetic intensity profiles Hawaii to Japan, depth in tau, total intensity values in gammas. 


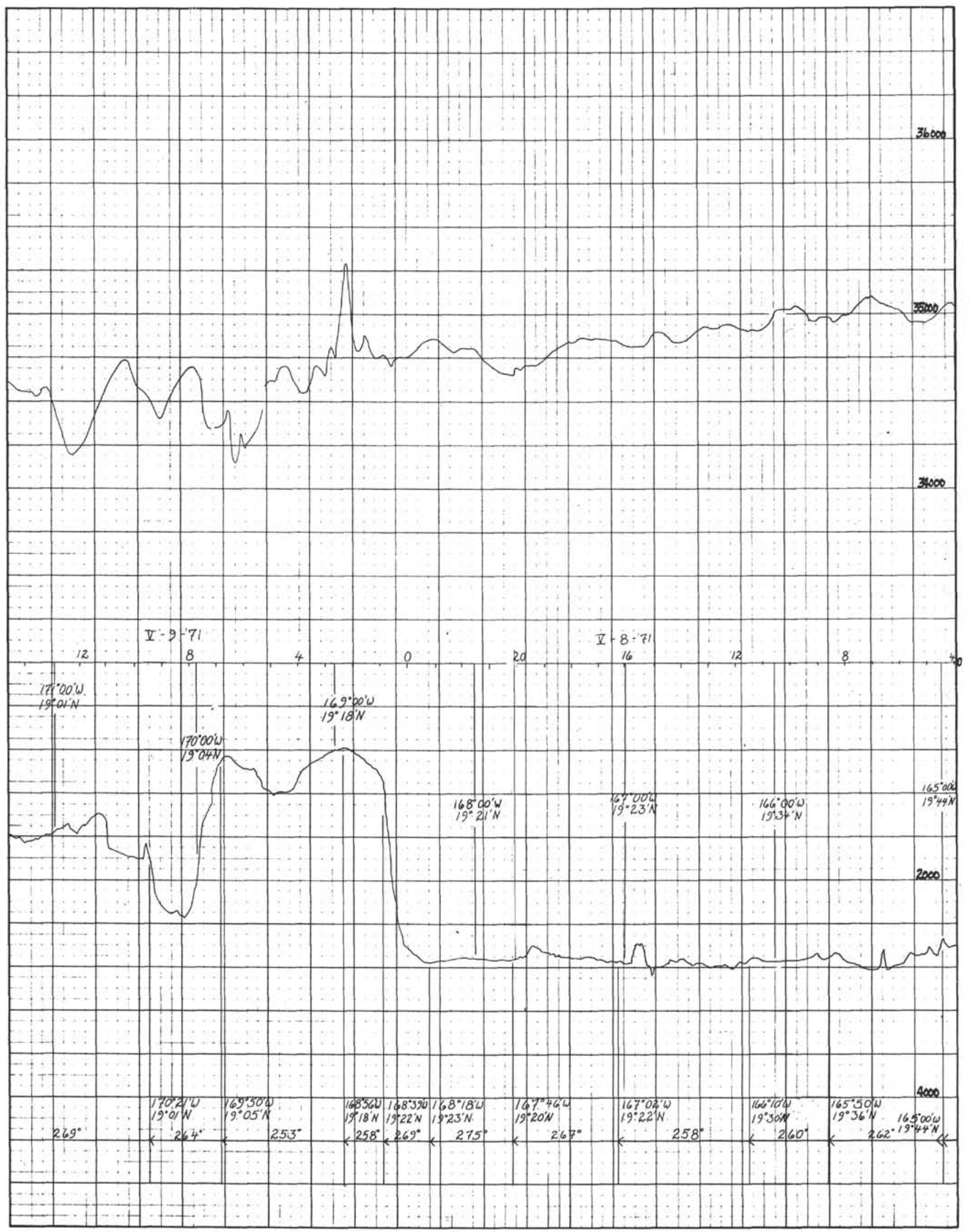

Figure 59. (Continued). 


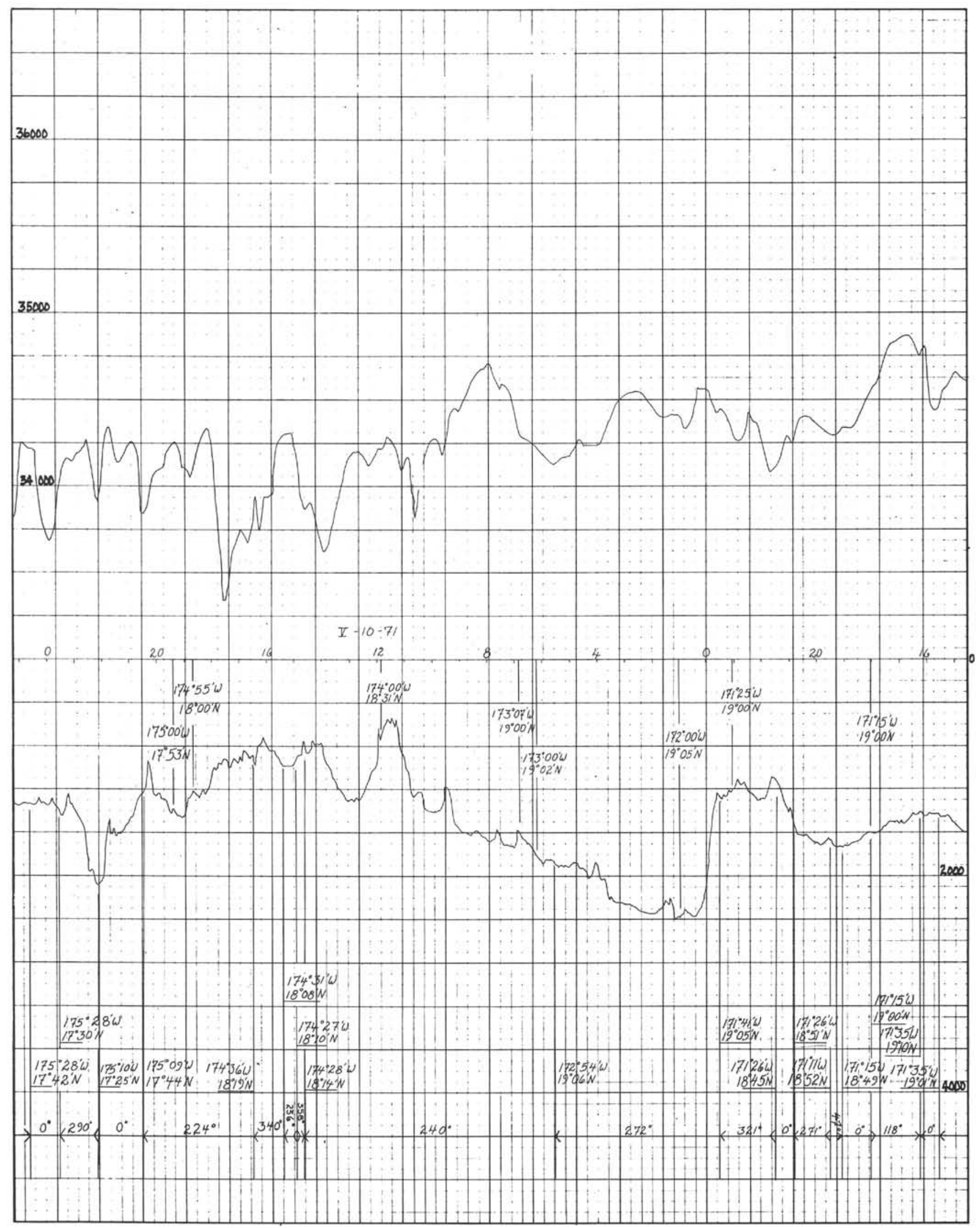

Figure 59. (Continued). 


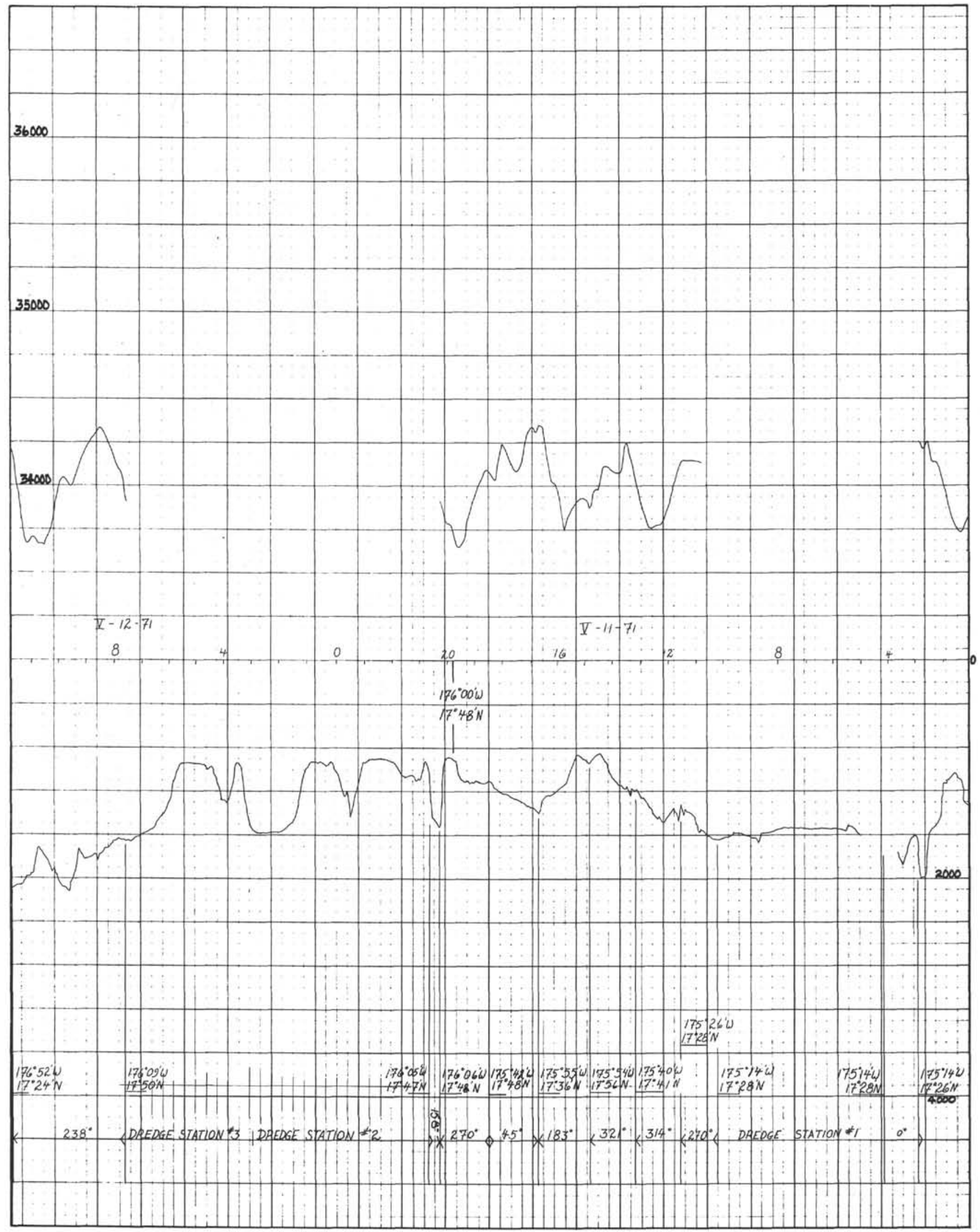

Figure 59. (Continued). 


\section{B. HEEZEN, M. THARP}

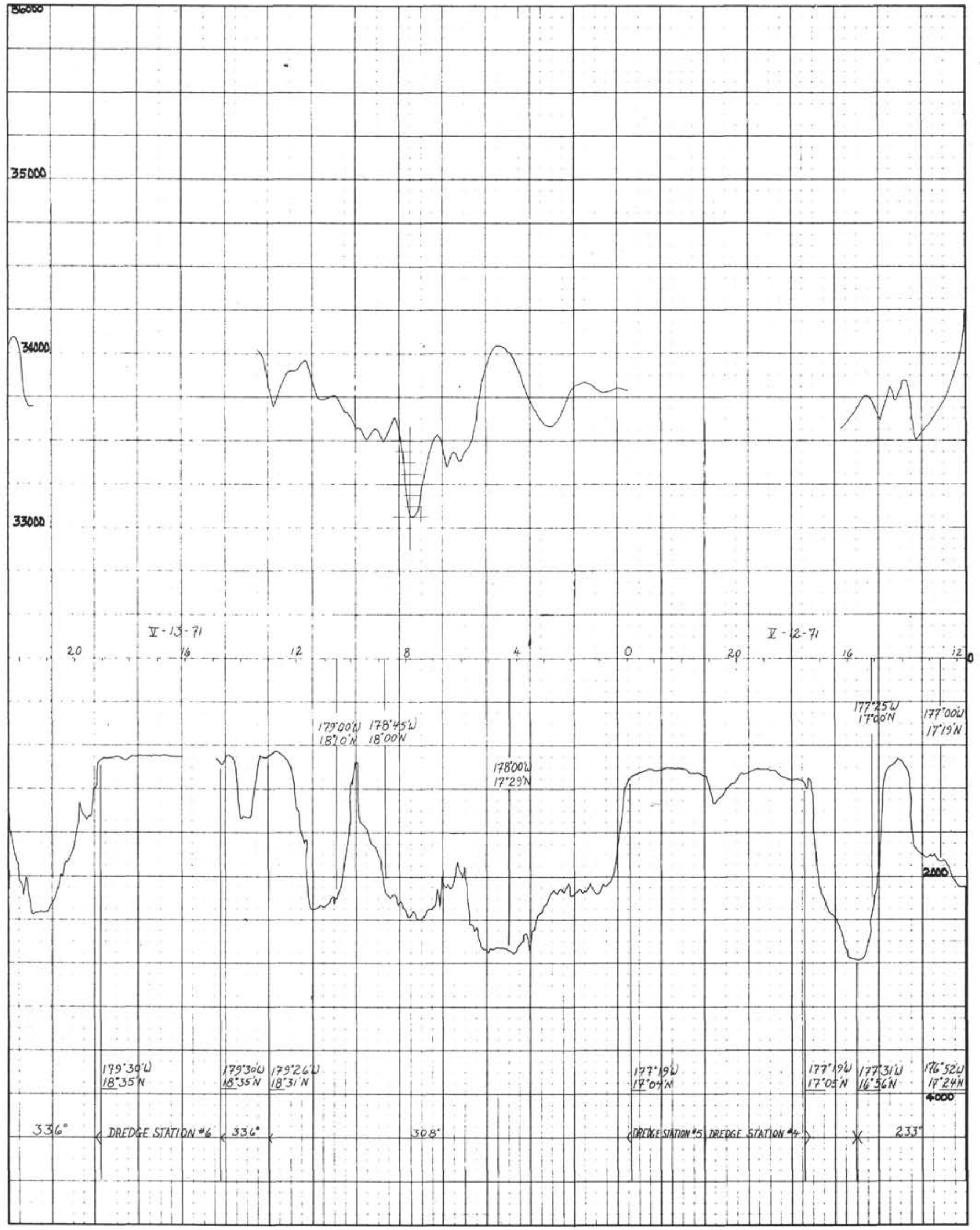

Figure 59. (Continued). 


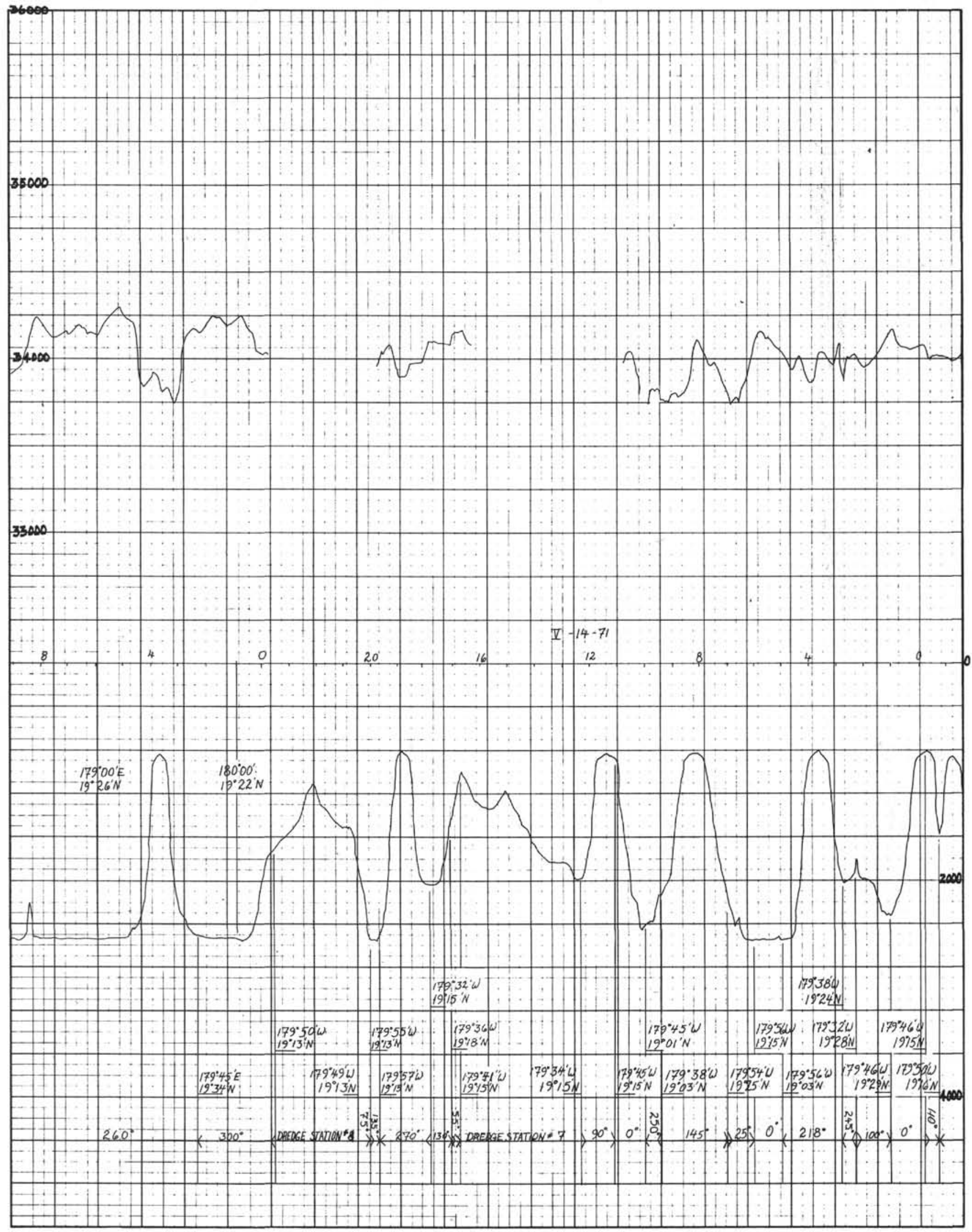

Figure 59. (Continued). 


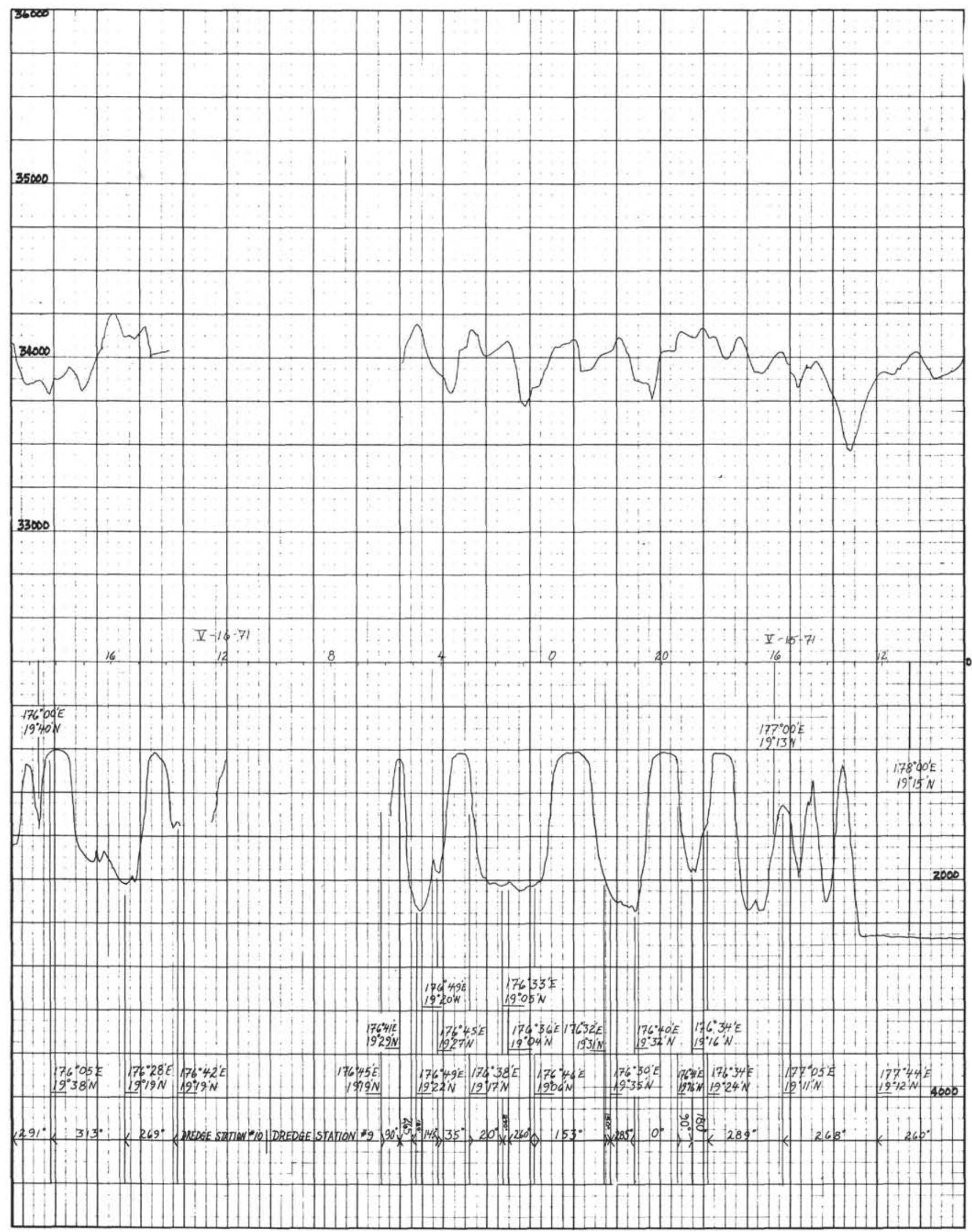

Figure 59. (Continued). 


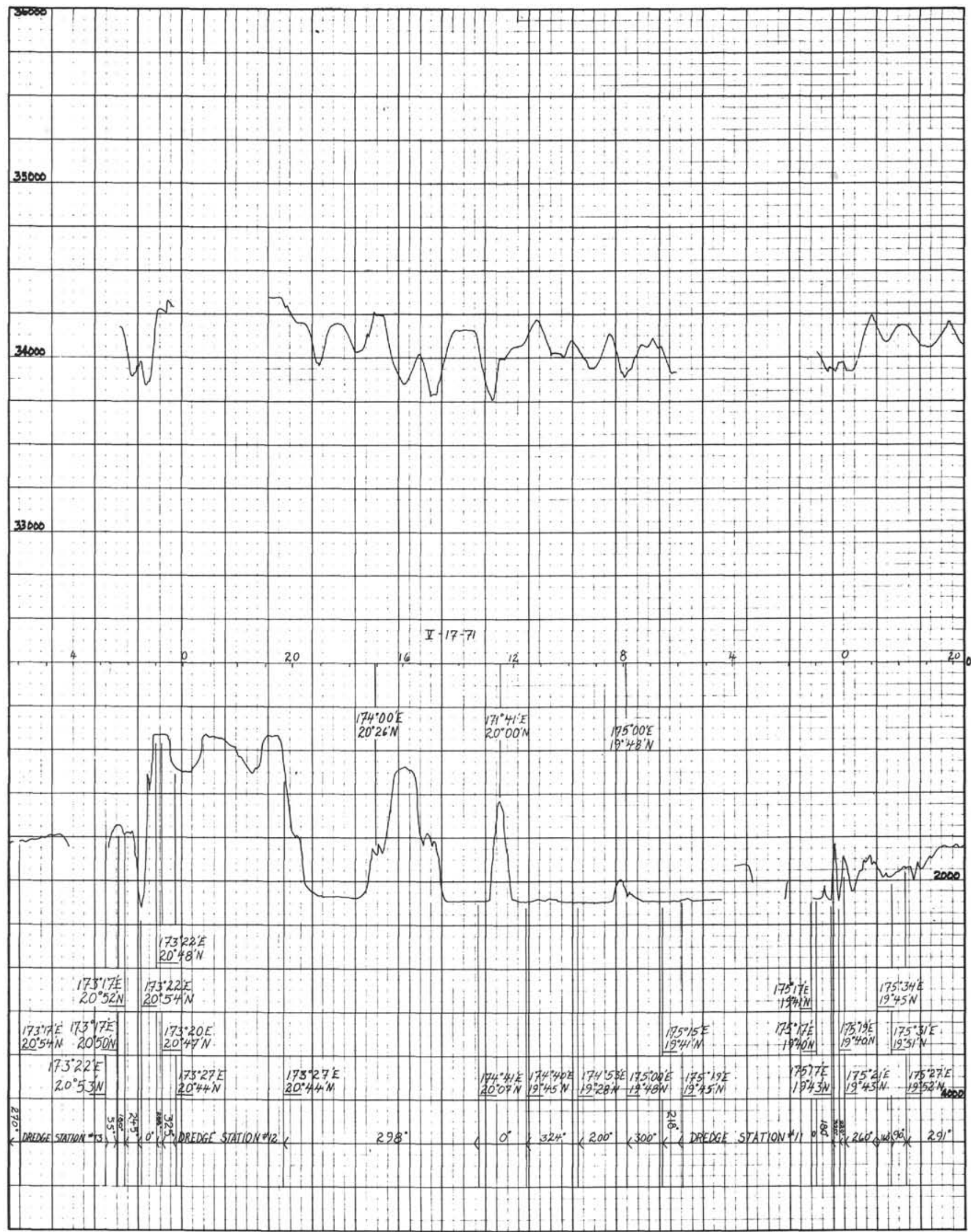

Figure 59. (Continued). 


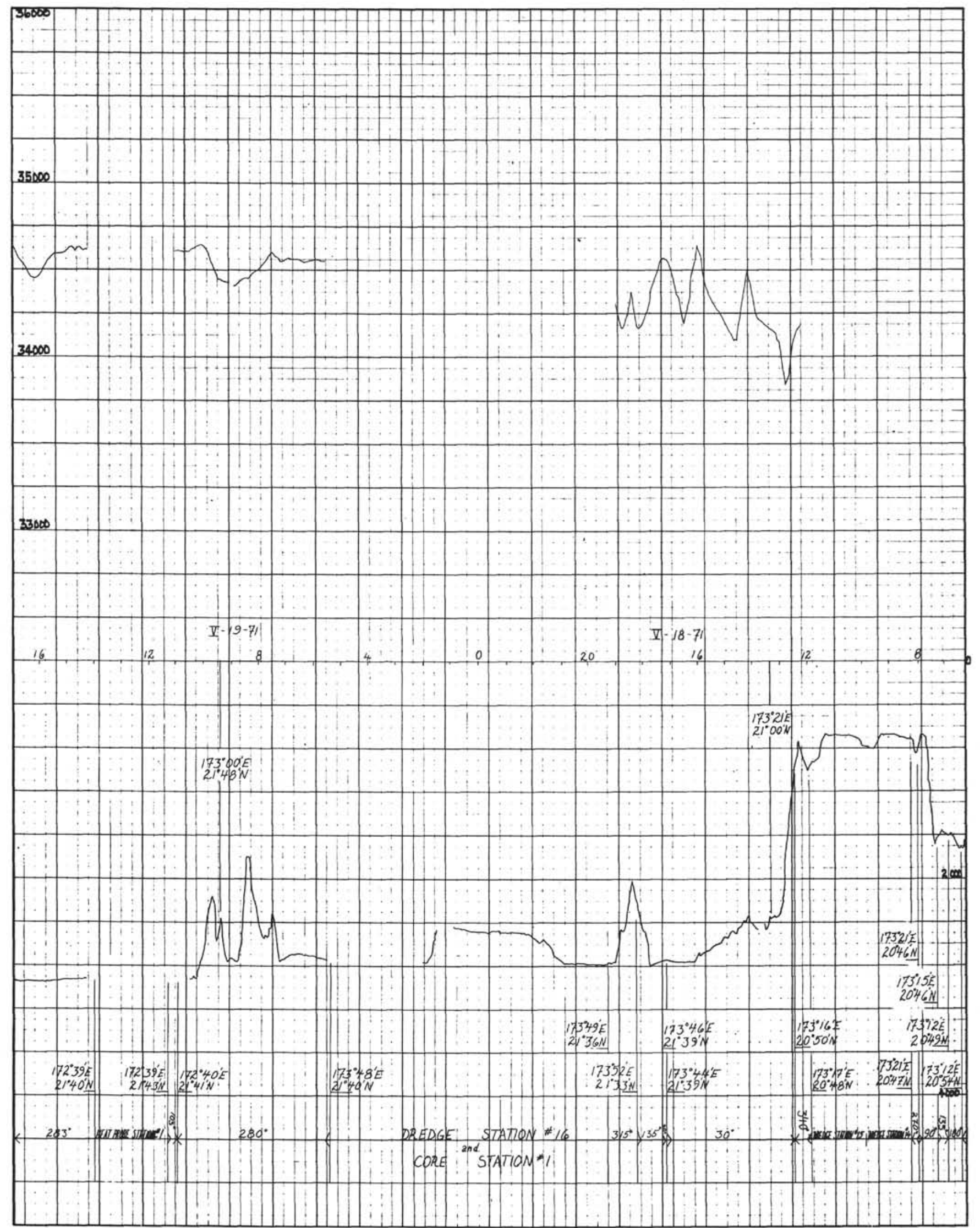

Figure 59. (Continued). 


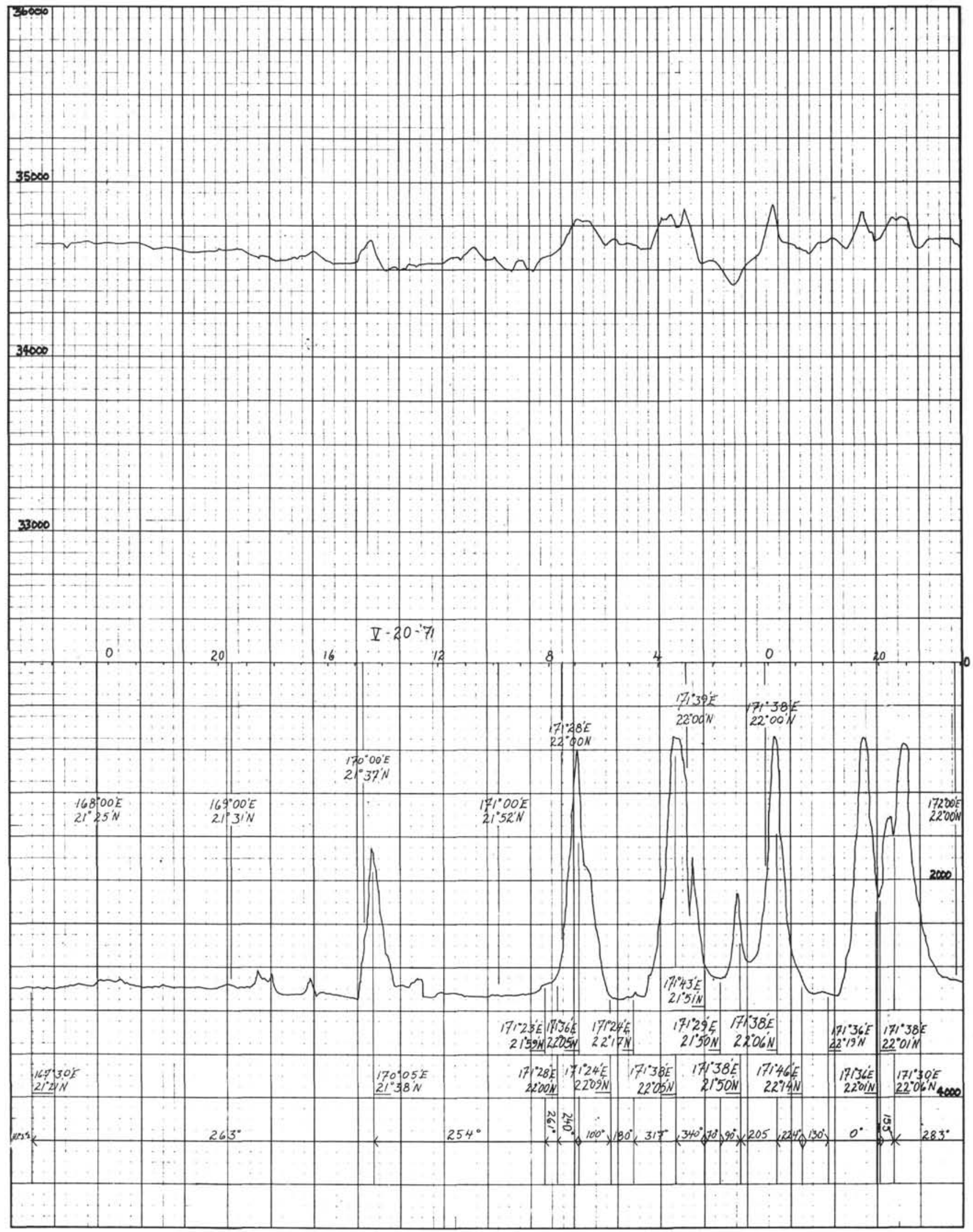

Figure 59. (Continued). 


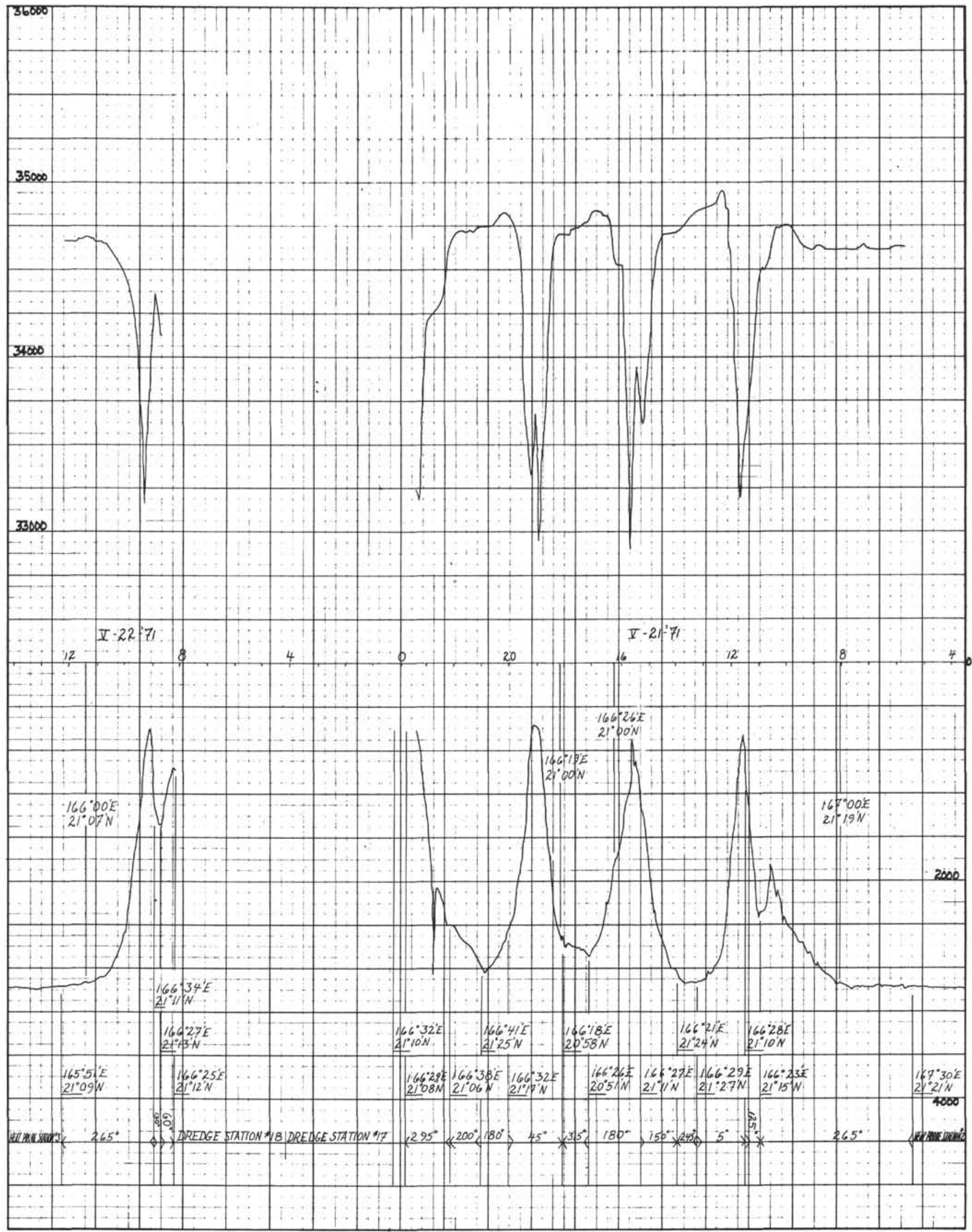

Figure 59. (Continued). 


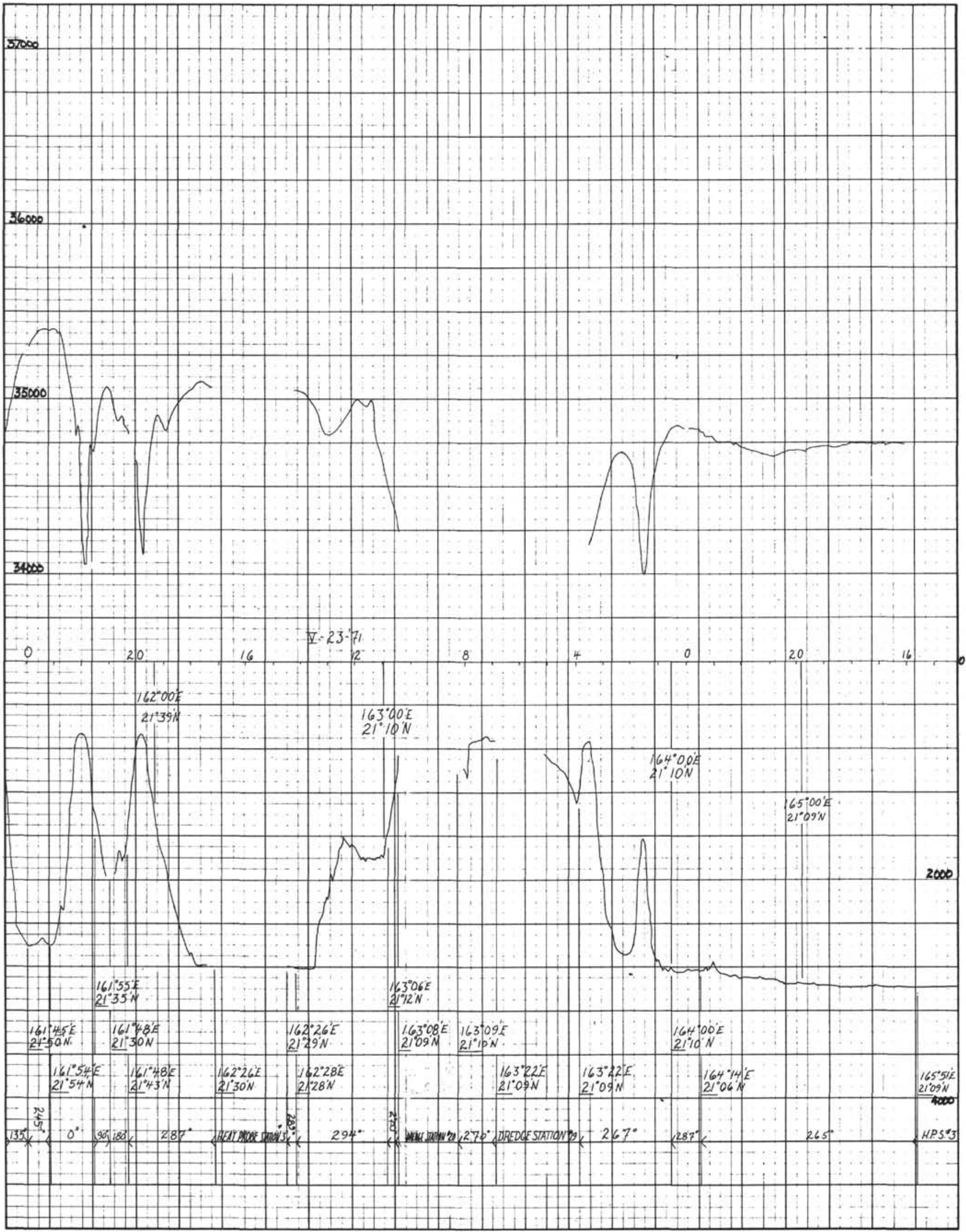

Figure 59. (Continued). 


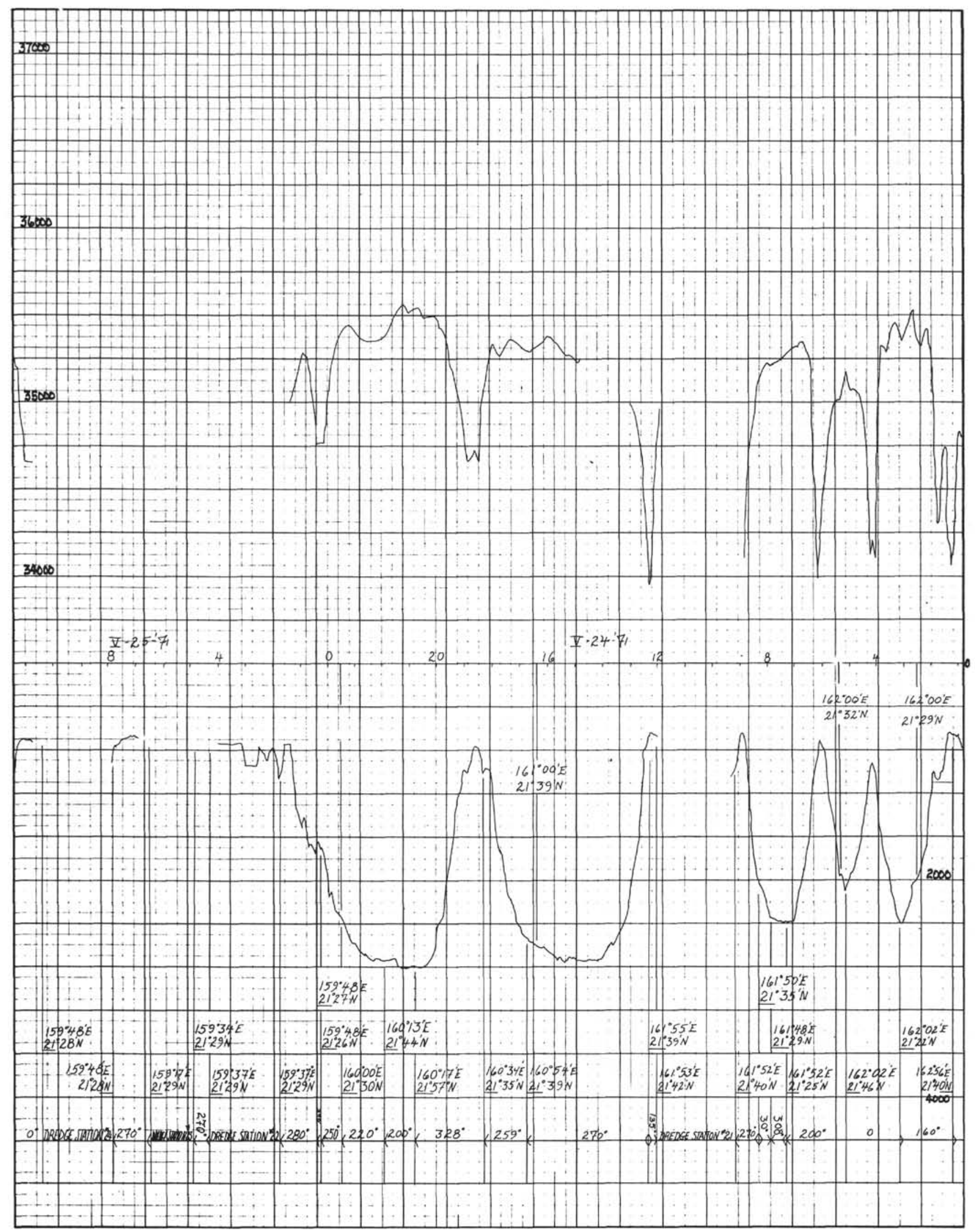

Figure 59. (Continued). 


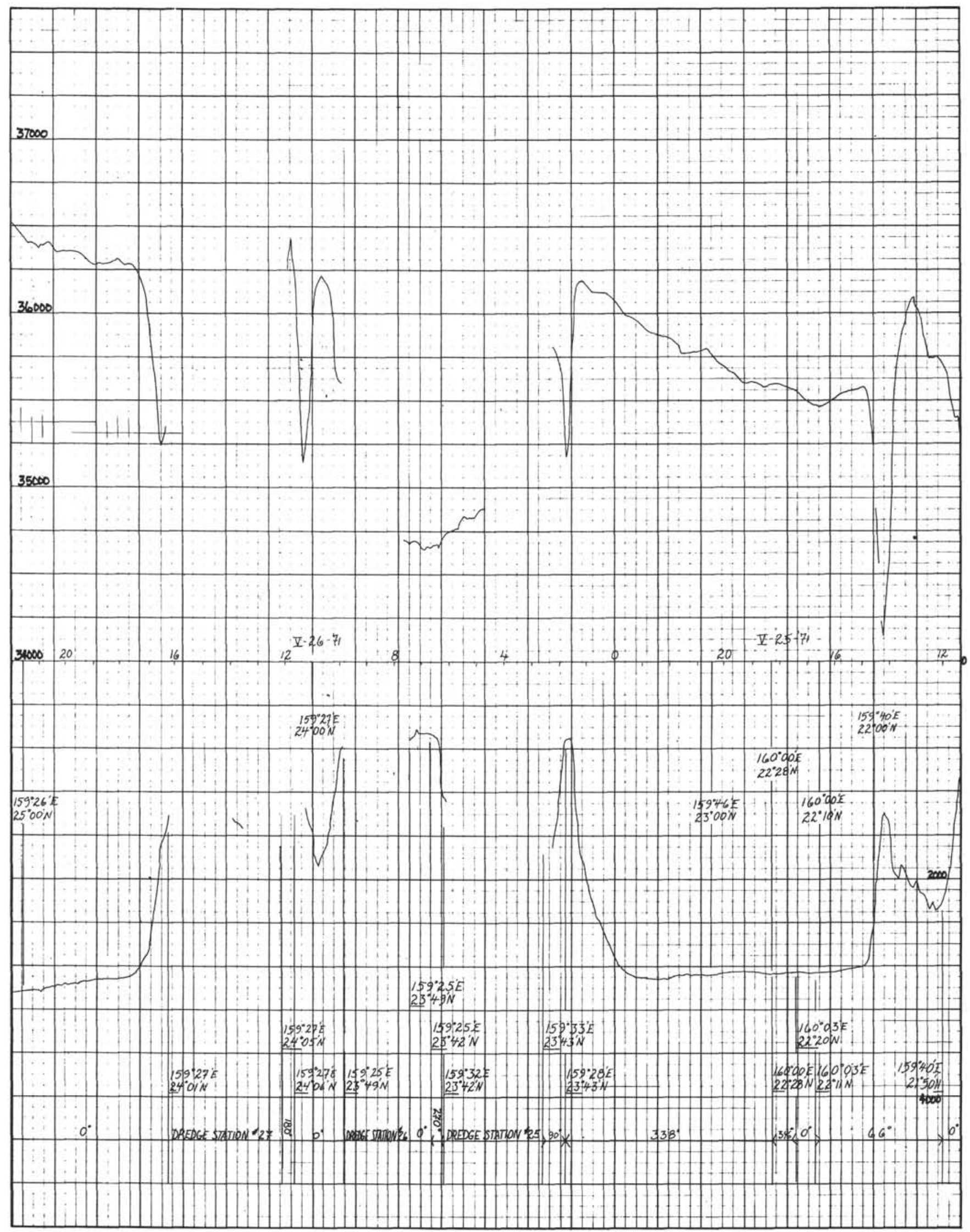

Figure 59. (Continued). 


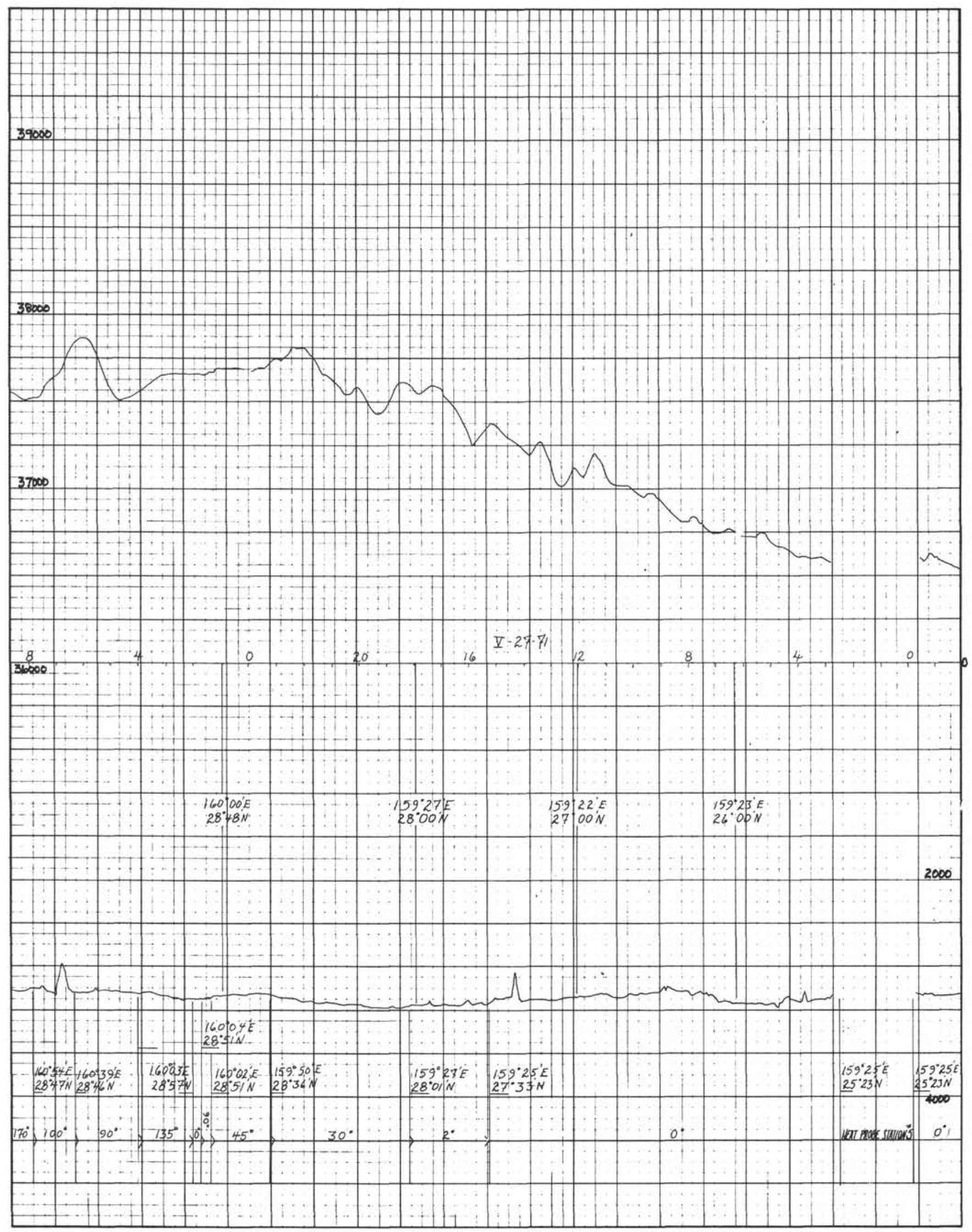

Figure 59. (Continued). 


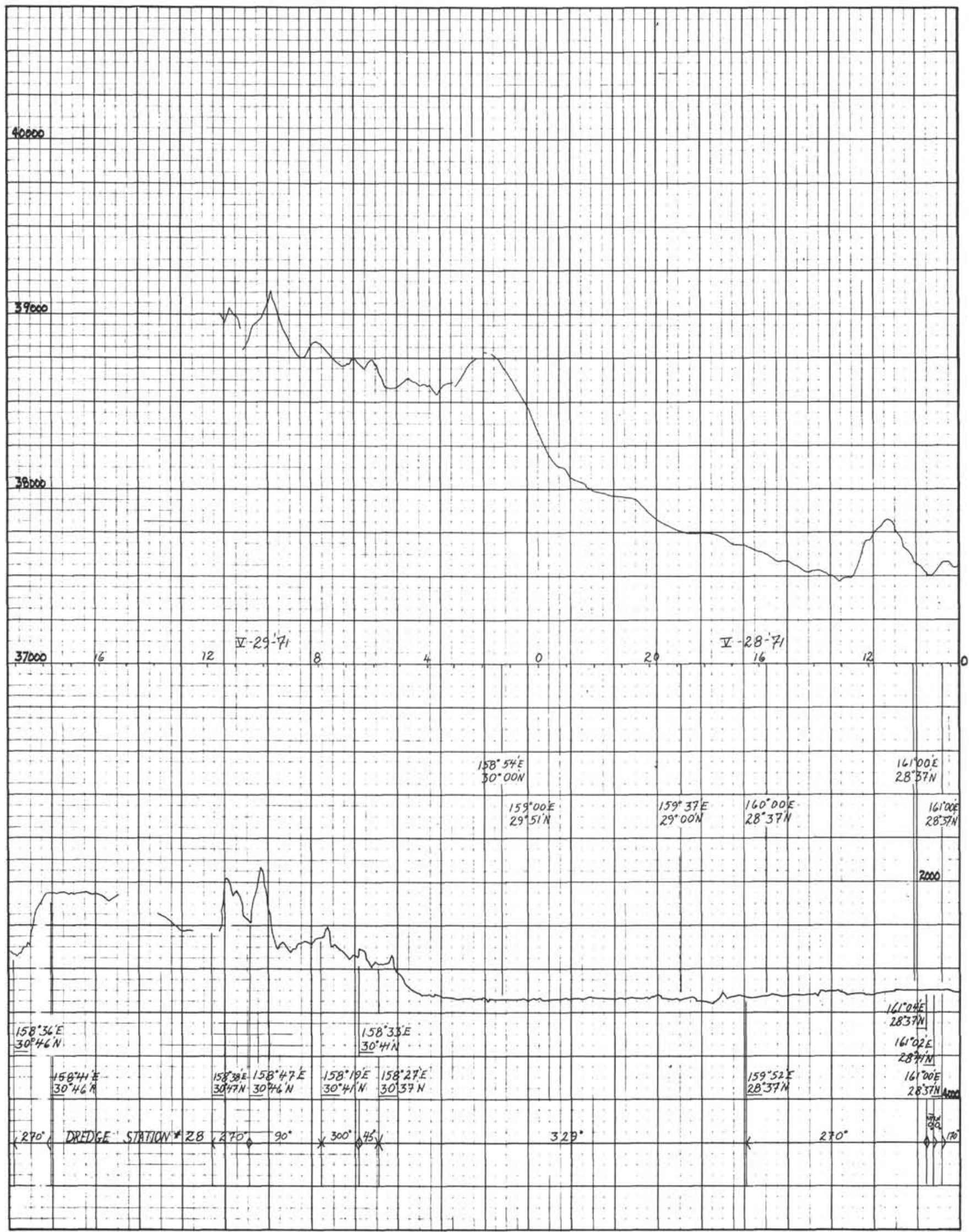

Figure 59. (Continued). 


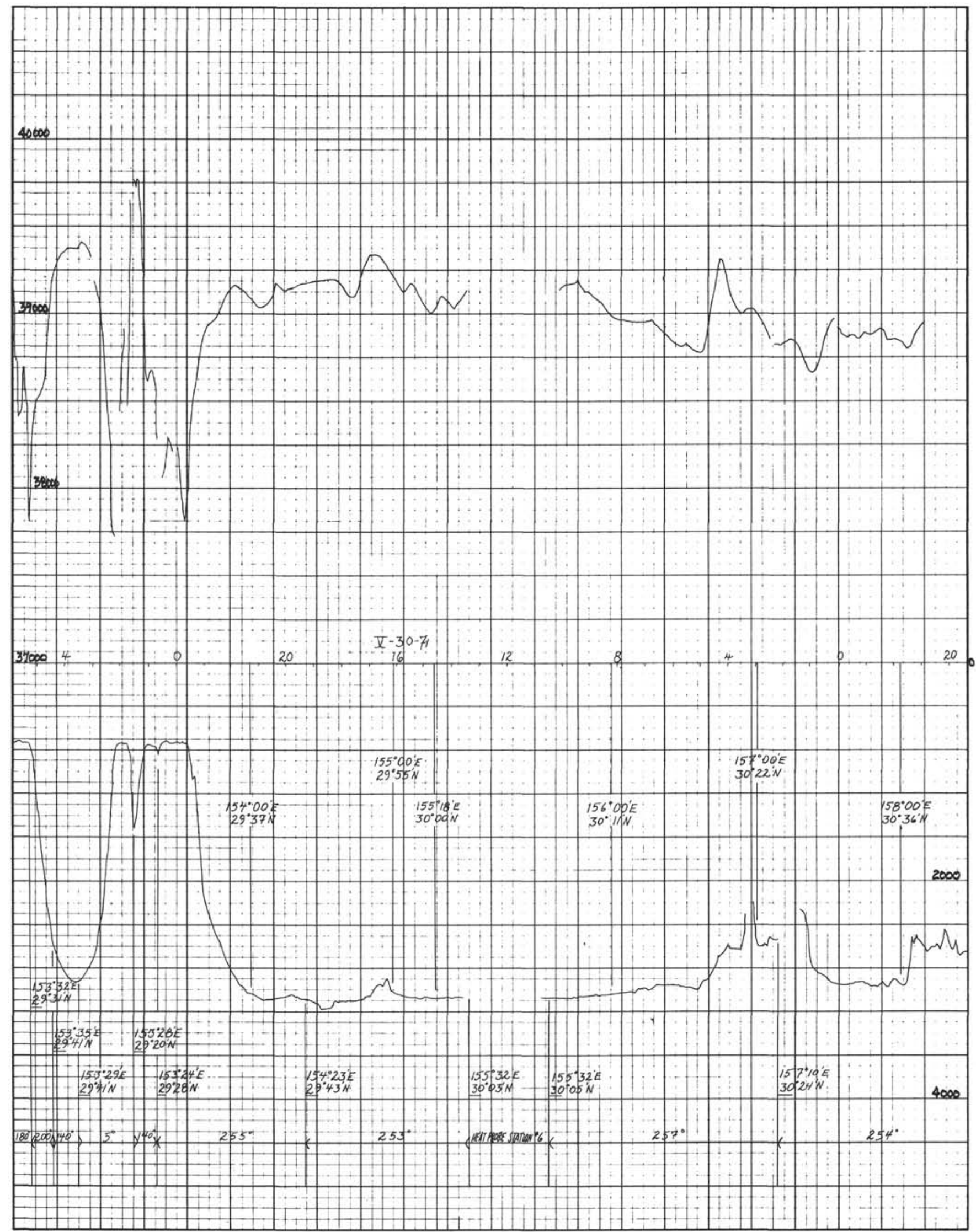

Figure 59. (Continued). 


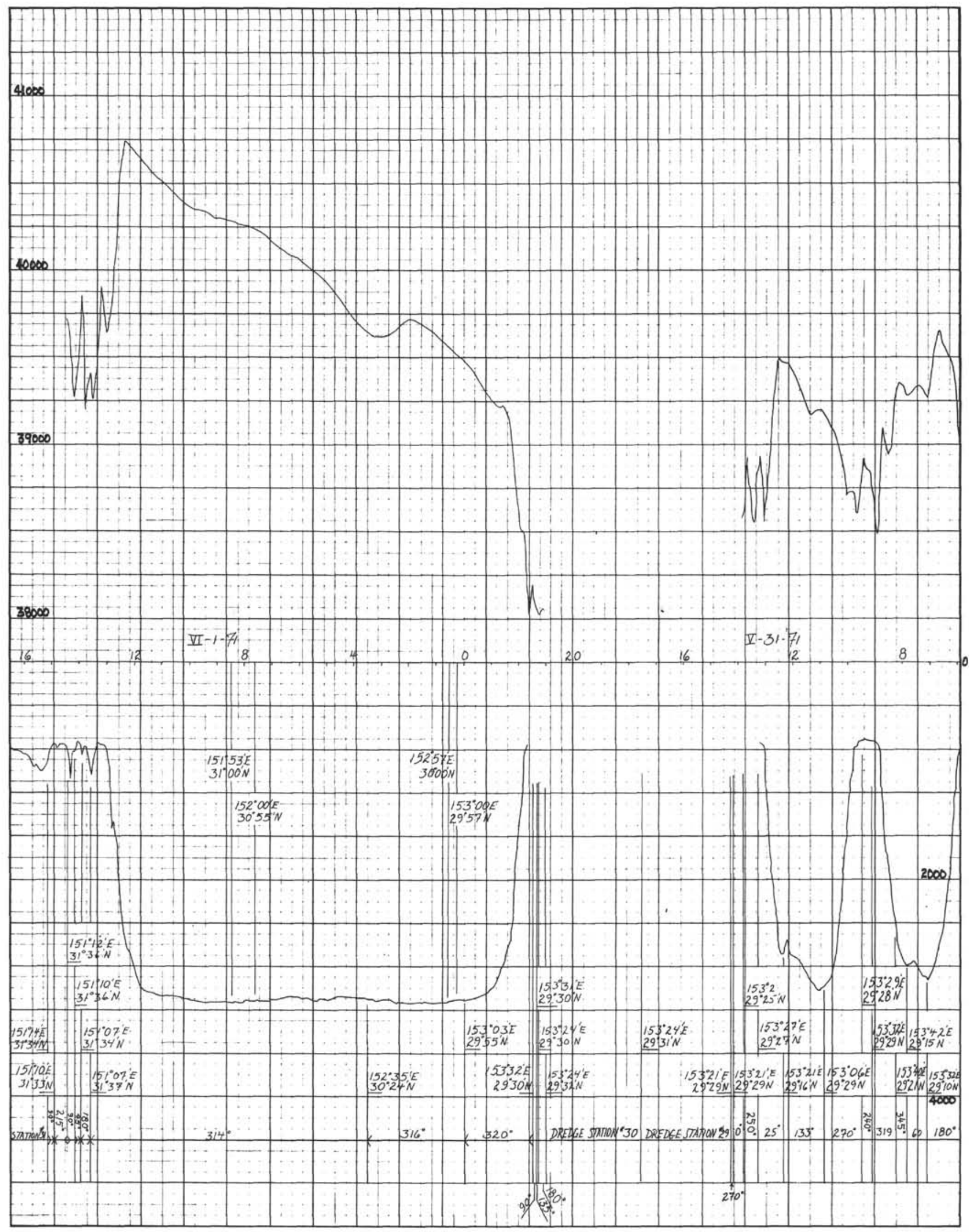

Figure 59. (Continued). 


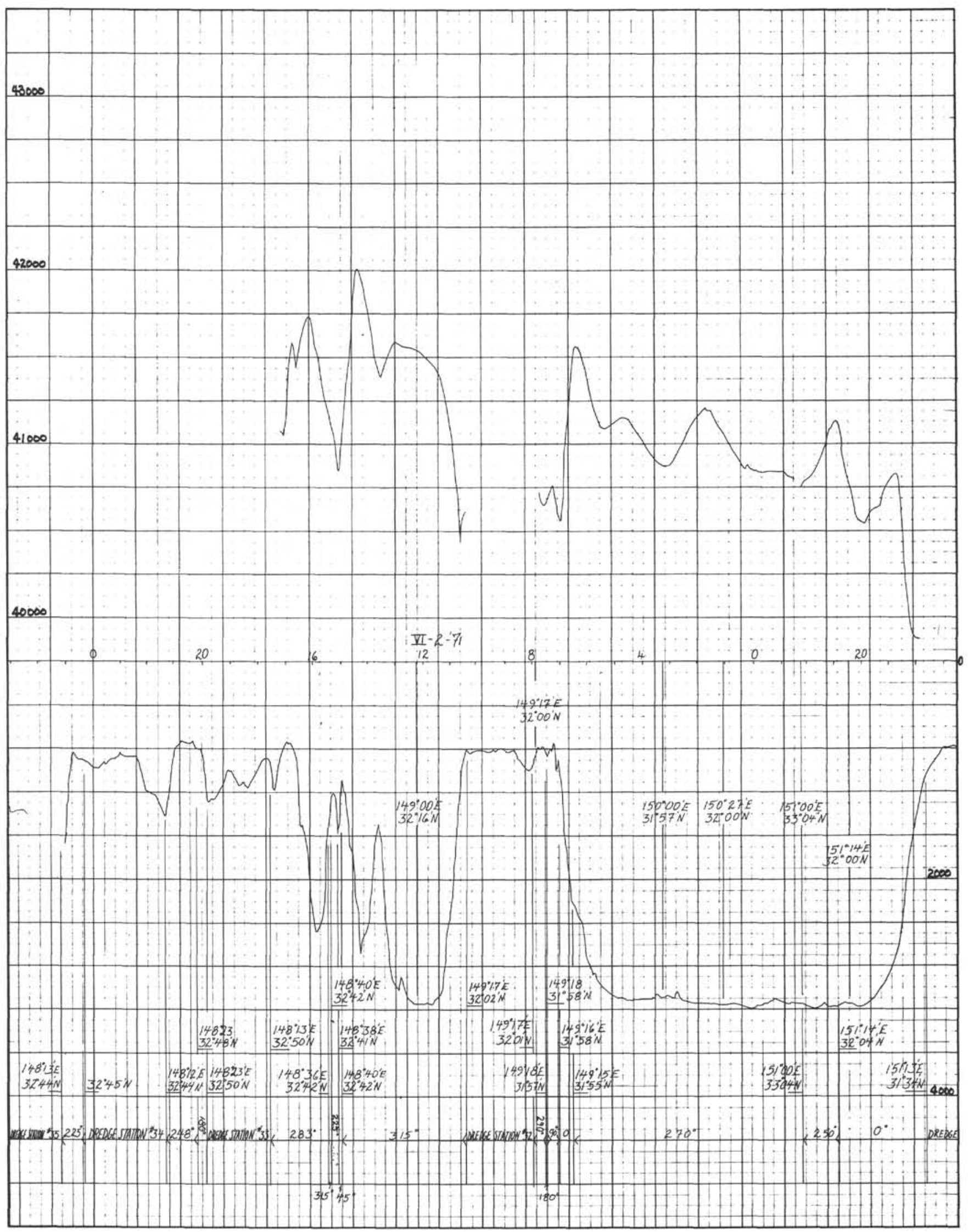

Figure 59. (Continued). 


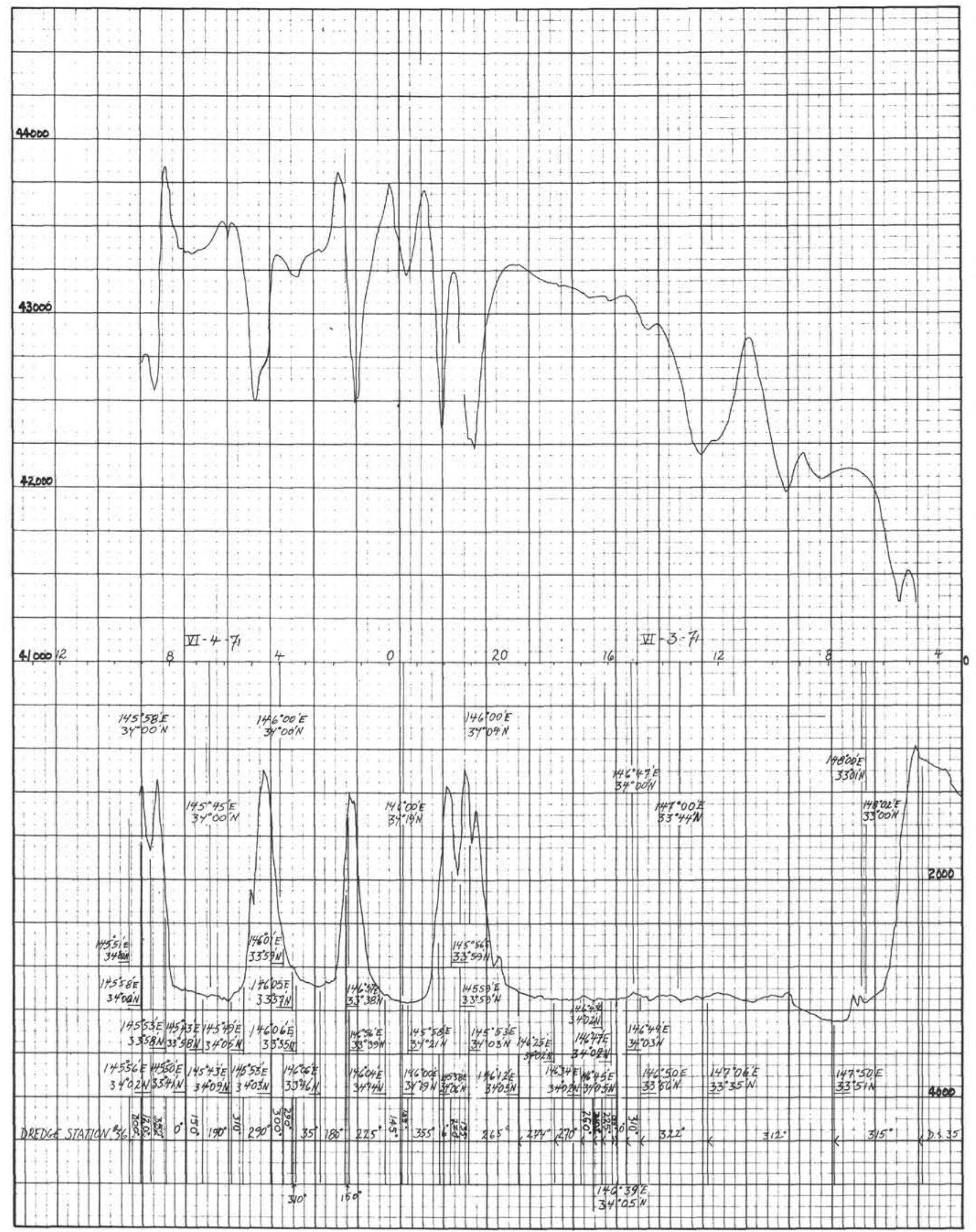

Figure 59. (Continued). 


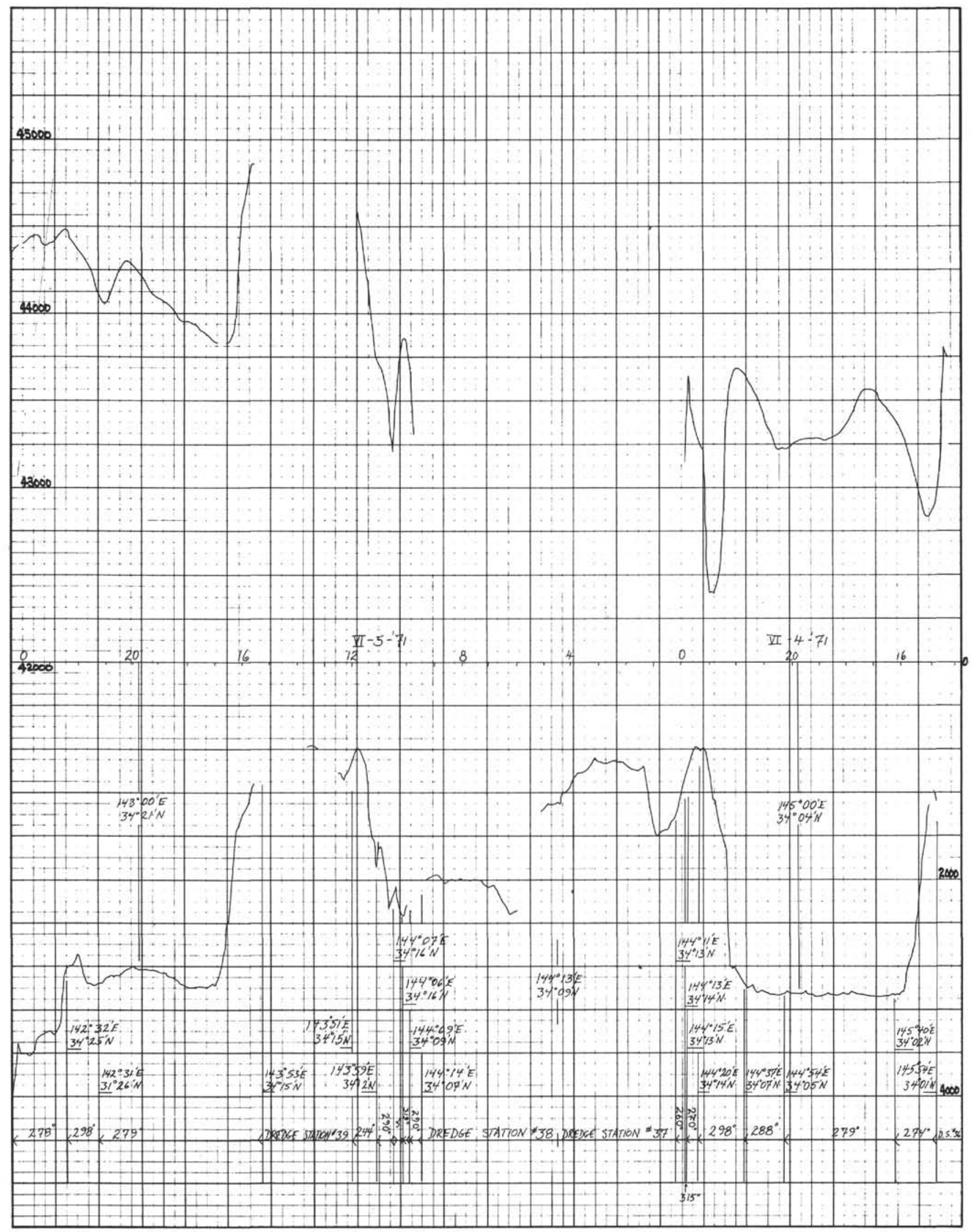

Figure 59. (Continued). 


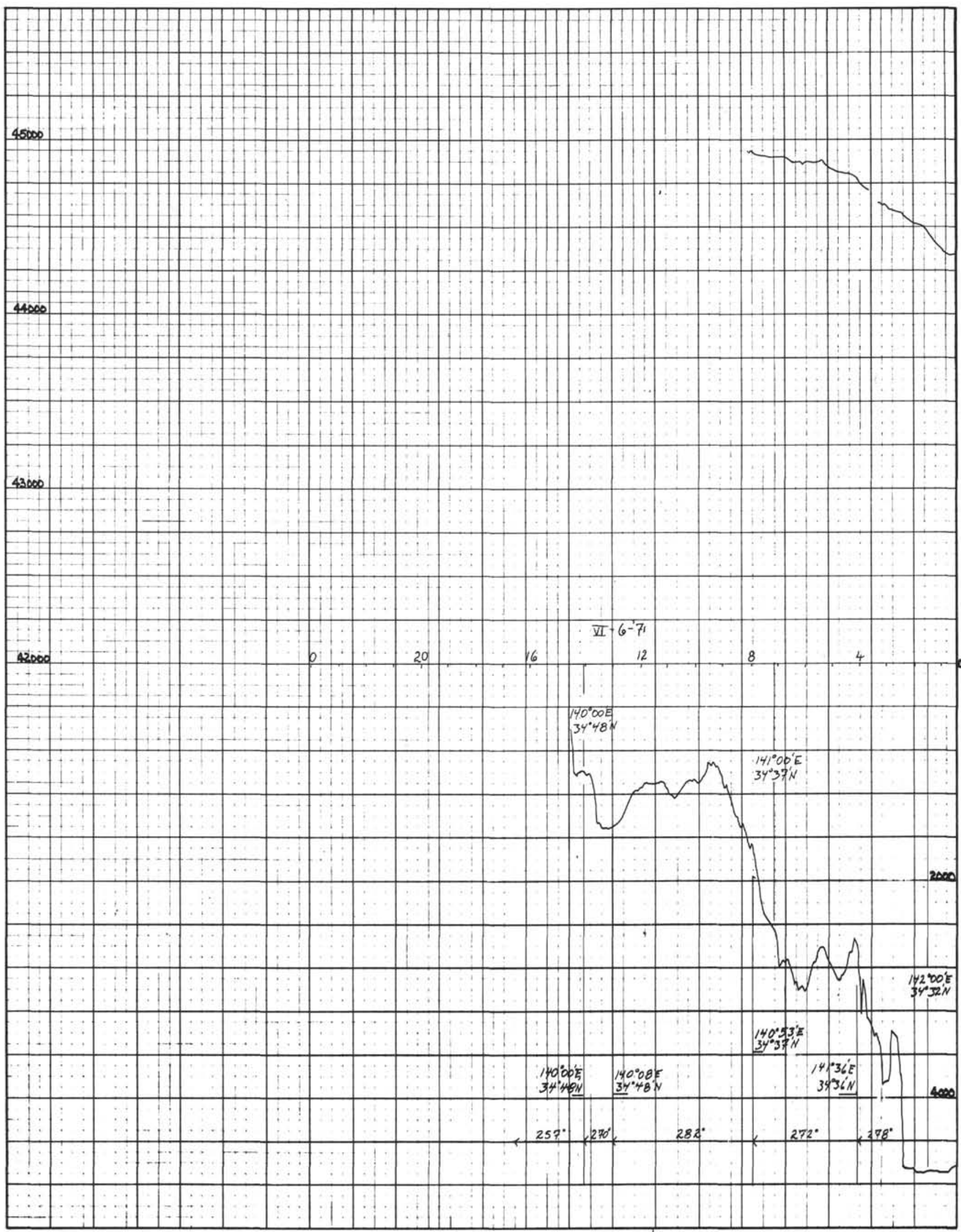

Figure 59. (Continued). 